Aus der Königl. Universitäts-Frauenklinik zu Berlin.

Direktor: Geh. Med.-Rat Prof. Dr. Bumm.

\title{
Zur Prognose der puerperalen Fiebersteigerungen auf Grund bakteriologischer und histologischer Untersuchungen.
}

\author{
Von \\ Privatdozent Dr. K. Warnekros, \\ Assistenzarzt. \\ (Hierzu Tafel IV-X.)
}

Die Erkenntnis der infektiôsen Natur des Puerperalfiebers hat ihren hauptsächlichen Erfolg auf dem Gebiete der Prophylaxe gezeitigt. Die therapeutischen Maassnahmen, welche auf Grund unserer Kenntnisse von dem Wirken der Keime in dem infizierten Körper der Wöchnerin ersonnen und unternommen worden sind, haben dagegen versagt; weder die lokale Antisepsis noch die Serumbehandlung hat grosse Erfolge aufzuweisen. Dies ist weiter nicht merkwürdig, denn bei anderen Infektionskrankheiten, deren Erreger wir kennen, ist es, von wenigen Ausnahmen (Syphilis, Diphtherie) abgesehen, mit der Ausbildung spezifischer Heilmethoden ebenso gegangen.

Auffallend aber muss es bleiben, dass die Kenntnis des infektiösen Ursprungs des Puerperalfiebers und der dabei beteiligten Bakterien bis heute die Diagnose und die darauf sich stützende Prognose der puerperalen Fiebersteigerungen noch in so geringem Maasse gefördert hat. Wir wissen, es handelt sich um eine Infektion, aber den Verlauf und Ausgang des Infektionsprozesses im Voraus zu bestimmen, fällt sehr schwer. Ich will an der Hand einer grösseren Reihe eingehend untersuchter Fälle puerperaler Fiebersteigerungen zu entwickeln versuchen, wie wir eine möglichst exakte Diagnosen- und somit eine möglichst sichere Prognosenstellung gewinnen können.

Man war natürlich schon lange bemüht, eine Grundlage für die Beurteilung des Krankheitsprozesses aus dem einen oder dem anderen klinischen Symptomenkomplex oder aus dem bakteriologischen Untersuchungsergebnis zu gewinnen. Mit dem Nachweis bestimmter Bakterien in den Sekreten der erkrankten Organe verband sich der Versuch, aus den Lebensbedingungen und Wachstumsverhält- 
nissen der Mikroben Rückschlüsse auf ihre Pathogenität zu ziehen. Gleichzeitig suchte man sich aus der Beschaffenheit der Sekrete und des Blutbildes des erkrankten Individuums eine Vorstellung von dem jeweiligen Stande des Infektionskampfes und dem voraussichtlichen Erfolg oder der Aussichtslosigkeit dieses Kampfes zu machen.

Einen wesentlichen Schritt vorwärts brachte uns aber erst die sichere Entscheidung über die Lokalisation bzw. über die Ausbreitung des Krankheitsprozesses, die uns das Ergebnis der systematischen bakteriologischen Blutuntersuchungen zu stellen gestattete. Jetzt war es uns schon während des klinischen Verlaufes, unabhängig von der nachhinkenden Sektion, ermöglicht, zwei grosse Hauptgruppen von grundverschiedener prognostischer Bewertung zu unterscheiden: die begrenzte und die verallgemeinerte puerperale Erkrankung.

So wichtig aber auch der positive oder negative Ausfall der Blutproben war, er bedurfte zur Beurteilung einer ergänzeniden Einschränkung, nämlich der Berücksichtigung der differierenden anatomischen Verhältnisse.

Damit tritt als neues Moment in die Epikrise der puerperalen Erkrankungen die mechanisch-anatomische Gelegenheitsursache als Erklärung der temporären Bakteriämien.

Es genügt zur folgerichtigen Bewertung der bakteriologischen Blutbefunde nicht mehr die einfache Angabe der Resultate im positiven oder negativen Sinne, sondern die Kritik verlangt als notwendige Ergänzung die gleichzeitige Berücksichtigung der zur Zeit der Untersuchung bestehenden anatomischen Verhältnisse bzw. der eventuellen Komplikationen und Abweichungen vom physiologischen Verlauf.

Die vermittelnde Rolle des uteroplazentaren Kreislaufes z. B. ist für den Ausfall der Blutproben eine so eminent wichtige, dass ihre Vernachlässigung zu einer falschen Einschätzung der gefundenen Bakterien und somit zu einer falschen Vorstellung über den Stand der Infektion führen muss.

Es ist demnach zur endgültigen prognostischen Entscheidung über das jeweilige Stadium des Krankheitsprozesses neben einer systematischen Kontrolle der Einzelsymptome die Berücksichtigung der anatomischen Verhältnisse durchaus erforderlich; das eine ergänzt und erklärt das andere, und aus der Betrachtung des Ganzen ergibt sich als logische Schlussfolgerung die Prognose.

Ich habe daher bei den verschiedenen Formen von Fiebersteigerungen während des Abortes, während der Geburt und im 
Wochenbett neben der Blutuntersuchung der histologischen Frage besondere Aufmerksamkeit geschenkt, um so bei richtiger Einschätzung der einzelnen Symptome und unter Berücksichtigung ihrer Relationen zu einander zu einer möglichst genauen Prognosenstellung zu gelangen.

Bevor ich auf die Besprechung der verschiedenen Krankheitsbilder eingehe, will ich wegen der Bedeutung, die ich der Blutuntersuchung beilege, einige Bemerkungen über die Technik vorausschicken, die sich uns im Laufe von mehreren hundert Blutuntersuchungen am zweckmässigsten erwiesen hat und die nach unserer Erfahrung sichere Resultate erwarten lässt.

Zum Nachweis der Blutkeime verwenden wir die grosse Traubenzucker-Agarröhre, wie sie von Schottmüller angegeben worden ist. Man kann dabei, und das ist zweifellos für den positiven Ausfall in vielen Fällen wichtig, eine relativ grosse Menge Blut $(20-30 \mathrm{ccm})$ kulturell verimpfen, was bei geringem Keimgehalt des Blutes die Chance des Nachweises selbstverständlich steigert. Ausserdem gibt aber die erstarrte Blutagarsäule allen Keimen Gelegenheit zur Entwickelung, indem sie in ihren verschiedenen Schichten dem verschiedenen Sauerstoffbedürfnis der verimpften Keime Rechnung trägt. Der anaerobe Keim wird sich in der Tiefe der Röhre, der aerobe in den oberen Schichten entwickeln. Wenn auch die Rolle der obligat anaeroben Bakterien bei diesen Temperatursteigerungen keine so wesentliche ist, wie man nach den ersten Veröffentichungen von Schottmüller annehmen musste, so ist trotzdem die anaerobe Verimpfung der Blutprobe geboten, da ganz allgemein die Blutkeime, die man während des Frostes der Armvene entnimmt, anaerophil sind, d. h. die sauerstoffärmeren unteren Schichten der Agarröhre bevorzugen. Man wird häufig beobachten können, dass die obere Zone keimfrei bleibt, ohne dass aber die in der Tiefe aufgegangenen Keime sich bei der Weiterverimpfung als obligate Anaerobier erwiesen. Es scheint demnach, dass die gerade bei Aborten so häufig im Blute kreisenden Saprophyten bei der Verimpfung auf künstliche Nährböden als Uebergang sauerstoffärmere bzw. -freie Nährsubstrate beanspruchen. Diesem Bedürfnis entspricht am einfachsten die grosse Traubenzucker-Agarröhre.

Beim Plattenverfahren ist man unter Berücksichtigung dieser Wachstumseigentümlichkeit gezwungen, neben den aeroben auch anaerobe Pyrogallolplatten zu giessen, was bei weitem umständ- 
licher und, wie ich gefunden habe, auch nicht ohne nachteiligen Einfluss auf das Angehen der Kolonien ist. Bei meinen Versuchen mit den Dreuw'schen anaeroben Platten habe ich wiederholt die Beobachtung gemacht, dass auf den Pyrogallolplatten auffallend wenige oder bisweilen auch gar keine Kolonien aufgegangen waren, während in den glejchzeitig hergestellten grossen Röhren Kolonien in reichlicher Anzahl durch die ganze Röhre hindurch bis in die Tiefe, also neben aeroben auch wenigstens fakultativ anaerobe, gewachsen waren. Es ist wohl denkbar, dass die bei der Herstellnng der Pyrogallollösung verwandte Kalilauge einen schädigenden Einfluss auf das Wachstum der Bakterien ausübt; die Verfärbung und vor allem die Fintrocknung des Blutagars im Blutschrank zeigt bei diesen Pyrogallolplatten jedenfalls eine nicht unwesentliche und gewiss auch nicht gleichgültige Veränderung des Nährbodens. Aus allen diesen Gründen empfiehlt sich die grosse TraubenzuckerAgarröhre am meisten zur kulturellen Prüfung des Blutes auf seinen Bakteriengehalt.

Zur Punktion der Vene benutzen wir die Luer'sche Spritze, die in einer eigens konstruierten Glashülse trocken sterilisiert wird; die Spitze der gleichfalls trocken sterilisierten Kanüle wird kurz vor dem Einstich glühend gemacht und so in die leicht gestaute Vene eingestochen. Auf diese Weise vermeidet man am leichtesten eine Verunreinigung der Kultur mit Hautkeimen.

Hat man nach Reinigung der Haut mit Aether der Armvene $20 \mathrm{ccm}$ Blut entnommen, so ist vor der Mischung bei diesen grossen Röhren ganz besonders auf eine genügende Abkühlung des Agars zu achten. Der Nährboden muss mindestens 15 Minuten im Wasser von $40^{\circ}$ abgekühlt werden, bis er in seiner ganzen Schicht die gewünschte Temperatur von etwa $42^{\circ}$ angenommen hat. Die Abkühlung kann natürlich durch kaltes Wasser beschleunigt werden; man muss sich dann aber durch Umschütteln überzeugen, dass auch die ganze Masse hinreichend abgekühlt ist. Bei zu früher Verimpfung werden die Keime leicht durch den zu heissen Nährboden in ihrer Entwickelung gehemmt und so gerade bei diesen grossen Röhren Fehler in den Untersuchungsresultaten entstehen können.

Die gut vermischte und rasch zum Erstarren gebrachte Blutagarröhre bleibt, sofern nicht schon vorher ein Angehen von Kolonien makroskopisch sichtbar wird, bis zum 4. Tage unaufgeschnitten im Brutschrank stehen. Eine so lange Beobachtungs- 
zeit ist für die sichere Entscheidung, ob die Probe steril war oder nicht, erforderlich. Wenn bis zu diesem Zeitpunkt äusserlich keine Kolonien sichtbar sind, wird die Röhre geöffnet und die Blutagarsäule in möglichst feine Seheiben zerschnitten. Man wird dann bisweilen noch zentral gelegene Kolonien finden, die bei der unzerschnittenen Röhre nicht hatten gesehen werden können.

Ein weiterer äusserst beachtenswerter Punkt bei der bakteriologischen Blutuntersuchung ist die Zeit der Blutentnahme. Wenn wir bei den Krankheitsformen, die hier besprochen werden sollen, den Temperaturanstieg als Reaktion des Körpers beim Eindringen der Keime in die Blutbahn und den Schüttelfrost als verstärkten reaktiven Ausschlag auf eine momentane grössere Blutüberschwemmung ansehen, so bedeutet andererseits der Fieberabfall den Sieg des Organismus über die importierten bzw. eingedrungenen Keime. Es wird daher ein positiver Befund nur zu erwarten sein, wenn unter genauer Temperaturkontrolle im Fieberanstieg bzw. zu Beginn des Frostes das Blut entnommen wird. Man wird zuweilen Fälle beobachten können, bei denen die Blutproben trotz sicheren Keimgehaltes steril bleiben, wenn diese nur kurze Zeit nach dem Schiittelfrost oder auch nur in seiner letzten Phase verimpft worden sind. Der negative Ausfall beweist dann nicht etwa das Fehlen der Keime im Blut überhaupt, sondern nur die verspätete Entnahme. Der kulturelle Nachweis misslingt, weil der Körper infolge seiner natürlichen Abwehrstoffe die Keime bereits abgetötet hat, wenn die Probe entnommen wird.

Hamm hat neuerdings an der Hand eines prägnanten Falles von sicherer Colisepsis die Vermutung ausgesprochen, dass die klinischen zum Teil spezifischen Erscheinungen während eines Frostes nicht mehr auf das Eindringen selbst, sondern schon auf den Untergang der Keime im Blut zurückzuführen seien. Bei dem parenteralen Abbau des Bakterien- also körperfremden Eiweisses entstehen giftige Zwischenprodukte, die sogenannten Bakterienanaphylatoxine, die dann erst die schweren Vergiftungserscheinungen auslösen, die wir klinisch beim Frost beobachten. Bei dem von ihm untersuchten Fall blieben nämlich trotz einer ausgedehnten Thrombose des ganzen Venengebietes der unteren Körperhäfte, aus dessen weichem Material ebenso wie aus dem Herzblut und aus der Milz bei der Sektion Reinkulturen von Colibakterien nachgewiesen werden konnten, sämtliche während des Lebens auch im Frost entnommenen Blutproben. steril. Es hatte also hier zweifel- 
los eine so aussergewöhnlich rapide Zerstörung der Infektionserreger stattgefunden, dass die bakteriologische Kontrolle während des Lebens stets zu spät kam, wenn das klinische Symptom des Frostes eine neue Keimverschleppung durch Thrombenzerfall anzeigte. Der Nachweis wäre wahrscheinlich gelungen, wenn die Blutproben bei steigender Temperatur kurz vor Ausbruch des Frostes entnommen worden wären. Denn dass Bakterien im Blute gekreist haben mussten, bewies der Sektionsbefund. Wenn solche Fälle gewiss auch selten sind, so zeigen sie doch die Wichtigkeit der rechtzeitigen, dem einzelnen Fall angepassten Blutentnahme; man muss diese erhöhte Selbstreinigungskraft des Körpers, d. h. die Möglichkeit einer abnorm raschen Vernichtung der Koime im Blute kennen, um sich auch bei eventuell negativen Resultaten der bakteriologischen Untersuchung den Fall erklären und dem Fehler durch eine Aenderung der Technik abhelfen zu können.

\section{Der fieberhafte Abort.}

Bei der Besprechung der fieberhaften Aborte sind zwei Hauptgruppen zu unterscheiden, die klinisch verschieden zu erklären und prognostisch verschieden zu bewerten sind:

A. Die akute, vorübergehende oder mechanische Bakteriämie, bei der die Bakterien nur zu bestimmten Zeiten im Blute kreisend gefunden werden und

B. die dauernde bzw. spontane Bakteriämie, bei der jede Blutentnahme einen mehr oder minder reichlichen Keimgehalt des Blutes ergibt.

Die mechanische Bakteriämie beobachten wir im Verlauf eines kurz dauernden fieberhaften Abortes bis zu seiner vollständigen Ausräumung; die dauernde bzw. spontane Bakteriämie entweder anschliessend an den vollendeten Abort oder im Verlauf eines über längere Zeit verschleppten Falles.

Eng verknüpft mit dieser sich aus den bakteriologischen Untersuchungen ergebenden klinischen Trennung der beiden Krankheitsbilder ist unsere Vorstellung über den jeweiligen voneinander abweichenden pathologisch-anatomischen Organzustand. Wir müssen annehmen, dass bei der akuten, mechanischen Bakteriämie die Quelle der Keimüberschwemmung in der Plazenta, d. b. ausserhalb der eigentlichen Gebärmutterwand bzw. der sich daraus entwickelnden Gefässstämme gelegen ist, bei der dauernden bzw. spontanen Bakteriämie dagegen bereits innerhalb der Uterus- 
muskulatur und in den Wurzeln und Verzweigungen der abführenden Venenstämme. In dieser anatomischen Differenz liegt der prognostisch so äusserst wichtige Unterschied für die Bewertung eines klinisch an sich gleichen Krankheitsymptoms: des positiven Blutbefundes.

Da gerade dieses Symptom, der Keimnachweis im strömenden Blute, vielfach zu einer irrtümlichen Bewertung der gefundenen Bakterien geführt und auch die Erklärung für diese Erscheinung mannigfache Auslegung gefunden hat, sollen lolgende Bemerkungen vorausgeschickt werden.

Die beim Abort so häufigen positiven Ergebnisse der Blutuntersuchungen waren Veranlassung gewesen, dass hier zuerst die Aufmerksamkeit auf die bakterielle Aetiologie dieser oft nur vorübergehenden Fiebersteigerungen gelenkt and daraufhin die Vorstẹllung einer Toxinresorption überhaupt als Erklärung aller Temperatursteigerungen angezweifelt wurde.

Schottmüller hatte durch seine systematischen Blutuntersuchungen den Nachweis der Hänfigkeit einer akuten Bakteriämie im Verlauf fieberhafter Aborte erbracht.

Dabei kam es aber weniger, worauf Schottmüller das Hauptgewicht legte, auf die anaerobe Kultur an, als auf die zur rechten Zeit entnommene und richtig verimpfte Blutprobe. Der häufige Nachweis obligat anaerober Bakterien, besonders des Streptococcus putridus, wie es Schottmüller beschrieb, wurde von anderer Seite nicht bestätigt; der obligat anaerobe Streptokokkus war ein gelegentlicher Nebenbefund. Dagegen fand man, und das war neu und bedurfte der Erklärung, Keime verschiedenster Art vorübergehend im Blute der Fiebernden und zwar nicht Reinkulturen von Strepto- oder Staphylokokken, wie man es von früher her bei den puerperalen Infektionsfällen gewohnt war, sondern Gemische von Bakterien, die man bisher als Saprophyten betrachtet und im Blutbild zu finden nicht erwartet hatte.

Damit war scheinbar die Scheidewand zwischen Saprophyten und Parasiten gefallen, und wenn man die Trennung dieser Begriffe nicht ganz aufheben und alle im Blut gefundenen Keime hinsichtlich ihrer Pathogenität gleichstellen wollte, so musste die Erklärung nicht wie bisher in den Bakterien, sondern in begleitenden Nebenumständen gesucht werden. Es war somit zur Deutung der bakteriologischen Resultate die Berücksichtigung der anatomisehen Strukturverhältnisse, d. h. des Zustandes, wie wir uns 
jeweilig zur Zeit der Blutuntersuchung die Uterushöhle vorstellen müssen, durchaus erforderlich. Meiner Meinung nach war es eine grobe Verkennung dieser anatomischen Momente, die zu einer einseitigen und falschen Bewertung der bakteriologischen Befunde führen musste, wenn man bestritt, dass durch Manipulationen bei Abortausräumung und bei Drucksehwankungen verschiedenster Art auch Saprophyten in so grosser Menge in die Blutbahn hineingepresst werden können, dass sie nach einer gewissen Zeit noch im strömenden Blute nachweisbar sind, oder wenn man behauptete (Hamm), dass alle Keime, die wir mit unseren' gewöhnlichen Untersuchungsmethoden im Blute nachweisen können, unbedingt zu den echten Parasiten gezählt werden müssen. In Verfolgung dieser Anschauung hat Hamm die ganze Flora der in der Scheide vorkommenden Keime daraufhin untersucht, ob gelegentlich der eine oder andere Keim im Blute nachgewiesen werden konnte, und hat an der Hand seiner eigenen und der in der Literatur mitgeteilten Fälle fast von jedem der in Betracht kommenden Bakterien sein gelegentliches Vorkommen im Blute angegeben gefunden. Damit haben die betreffenden Keime für ihn ihren parasitären Charakter bewiesen. Wohin diese einseitige Bewertung der bakteriologischen Befunde ohne Berücksichtigung der anatomischen Verhältnisse geführt hat, geht aus der von $\mathrm{Hamm}$ zusammengestellten Statistik zur Genüge hervor. Von der ganzen Vaginalflora bleiben als obligate Saprophyten vorläufig nur noch 6 Keime übrig: B. vaginalis Doederlein, Pseudodiphtherie, Futterbazillen, Sarzine, Sacharomyzeten und B. bifidus com. Tissier. Alle übrigen von ihm namentlich angeführten Mikroorganismen sind nach seiner Meinung penetrationsfähig, sie alle haben Beweise für ihre Invasionskraft erbracht, sie alle können einmal virulent werden. Die Zahl der "echten Parasiten" steigt damit zu einer erstaunlichen Höhe: Coli, Gonokokken, B. proteus, Micrococcus tetragenus albus, B. pnenmoniae, Korynebakterien, Milzbrandbazillen, Microc. tetrag. anaerobius, Bac. aerogenes capsulatus, B. haemophilus, B. nebulosus, B. tetani, B. oedematis maligni, B. fusiformis und noch andere seltenere anaerobe Parasiten der Vagina, sie alle werden mit den höchst virulenten Streptokokken und Staphylokokken auf eine Stufe gestellt. Und als Begründung dieser jeder klinischen Erfahrung widersprechenden Virulenzanschauung nichts weiter als der gelegentliche Nachweis im Blute. Diese Klassifizierung und Ueberschätzung der genannten Keime ist um so verwunderlicher, als 
Hamm selbst ausdrücklich als begünstigende Momente für die Entstehung der puerperalen Wundinfektion neben der Allgemeindisposition die "lokale Disposition" besonders gewürdigt wissen will, und in auschaulicher Weise die Rolle des Plazentarkreislaufes für das Entstehen dieser Krankheitserscheinungen schildert. Trotzdem hält er aber an dem primär parasitären Charakter und der penetrativen Fähigkeit aller einmal im Blute gefundenen Keime fest, so wenig sich diese Anschauung auch mit den jetzt hundertfach gemachten Beobachtungen beim fieberhaften Abort vereinigen lässt.

Die lokale Disposition, die wir zur Erklärung aller bakteriologischen Befunde bei puerperalen Erkrankungen heranziehen müssen, ist der uteroplazentare Kreislauf, der die verbindende Brücke zwischen dem infizierten fötalen Abortgewebe und dem mütterlichen Organismus darstellt. Solange hier Zirkulation besteht, besteht auch die Möglichkeit einer rein mechanischen Bakteriämie. Der positive Blutbefund aller möglichen gerade im Uteruslumen befindlichen Keime besagt bei erhaltenem Kreislauf nichts über die Pathogenität der Bakterien; auf keinen Fall ist er ausnahmslos als ein spontanes Eindringen anzusehen und als solches kritisch zu bewerten.

Wenn man nämlich den Blutnachweis aller intra abortum gefundenen Keime als ein spontanes Eindringen echter Parasiten auffasst, so wäre nicht zu verstehen, weshalb nach der Ausräumung rechtzeitig behandelter Aborte das Blut keimfrei bleibt, obwohl die Uterushöhle, wie man sich nach jedem Abort leicht überzengen kann, noch für längere Zeit keimhaltig ist. Es fehlt bei dieser Auffassung die Erklärung, weshalb vom Moment der Uterusentleerung ein Umschwung der klinischen Erscheinung eintritt und den angeblich parasitären Keimen jetzt plötzlich die Fähigkeit des weiteren Eindringens in den Kreislauf genommen sein sollte. Es müsste vielmehr unabhängig von dem Eingriff und der dadurch bedingten Strukturveränderung der Keimnachweis weiter gulingen, und der Körper entweder der Infektion erliegen oder erst nach schwerem Krankheitsverlauf allmäblich mit ihr fertig werden. Wie ganz anders das klinische Bild und die bakteriologischen Resultate! Die vor der Ausräumung bei jeder Druckschwankung massenhaft in die Blutbahn gepressten Keime der verschiedensten Art sind nach. Unterbrechung des Uteroplazentarkreislaufes wie abgeschnitten aus dem mütterlichen Kreislauf verschwunden. Die Temperatur fällt ab, der Krankheitsprozess ist auf das Endometrium lokalisiert. 
Die Keime sind nach wie vor der Ausräumung die gleichen geblieben. Verändert hat sich allein die anatomisehe Struktur der Uteruswand, indem sich durch ihre Kontraktion die klaffenden Gefässlumina geschlossen haben, und somit die direkte angiotische Verbindung zwischen Uterushöhle und mütterlichem Gefässsystem fortgefallen ist. Eine weitere mechanische Keimverschleppung ist unmöglich geworden, und die Blutbefunde entsprechen dem durch die Ausräumung geschaffenen neuen anatomischen Zustande; die Blutproben bleiben steril.

Sachs hat neuerdings die wichtige Rolle, die der uteroplazentare Kreislauf zur Erklärung der bakteriologischen Befunde als lokale Disposition spielt, angezweifelt, und die Begriffe der akuten und chronischen Resorption zur Begründung und Erklärung der klinischen und bakteriologischen Erscheinungen einzuführen versucht.

Auch aus seinen Ausführungen geht hervor, dass er zur Deutung der bakteriologischen Blutbefunde und zur Bewertung der gefundenen Keime eine anatomische Gelegenheitsursache als erforderlich betrachtet, die er aber nicht in dem uteroplazentaren Kreislauf, sondern in der resorbierenden Wundfläche des abortierenden bzw. puerperalen Uterus sieht. Alle Keime, die im Stadium der akuten Resorption, d. h. in dem Stadium, in dem sich eine frische Wundfläche im Uterus befindet, im Blute nachweisbar sind, gestatten keinen Rückschluss auf ihre Pathogenität; erst der Keimnachweis im weiteren Verlauf der Erkrankung, die dann in das Stadium der chronischen Resorption getreten ist, lässt infolge von Vermehrung der Keime im strömenden Blut eine üble Prognose stellen.

Nun haben aber die kontrollierenden Blutuntersuchungen bei fieberhaften Aborten und ebenso bei Fieber unter der Geburt, auf das später eingegangen werden soll, einwandfrei gezeigt, dass der positive Ausfall der Blutproben von der puerperalen Wundfläehe ganz unabhängig ist, und dass die Blutbefunde gerade im Gegensatz zu einem einfachen Resorptionsvorgang stehen und aus ihm nio orklärt worden können.

Wir finden nämlich die Hauptaussaat der Bakterien bei noch nicht unterbrochenem Plazentarkreislauf, zu einer Zeit also, wo eine resorbierende Wundfläche im Uterus noch gar nicht, oder doch in weit geringerem Umfange vorhanden ist als nach der Ausräumung. Durch die Manipulationen bei der Ausräumung erfolgt dann noch 
einmal eine grössere Ueberschwemmung durch mechanisches Einpressen der Keime in die durch den Eingriff direkt eröffneten Uteroplazentargefässe. Aber schon kurze Zeit danach fallen die Blutproben negativ aus, obwohl jetzt doch eine puerperale Wundfläche zur Resorption geschaffen ist, wie man sie sich günstiger nicht vorstellen kann. Schon wenige Minuten nach der Ausräumung zeigte sich auch in den von Sachs mitgeteilten Fällen trotz Keimgehalt der Uterushöhle das untersuchte Blut keimfrei, womit doch hinreichend bewiesen war, dass die puerperale Wundfläche und die einfache Resorption mit dem Keimnachweis im Blut nichts zu tun hat. Durch die kontrollierenden bakteriologischen Befunde wird gerade das Gegenteil bewiesen: Trotz der puerperalen Wund- und Resorptionsfläche und trotz der Keime im Uteruscavum findet kein Uebertritt der Bakterien in die Blutbahn mehr statt, weil eben der Uteroplazentarkreislauf unterbrochen wurde. Durch ihn werden die Blutbefunde in so zwangloser Weise erklärt, dass man nicht recht versteht, weshalb von Sachs diese durch die Tatsachen direkt widerlegte Resorption als neues Moment in die ganze Frage hineingebracht wurde.

Auch den Begriff der chronischen Resorption, die nach Sachs im Verlauf eines Kindbettfiebers oder bei Douglasabszessen eintritt, kann ich nicht gelten lassen. Wenn während des Wochenbettes mehrere Tage post partum Keime im Blut der Patientin gefunden werden, so hat dieser Nachweis mit einer Resorption nichts mehr zu tun. Resorbiert wären die Keime, wenn überhaupt dieser Vorgang in Frage käme, direkt im Anschluss an die Geburt bei der frischen ausgedehnten puerperalen Verletzung der Uterusschleimhant; der Nachweis von Keimen im Laufe der Erkrankung ist der Ausdruck einer spontanen Invasion penetrationsfähiger, primär virulenter Keime, aber nie ein Resorptionsvorgang.

\section{A. Die akut-fieberhaften Aborte}

(vorübergehende, mechanische Bakteriämie).

In diese Kategorie gehören alle die Fälle von fieberhaften Aborten, die, gleichgültig welche Bakterien sich bei ihnen im Blute nachweisen lassen, rechtzeitig zur Behandlung kommen, und bei denen eine Unterbrechung des Keimtransportes durch die Ausräumung gelingt, bevor irreparable Schäden im Organismus eingetreten sind. Sie sind der Typus einer mechanischen Bakteriämie. Ihr Verlauf und die bakteriologischen Befunde entsprechen der 
anatomischen Vorstellung. Die Patientinnen kommen hochfiebernd, mit noch ganz oder teilweise erhaltener Schwangerschaft zur Behandlung. Vor der Ausräumung fallen die Blutproben bei Fieberanstieg und besonders im Schüttelfrost positiv aus, im Anschluss an die Operation erfolgt noch einmal als Ausdruck der durch den Eingriff bedingten vermehrten mechanischen Keimaufnahme ein Temperaturanstieg mit positiven Befunden; dann aber zeigt uns die kritische Entfieberung und der negative Blutbefund, auch wenn in den nächsten Tagen noch Temperaturen auftreten sollten, den jetzt auf das Endometrium beschränkten Krankheitsprozess.

Die Zahl der von mir durch kontrollierende Blutuntersuchungen beobachteten Fälle dieser mechanischen Bakteriämien beträgt 100 . Die Frauen kamen hochfiebernd, aber, wie die Allgemein- und die Blutuntersuchung ergab, noch nicht im verschleppten Zustand zur Behandlung.

Im Lochialsekret wurden 32 mal Streptokokken, und zwar $22 \mathrm{mal}$ hämolytische gefunden.

Die ersten Blutproben vor der Ausräumung fielen in dieser Serie 89 mal positiv aus und liessen fast stets Bakteriengemische angehen, nur 12 mal handelte es sich um Reinkulturen, und zwar wurden als solche Streptokokken, Staphylokokken, Coli, Emphysematosus und Stäbchen gefunden. Unter den zahlreichen verschiedenartigsten Blutkeimen der Mischinfektionen fanden sich bei diesen ersten Blutproben $25 \mathrm{mal}$ Streptokokken, $10 \mathrm{mal}$ mit deutlicher Hämolyse.

Die Blutproben fielen aber in allen diesen Fällen nur dann positiv aus, wenn das Blut im Fieberanstieg oder während eines Frostes entnommen wurde; im Fieberabfall war das Blut ganz oder doch fast vollständig keimfrei.

Diese Feststellung einer vorübergehenden Bakteriämie war wichtig, da sie uns bei gleichzeitig fehlenden peritonitischen Erscheinungen den Fall als noch nicht "verschleppt" zu bezeichnen gestattete.

Die sichere Prognose wurde bei diesen Fällen an den der Ausräumung folgenden Tagen gestellt. Sämtliche jetzt entnommene Blutproben blieben in diesen hundert Fällen steril, so dass der Krankheitsprozess als abgeschlossen gelten konnte.

Unterstützend für die günstige Prognosenstellung war von vornherein, wenn, abgesehen von der erwähnten Keimfreiheit des Blutes im Fieberabfall, in der ersten Blutentnahme mehrere Bakterienarten wuchsen und bis zu ihrer makroskopischen Wahrnehmung 
mindestens 24 Stunden vergingen. Ein sehr rasches Wachstum einer in Reinkultur und in sehr grosser Anzahl angehenden Bakterienart liess, ganz abgesehen von dem Allgemeinbefinden, die Prognose von Anfang an ungünstig stellen. Eine Reinkultur wurde zwar, wie erwähnt, unter den hundert Fällen, die trotzdem alle geheilt sind, zwölfmal beobachtet; aber stets handelte es sich um eine relativ sehr geringe Anzahl von Kolonien (höchstens 20 bis 30), die ferner niemals vor 24 Stunden makroskopisch in der Röhre sichtbar geworden waren.

Von diesen hundert rechtzeitig behandelten vorübergehenden Bakterämien ist keine Patientin gestorben; die meisten entfieberten prompt nach der Ausräumung und blieben auch weiterhin fieberfrei, nur in wenigen Fällen schloss sich eine lokalisierte Endometritis mit leichteren Temperatursteigerungen an; niemals wurde das Entstehen eines thrombophlebitischen Prozesses beobachtet.

\section{B. Die chronisch-fieberhaften Aborte}

(dauernde bzw. spontane Bakteriämie).

Bei allen diesen Formen fieberhafter Aborte finden wir das Blut bei jeder Entnahme mehr oder minder reichlich mit Keimen überladen, gleichgültig ob die Probe bei noch erhaltenem oder bereits unterbrochenem Uteroplazentarkreislaụf entnommen wird.

Wenn auch mit dieser. Feststellung die Prognose des betreffenden Falles schon entschieden ist, so empfiehlt es sich doch vom bakteriologischen Standpunkte aus, je nach dem Einsetzen der Krankheitserscheinungen zwei ätiologisch verschiedene Formen $z u$ unterscheiden. Um sich nämlich die differierenden Befunde der Keimarten bei diesen permanenten Bakteriämien erklären zu können, wird man jedesmal zu unterscheiden haben, ob die positiven Befunde erst im Laufe des Puerperiums, in den ersten Tagen nach der Ausräumung eines nur leicht fiebernden oder anfangs fieberfreien Abortes, zur Beobachtung gekommen sind (spontane, postabortive Bakteriämie), oder ob sich die Infektionserscheinungen kontinuierlich an die Ausräumung eines bereits fieberhaften Abortes angeschlossen haben, ob also mit anderen Worten im Gegensatz zu den vorübergehenden Bakteriämien die Erscheinungen mit der Ausräumung nicht abklingen, sondern in bedrohlicher Weise fortdauern (dauernde Bakteriämie). 
314 Warnekros, Zur Prognose der puerperalen Fieberstejgerungen.

Zur Erklärung der bakteriologisehen Befunde bei diesen beiden Krankheitsformen müssen wiederum die anatomischen Verhältnisse herangezogen werden.

Es ist für die Entstehungserklärung der Infektion und besonders für die Beurteilung und Klassifikation der Keime, die schliesslich diesen Zustand einer Allgemeininfektion herbeigeführt haben, ron wesentlicher Bedeutung, ob die Bakterien bei noch erhaltenem Uteroplazentarkreislauf oder erst nach seiner Unterbrechung, im Verlauf des Puerperiums, in die Uterushöhle und von dort in die Blutbahn gelangt sind.

Wie wir nämlich gesehen haben, steht bei noch erhaltenem Uteroplazentarkreislauf allen in das Cavum uteri gelangten Bakterien der Weg in die Blutbahn offen, da sie unabhängig von penetrativen Eigenschaften rein mechanisch von dem Blutstrom in den allgemeinen Kreislauf mitgenommen werden.

Nicht so beim ausgeräumten, entleerten Uterus mit gut kontrahierter Wand, wie wir ibn uns im Puerperium vorstellen müssen, da sich jetzt nach Fortfall der Gefässbrücke nur der mit invasiver Fähigkeit ausgestattete Keim spontan den Weg in das Lymph- und Blutgefässsystem bahnen kann.

Man wird daher in allen Fällen, wo nach anfangs fieberfreiem Verlauf die Erscheinungen der Infektion erst in den ersten Tagen nach der Ausräumung auftreten (spontane postabortive Bakteriämie), zu einer Zeit also, wo die Möglickeit einer mechanischen Verschleppung fortfällt, nur primärpathogene Keime mit ausgesprochen invasiver Fähigkeit im Blute finden.

Im Gegensatz zur entsprechenden puerperalen Infektion im Anschluss an eine fieberfreie Geburt sind diese erst im Anschluss an die vollständig und rite ausgeführte Ausräumung auftretenden Infektionen nach Abort aber relativ selten. Die Aborte, die wir fieberfrei zur Behandlung bekommen, bleiben für gewöhnlich auch in ihrem weiteren Verlauf fieberfrei, was sich aus der geringeren Entwickelung der Lymph- und Blutgefässe während der früheren Monate der Schwangerschaft erklären dürfte. Kommt es aber gelegentlich der Ausräumung zu einer artifiziellen oder im Anschluss an den Abortverlauf zu einer aszendierenden Infektion, so sind die Erreger der sich jetzt erst manifestierenden Allgemeinerscheinungen, abgesehen von grobmechanischen Perforationsverletzungen, ausnahmslos Strepto- oder Staphylokokken. Wenn 
auch die Staphylokokken im allgemeinen ein weit geringeres Penetrationsvermögen besitzen, als die Streptokokken, so sind doch gerade bei Aborten mehrere tödlich endigende Staphylokokkeninfektionen, die in diese Gruppe gehören, d. h. also erst im Anschluss an die Ausräumung eines fieberfreien Abortes, beschrieben worden. Dagegen wurde kein einziger der übrigen zahlreichen Keime unter den gleichen anatomischen Verhältnissen als der Krreger einer spontanen postabortiven Bakteriämie angetroffen.

Die Prognose ist in allen diesen Fällen eine durchaus ungünstige. Finden wir bei einer anfangs fieberfreien Patientin, mit dementsprechend negativen Blutbefunden, erst im Laufe des Wochenbettes einen Keimübertritt ins Blut, so ergibt die Ueberlegung, dass es sich nur um primär virulente Bakterien handeln kann, die sich selbständig den Weg in den Blutkreislauf gebahnt haben.

Damit ist die Prognose absolut infaust zu stellen, wie denn auch alle in der Literatur beschriebenen Fälle letal geendigt haben.

Bakteriologisch und anatomisch wesentlich anders liegen dagegen die Verhältnisse bei allen Fällen von fieberhaften Aborten, bei denen hohe Temperatursteigerungen schon vor der Ausräumung bestanden, und bei denen sich die Erscheinungen der Sepsis bzw. Pyämie kontinuierlich an die spontane oder operative Unterbrechung der Schwangerschaft anschlossen (dauernde Bakteriämie).

Die Gelegenheit, ins Blut zu kommen, war hier bis zur Ausräumung allen Keimen, eben weil sie bereits bei noch erhaltenem Uteroplazentarkreislauf in die Uterushöhle gelangt waren, gleichmässig gegeben, und es fragt sich nun, ob sich unter diesen Umständen neben echten Parasiten auch sonst nicht pathogene Keime, wenn dieser Keimtransport über längere Zeit in grosser Menge erfolgt, die Fähigkeit der Virulenz gegenüber dem Wirt aneignen können, nachdem sie einmal ohne ihr Zutun durch besonders günstige anatomische Umstände bis in die Blutbahn transportiert worden sind.

Selbstverständlich werden sich auch bei diesen Infektionen wieder die primär-pathogenen Keime am schnellsten und häufigsten dem Wirt gegenüber virulent und deletär erweisen. Das bedarf keiner weiteren Begründung. Wir finden daher auch in der weitaus überwiegenden Anzahl aller Fälle, die in diese Gruppe gehören 
und die zur schweren Allgemeininfektion oder zum Exitus der Patienten geführt haben, als Erreger der Krankheitserscheinungen wiederum Strepto- und Staphylokokken.

Es hat sich aber gezeigt, dass unter Voraussetzung einer länger dauernden plazentaren Bakteriämie gelegentlich auch Keime die Fähigkeit der Weiterentwickelung und Vermehrung im Blate des Wirtes erwerben können, denen man eine primäre Pathogenität und die Fähigkeit der spontanen Invasion absprechen muss. Es handelt sich bei diesen Keimen um eine erworbene sekundäre Virulenz; die Keime sind dem Wirt nur deshalb pathogen geworden, weil sie auf einem so bequemen Wege durch den Uteroplazentarkreislauf immer wieder in überaus grossen Mengen direkt in ein so lebenswichtiges Gewebe, wie es das Blut ist, gelangt sind und hier immer wieder eine Veränderung und Zersetzung des Blutes hervorgerufen und so ein allmähliches Versiegen der bakteriziden Stoffe bewirkt haben. Die Keime wären dem Wirt nie deletär geworden, wenn sie nicht die präformierten Wege in die Blutbahn vorgefunden hätten, wenn sie also erst nach der Ausräumung in das Cavum uteri gekommen wären und sich von hier selbständig hätten weiter arbeiten müssen. Sind aber die Vorbedingungen einer mechanischen Verschleppung erfüllt, dann können allerdings auch diese sekundär virulenten Keime die Widerstandskraft des Organismus so schwer treffen, dass ein irreparabler Zustand eintritt. Die Entfaltung des pathogenen Einflusses ist aher, wie gesagt, abhängig von den anatomischen Verhältnissen und von der Dauer der Einwirkung auf den Organismus. Darin liegt der prinzipielle Unterschied gegenüber den primär-virulenten Bakterien, den echten Parasiten.

Wir werden daher diese Infektion mit sekundär virulent gewordenen Keimen nur in solchen Fällen beobachten können, wo ein fiebernder, unausgeräumter oder unvollständig ausgeräumter Abort längere Zeit unbehandelt liegen bleibt, und somit für die betreffenden Bakterien die Vorbedingungen zur Entwickelung und Entfaltung ihres deletären Einflusses erfüllt sind: bequemer, rein mechanischer Transport in die Blutbahn, der über längere Zeit anhält.

Wenn auch die Zahl der Keime, bei denen man diese erworbene Pathogenität beobachtet hat, bis jetzt relativ gering und auch die Zahl der hierher gehörenden Krankheitsfälle im Vergleich zur Häufigkeit der fieberhaften Aborte eine sehr kleine ist, so ist 
doch durch die systematisch durchgeführte Blutuntersuchung aller Temperatursteigerungen in einer Reihe von Fällen der Beweis erbracht, dass einzelne für gewöhnlich als Saprophyten vegetierende Keime sekundär die Fähigkeit erwerben können, sich dem Blutmedium anzupassen, sich darin zu vermehren und einen schwer krankmachenden und selbst tödlichen Einfluss auf den Organismus auszuüben.

Das sind die Fälle, die die Trennung zwischen Saprophyten und Parasitén scheinbar hinfällig gemacht haben, und die man sich nur richtig erklären kann, wenn man strikt an dem Begriff der primären und sekundär erworbenen Virulenz festhält. Unterzieht man die in der Literatur mitgeteilten Krankheitsfälle daraufhin der Kritik, so findet man, dass es sich stets um Aborte gehandelt hat, die bereits vor der Ausräumung gefiebert hatten, und bei denen sehr häufig kriminelle Eingriffe vorgenommen worden waren. Es hatte also den Keimen stets die Vermittlung des Uteroplazentarkreislaufes zu Verfügung gestanden, und es handelt sich demnach in allen diesen Fällen um eine erst erworbene Virulenz der betreffenden Bakterien.

Gefunden wurden im Blute auch anschliessend an die Ausräumung, also nicht nur bei noch erhaltenem Plazentarkreislauf, an den folgenden Tagen bzw. bei der Sektion in den Organen als ursächliche Erreger der Infektion:

1. Coli (Sachs).

2. Micrococcus tetragenus anaerobius ( $\mathrm{Hamm}$ ).

3. B. aerogenes capsulatus (Heynemann, Schindler, Bondy, Little).

4. Pseudotetanus (Burkhard).

5. Tetanus (Gregory, Ballint, Commandeur, Brault und Faroy, Gache, Métal).

6. Pneumokokken (Bondy, Jensen).

7. B. pneumoniae Friedländer (Heinemann).

Ich habe dreimal eine solche erworbene Virulenz, und zwar zweimal mit tödlichem Ausgang, unter den von mir untersuchten Fällen beobachten können.

Damit haben diese Keime, soweit sie den Tod oder ein lebensbedrohliches Krankheitsbild herbeigeführt haben, zweifellos ihren saprophytären Charakter aufgegeben und sind in dem speziellen Fall pathogen geworden; die Möglichkeit dieser Charakteränderung war aber an ganz bestimmte Vorbedingungen geknüpft gewesen, ohne 
welche sie niemals einen dominierenden Einfluss über den erkrankten Organismus gewonnen hätten.

Deshalb halte ich die unterschiedliche Bezeichnung einer sekundär erworbenen Virulenz für durchaus erforderlich und möchte die betreffenden Keime nicht ohne weiteres mit den echten primär-virulenten Keimen anf eine Stufe stellen, da ihnen die wichtige penetrative Fähigkeit der spontanen Invasion nicht gegeben ist.

Immerhin ist aber die scharfe Trennung zwischen Saprophyten und Parasiten durch den Nachweis dieser Krankheitsbilder gefallen, und unter gewissen mechanisch-anatomischen Voraussetzungen die Uebergangsmöglichkeit von der einen zur anderen Form bakteriologisch und klinisch festgestellt.

Inwieweit und ob überhaupt dieser Uebergang sich bakteriologisch verallgemeinern lässt, ist schwer zu entscheiden; soviel steht aber fest, dass unter den ganz einzigartigen anatomischen Verhältnissen, wie wir sie nur an dem puerperalen Cterus mit seinem neu erstandenen, dem Körper eingeschalteten Kreislauf beobachten können, saprophytäre Keime ausnahmsweise virulenten Charakter annehmen. Die Conditio sine qua non bleibt aber die "lokale Disposition", und das ist in unseren Fällen der uteroplazentare Kreislauf.

Bei den von mir beobachteten 13 Fällen einer chronischen Bakteriämie handelte es sich $10 \mathrm{mal} \mathrm{um} \mathrm{primär} \mathrm{virulente}$ Keime, 8 mal um Streptokokken und 2 mal um Staphylokokken. Die Streptokokken zeigten 5 mal eine ausgesprochene Hämolyse, ebenso beide Male die Staphylokokken.

Die Patientinnen kamen ausnahmslos in arg verschlepptem Zustande zur Behandlung; alle hatten Tage und Wochen lang draussen geblutet und gefiebert.

Die ersten Blutproben liessen, auch wenn sie im Fieberabfall entnommen worden waren, schon nach wenigen Stunden sehr zahlreiche Kolonien in der Röhre angehen; 5 mal wurde neben der Blutinfektion bereits bei der Aufnahme eine manifeste eiterige Bauchfellentzündung diagnostiziert und durch Punktion. bestätigt.

Die Befunde der weiteren Blutuntersuchung blieben durch die Ausräumung, Totalexstirpation und Drainage unbeeinflusst; regelmässig konnten die Keime in zunehmender Menge im Blut nachgewiesen werden. Sämtliche Frauen sind gestorben. 
Etwas günstiger liegen die Verhältnisse bei den dauernden Blutinfektionen mit sekundär virulenten Keimen. Ich habe drei derartige Fälle beobachtet; auch diese Frauen kamen erst nach tagelangem Abwarten in schwerkrankem Zustande zur Behandlung in die Klinik.

In dem einen Fall wurden im Blute der Patientin vor und nach der Ausräumung unabhängig von der Temperaturkurve Tausende von Kolonien gramnegativer kurzer Stäbchen gefunden, die sich auf verschiedenen Agararten nicht weiter züchten liessen und nur in Aszitesbouillon ein schwaches Wachstum zeigten. Nach einem Bericht aus dem hiesigen Institut für Infektionskrankheiten, wohin ich die Kulturen zur Untersuchung gesandt hatte, sind ähnliche Bakterien bei der Abortseuche der Rinder beschrieben worden. Die Patientin starb zwei Tage nach der Aufnahme.

In dem zweiten Falle handelte es sich um eine Infektion mit dem B. aerogenes capsulatus. Die Frau hatte sich vor mehreren Tagen den Abort mit einer schmutzigen Spritze einzuleiten versucht. Sie kam stark ikterisch verfärbt in sehwerkrankem, leichtsomnolentem Zustande in unsere Behandlung. Auch hier fielen die Blutproben beim Fieberanstieg und -Abfall gleichmässig positiv aus; die grossen Traubenzucker-Agarröhren wurden von den Keimen nach wenigen Stunden gesprengt. Die Gasbildung im Gewebe, die bereits bei der Operation (es wurde die abdominale Totalexstirpation ausgeführt) konstatiert werden konnte, nahm am folgenden Tage sichtlich zu. Die Patientin starb 50 Stunden später unter den ausgesprochenen Zeichen einer schweren Dyspnoe.

Der dritte Fall endlich kam drei Wochen nach Abgang der Frucht fiebernd und blutend in die Klinik. In der Blutkultur wurden etwa 20 Kolonien zarter anaerober Stäbchen gefunden; aus dem Uterusfundus wurde ein grösserer Plazentarrest entfernt.

In der Blutprobe am Tage nach der Ausräumung wuchsen 4 Kolonien anaerober Stäbchen. In einer weiteren Entnahme am dritten Tage konnten nur noch 2 Kolonien derselben Stäbchen in $20 \mathrm{com}$ Blut gefunden werden. Die Frau entfeberte langsam und wurde gesund entlassen.

Aehnliche Fälle, die trotz des puerperalen Keimnachwejses geheilt wurden, sind in der Literatur, und zwar von $\mathrm{Hamm}$ für den Micrococcus tetragenus anaerobius und ron Heynemann für den B. pneumoniae Friedländer, beschrieben worden. Sie gehören 
aber zu den grossen Seltenheiten und werden nur ausnahmsweise beobachtet werden.

Die Prognose bei allen diesen fieberhaften Aborten mit einer dauernden, durch die Ausräumung nicht mehr koupierten, Bakteriämie ist somit eine schlechte, mag es sich nun um primär oder sekundär virulente Krankheitserreger handeln. Sobald wir, abgesehen von dem postoperativen Schüttelfrost, nach Unterbrechung des Uteroplazentarkreislaufes noch regelmässig Keime im Blut antreffen, müssen wir in diesem Nachweis ein Fiasko der körperlichen Abwehrstoffe erblicken; die Bakterien haben sich entweder die Fähigkeit der selbständigen Weiterentwickelung im Blute erworben, oder es hat sich in den abführenden Venenstämmen ein neuer Krankheitsherd gebildet, von dem aus das Blut der Patientinnen dauernd mit Keimen weiter gespeist wird.

Allerdings darf die Beurteilung nicht ganz unterschiedslos ausfallen, sondern wir können auch hier noch einmal zwischen den primär virulenten und den sekundär virulenten Keimen unterscheiden. Der fortgesetzte Nachweis von Strepto- bzw. Staphylokokken ist ausnahmslos letal, während ein Angehen eines der zahlreichen übrigen Mikroben mit erworbener Virulenz noch die Hoffnung auf einen eventuellen Sieg des Organismus zulässt, wie der eine von mir beobachtete und der von Hamm und Heynemann mitgeteilte Fall beweist.

Wie bei allen bakteriologischen Blutuntersuchungen sind folgende Punkte bei der speziellen prognostischen Beurteilung auch hier wieder besonders zu berücksichtigen: die Regelmässigkeit der Bakterien im Blut, die Zahl der gefundenen Keime, die Reinkultur und die Wachstumsschnelligkeit.

Ein rasches Angehen von Keinkulturen in zunehmender Menge bei jeder Blutentnahme ist durchaus ungünstig, und zeigt uns das völlige Fehlen einer Reaktion von Seiten des erkrankten Organismus, während der gelegentliche Nachweis einzelner langsam wachsender Kolonien selbst nach Unterbrechung des Uteroplazentarkreislaufes entschieden etwas besser zu beurteilen ist und den Fall nicht von vornherein ganz aussichtslos erscheinen lässt.

Selbstverständlich wird man auch das allgemeine Krankheitsbild, das uns die Patientinnen schon bei der Aufnahme bieten, prognostisch berücksichtigen und bei einer schwer ikterisch verfärbten Kranken mit lackfarbenem Blut und beschleunigter Atmung, 
ganz abgesehen von den bakteriologischen Ergebnissen, die Prognose ungünstig stellen.

\section{Die Peritonitis intra und post abortum.}

Einer kurzen Besprechung bedarf noch die eiterige Peritonitis im Verlauf eines fieberhaften Abortes hinsichtlich der bakteriologischen Befunde und ihrer prognostischen Bedeutung.

Die Bauchfellentzündung kann sich bei noch erhaltenem Plazentarkreislauf oder anschliessend an die Ausräumung eines Abortes entwickeln; ihr Entstehen ist, im Gegensatz zur Bakteriämie, vollkommen unabhängig von dieser anatomischen lokalen Disposition. Unsere Ueberlegung, wie die Bakterien und welche Arten von ihnen bis ins Bauchfell vordringen können, muss zwei Möglichkeiten berücksichtigen, je nachdem wir uns vorstellen, ob es sich um eine intakte oder artifiziell irgendwie lädierte Gebärmutterwand handelt.

Bei nicht verletzter Gebärmutterwand ist die einzige Kommunikation zwischen Uteruscavum und Bauchfell das Tubenlumen, das aber nach allen Erfahrungen äusserst selten als direkte Fort- und Ueberleitung der septischen Prozesse auf das Peritoneum benutzt wird. Wahrscheinlich schwillt die Tubenschleimhaut bei allen intrauterinen Entzündungsprozessen an, und das leicht verschlossene feine Lumen verhindert eine direkte Uebertragung auf das Bauchfell. Die eiterige Peritonitis ist daher, wenn eine Läsion nicht vorliegt, stets der Ausdruck einer Infektion mit hochvirulenten Këmen, die unabhängig von jeder anatomischen Gelegenheitsursache selbständig durch die Muskulatur der Gebärmutter bis ins Bauchfell vorgedrungen sind. Die bakteriologische Untersuchung wird daher in allen diesen Fällen nur primär virulente Keime (Strepto- bzw. Staphylokokken) ergeben, und die Prognose ist bei diesem Befund ausnahmslos letal zu stellen.

Hat dagegen bei den Ausräumungsversuchen eine perforierende Verletzung der Uteruswand stattgefunden, so ist unter diesen Umständen die Perforationsöffnung die lokale Disposition für das Entstehen einer Peritonitis. Das perforierende Instrument kann das Bauchfell mit den verschiedensten Keimen gleichsam geimpft haben. Es können daher neben primär virulenten Keimen auch sekundär virulente im Punktat gefunden werden. Der Nachweis einer Mischinfektion lässt daher, besonders beim Verdacht einer Verletzung, die Möglichkeit offen, dass es sich nicht um hochvirulente, spontan penetrative Bakterien zu handeln braucht; die Aussicht auf Lokali- 
322 Warnekros, Zur Prognose der puerperalen Fiebersteigerungen.

sation und eventuelle Heilung ist etwas grösser, wenngleich auch hier, wie bei jeder diagnostizierten exsudativen Peritonitis, die Prognose recht fraglich gestellt werden muss.

Hinsichtlich der Blutbefunde ist zu erwähnen, dass die eiterige Peritonitis nicht immer mit einer Bakteriämie einhergeht, wenn auch für gewöhnlich die Blutproben positiv ausfallen. Es kann sich aber auch einmal der Prozess allein auf den Lymphwegen und -spalten ausgebreitet und die Blutbahn verschont haben, so dass man dann die Prognose des betreffenden Falles nicht aus dem Blutbilde, sondern aus dem Perkussionsbefunde und dem Punktat der Bauchhöhle stellen muss.

Um sich von den anatomisch-pathologischen Verhältnissen und der wichtigen Rolle, die die Plazenta mit ihrem Kreislauf bei der Erscheinung der Bakteriämien spielt, einen möglichst sinnfälligen Begriff zu machen, habe ich von den steril aufgefangenen Plazenten fieberhafter Aborte und, wo es ging, auch aus der Wandung operativ oder bei der Sektion gewonnener Uteri Bakterienschnittfärbungen angefertigt.

Betrachten wir zunächst die Plazentarschnitte, so hat sich bei diesen Untersuchungen gezeigt, dass bei jedem fieberhaften Abort, gleichgültig ob der Fall günstig oder letal verlief, die Plazenta in ihren intervillösen Räumen mit Bakterien geradezu durchsetzt ist. Die Keime, die im Laufe eines Abortes spontan in die Uterushöhle aszendiert oder artifiziell in sie verschleppt worden sind, finden bei den zahlreichen Zerreissungen und Verletzungen, die die Plazenta infolge partieller Loslösung bei dem meist chronischen Abortverlauf erfährt, hinreichend Gelegenheit, auch ohne eigene invasive Fähigkeiten in das Plazentargewebe vorzudringen und sich hier, wie in dem denkbar günstigsten Nährboden, zu vermehren.

Die Figg. 1 und 2 (Taf. IV) zeigen Bakterienschnittfärbungen von Plazenten fieberhafter Aborte, die aus einer grösseren Reihe untersuchter Fälle als zwei Typen herausgegriffen sind. In Fig. 1 ist der Rand der Plazenta mit den noch anhaftenden Eihäuten getroffen; man sieht, wie die Bakterien in breiten Zügen durch die Häute bis in die intervillösen Räume vordringen, die in diesem Fall mit Diplokokken und in dem anderen (Fjg. 2) mit Keimen verschiedenster Art vollgepfropft sind. Man versteht bei diesen Bildern unter Berücksichtigung des Uteroplazentarkreislaufes ohne weiteres, wie von 
diesem Bakterien-Reservoir aus bei jeder grösseren Druckschwankung das mütterliche Gefässsystem mit Bakterien überschwemmt werden muss. Dass man dann bei der klinischen Reaktion, dem Schüttelfrost, das Blut mit allen möglichen gerade im Uterus befindlichen Keimsorten überladen findet, und dass man aus diesen positiven Blutbefunden keinen Rückschluss auf die Pathogenität der gefundenen Keime ziehen kann, bedarf keiner weiteren Begründung.

Von besonderem Interesse aber ist die Entscheidung der Frage, wie sich die Bakterien der Uteruswand gegenüber verhalten, und welche Unterschiede auch an den Organschnitten wiederum bei der vorübergehenden und dauernden Bakteriämie beobachtet werden können. Es sollen daher die rechtzeitig ausgeräumten und post abortum entfieberten Fälle den verschleppten und durch die Ausräumung nicht mehr beeinflussten Aborten bei der bakterioskopischen Betrachtung gegenübergestellt und an der Hand der einzelnen Präparate gezeigt werden, inwieweit sich auch bier ein Unterschied zwischen Saprophyten und Parasiten aufstellen lässt.

Schon aus dem klinischen Verlauf und den bakteriologischen Blutbefunden musste man annehmen, dass sich bei allen geheilten Fällen die Infektion, gleichgültig um welche Bakterienart es sich handelt, also auch bei virulenten Strepto- oder Staphylokokken, auf die Plazenta und Eihäute beschränkt und die eigentliche Uterusmuskelwand unbeeinflusst lässt. Der prompte Temperaturabfall und das Ausbleiben der Fröste nach der Ausräumung beweist uns klinisch schon den lokalisierten Sitz des Krankheitsherdes. Denn wenn der Prozess, z. B. bei einer akuten Streptokokkeninfektion, auch auf die Uteruswand übergegriffen hätte, müsste sich der weitere postabortive Verlauf als eine schwere Endometritis abspielen.

Der direkte histologische Nachweis über diese nur oberflächliche Lokalisation der Bakterien war allerdings durch Schnittfärbung schwer zu erbringen, da man eben in allen zur Heilung gekommenen Fällen das betreffende Organ nicht zur Untersuchung erhält.

Durch einen Zufall bin ich aber in den Besitz eines solchen Uterus gekommen. Es handelte sich um einen fieberhaften Abort im dritten Monat mit noch zum Teil retinierter Plazenta. Die Indikation zur Totalexstirpation des Uterus war nicht durch das Fieber, das wir uns rein plazentar-bakteriämisch erklärten, gegeben, sondern wurde bedingt durch eine ausgedehnte Verletzung 
des Organs, die sich die Patientin bei einem Abtreibungsversuch beigebracht hatte und die eine Erhaltung des Uterus unmöglich machte. Die Blutproben fielen beim Fieberanstieg und während des Frostes vor der Operation positiv aus, als Zeichen dafür, dass der Kreislauf wahrscheinlich von der Plazentarstelle aus mit Bakterien überschwemmt wurde. Nach der Exstirpation blieb das Blnt steril. Auch das Befinden der Patientin war nach der Operation vorïbergehend gut. Sie entfieberte zunächst, ging dann aber später an einer aufsteigenden Peritonitis zu Grunde, die von der. Verletzung des Abtreibungsversuches ausging, wobei auch neben der Perforation des Uterus das Douglasperitoneum in breiter Ausdehnung lädiert worden war. Ohne die Nebenverletzung, die zur Peritonitis geführt hatte, wäre die Patientin sicherlich durchgekommen, da sie mit den temporär in die Blutbahn verschleppten Keimen nach Unterbrechung des Uteroplazentarkreislaufes (Exstirpation), wie die postoperativen steril gebliebenen Blutproben bewiesen, fertig geworden war. Durch die Peritonitis wurde das klinische Bild etwas verwischt; der Uterus entspricht aber zweifellos dem Zustande, wie wir ihn uns bei allen vorübergehenden, akuten Bakteriämien im Verlauf eines fieberhaften Abortes vorstellen müssen.

Im Fundus uteri fand man noch einen grösseren Plazentarrest adhärent, der im Zusammenhang mit der Uteruswand herausgeschnitten und eingebettet wurde. Man hatte somit an dem Präparat Gelegenheit, neben der Uterusmuskulatur auch noch Uteruswand und Plazenta im Zusammenhang bakterioskopisch zu untersuchen.

Bei den Schnittfärbungen ergaben sich nun folgende interessante Befunde: Es zeigte sich. wie in Fig. 3 (Taf. IV) bei schwacher Vergrösserung abgebildet ist, dass das ganze Plazentarstück mit Bakterien durchsetzt ist, und dass die Keime mit den Zotten in die mütterlichen Gefässe der Uteruswand eine kurze Strecke weit hineinragen und so von hier aus direkt in das mütterliche Gefässsystem weiter transportiert werden mussten. Dagegen war die Uterusmuskulatur vollkommen frei von Keimen. Auch an der Stelle, an der der Plazentarrest noch adhärent war, waren die Bakterien, wie gesagt, nur soweit nachweisbar, als die Zotten in die abführenden Vonenstämme hineinragten; die eigentliche Muskulatur war scharf getrennt bakterienfrei. An den Stellen des Präparates, wo keine Plazentarreste der Wand mehr aufsassen, 
waren die Gefässe fest kontrahiert; Bakterien konnten hier nur in den aufgelagerten Blutmassen gefunden werden.

Die Infektion war somit rein plazentar; irgend eine spontane Invasion der Keime in das mütterliche Gewebe hatte trotz der positiven Blutbefunde vor der Operation nicht stattgefunden; die Verschleppung erfolgte rein mechanisch mit dem plazentaren Blutstrom, der die Erscheinungen restlos erklärt.

Der Fall kann als Typus aller fieberhaften noch nicht verschleppten Aborte mit vorübergehenden, mechanisch bedingten Bakteriämien angesehen werden — als ein Typus aller der Fälle, wo die rechtzeitige Ausräumung den Krankheitsprozess koupiert hat und durch sie fast momentan ein Umschwung sämtlicher Erscheinungen herbeigeführt wird.

Ich habe in mehreren solchen Fällen, die nach der Ausräumung prompt entfieberten und nach wenigen Tagen gesund entlassen werden konnten, vorsichtig kleinere Deziduastückchen mit einer scharfen Kurette aus dem Uteruskavum entfernt, um mir aus der bakterioskopischen Färbung dieser Schnitte eine Vorstellung von dem sich jetzt am Innern der Uterushöhle am Endometrium abspielenden Prozess machen zu können.

Die Untersuchung ergab in allen diesen Fällen eime auf die oberflächlichsten, nekrotischen Schleimhautschichten lokalisierte Keimansiedlung; nur in seltenen Fällen waren die Bakterien auch noch etwas tiefer zwischen den Drüsen und Gefässquerschnitten anzutreffen, aber nie so zahlreich, wie in der oberllächlichen nekrotischen Schicht. Fjg. 4 (Taf. IV) zeigt einen solchen bakterioskopischen Schnitt eines curettierten Stückchens, das aus dem Endometrium eines Uterus zwei Tage nach der Ausräumung eines schwer fieberhaften Abortes mit einer akuten Streptokokken-Bakteriämie entnommen worden war. Die Keime liegen dicht gedrängt in der oberflächlichen nekrotischen Zone; weiter hinein in das Gewebe der Uterusschleimhaut konnten sie nur ganz vereinzelt angetroffen werden.

Betrachten wir die bakterioskopischen Bilder der zweiten Abortgruppe, die zum Exitus der betreffenden Patientinnen geführt haben, weil die rechtzeitige Entfernung des Bakterienreservoirs versäumt wurde, so finden wir hinsichtlich der Plazentarbefunde keine wesentlichen Unterschiede gegenüber den geheilten Fällen. Auch hier sind die intervillösen Räume massenhaft mit Bakterien angefült und zum Teil von ihnen gleichsam ausgegossen. 
326 Warnekros, Zur Prognose der puerperalen Fiebersteigerungen.

Der wesentliche Unterschied liegt hier in dem Verhalten der Bakterien der Uteruswand gegenüber, allerdings nur in den Fällen, wo durch primär virulente Keime der Tod herbeigeführt wurde. Ueber die bakterioskopischen Befunde bei den tödlich endigenden Infektionen mit sekundär virulenten Partien wird zum Schluss berichtet werden.

Der Angriffspunkt aller primär virulenten Keime auf den mütterlichen Organismus ist ein zweifacher. Zunächst werden auch sie den bequem vermittelnden Weg des Uteroplazentarkreislaufes benutzen und von hier aus mehr oder minder rasch, je nach ihrer speziellen Virulenz, klinisch das Bild der Sepsis oder Pyämie herbeiführen.

Der zweite Angriffspunkt ist aber das Endometrium selbst; die spontan-invasiven Keime werden also auch unabhängig von der Plazentarstelle und den sich daraus entwickelnden Venen direkt in die Uterusmuskulatur einbrechen und hier je nach der Zeit der Erkrankung eine schwere Endometritis, Metritis oder fortleitend eine Peritonitis herbeiführen.

Die Bilder der Uteruswand entsprechen daher in den verschiedenen Fällen dem verschiedenen Virulenzgrad der Bakterien und der Dauer ihrer Einwirkung auf den erkrankten Organismus.

Die Figg. 5 und 6 (Taf. IV und V) zeigen Abschnitte der Gebärmutterwand, die von zwei verschiedenen Fällen bei der Sektion gewonnen wurden. Es handelte sich um fieberhafte Aborte, die verschleppt zur Behandlung kamen und kurze Zeit nach der Ausräumung gestorben sind.

In Fig. 5 sind die Bakterien direkt in die Muskulatur eingebrochen und diffus infiltrierend durch die Muskelwand weiter gewachsen. Am unteren Rande des Schnittes, der dem Endometrium entspricht, ist das Gewebe nekrotisch zerfetzt und eiterig zerfallen. Die betreffende Patientin ging unter den Zeichen einer Streptokokkenperitonitis zu Grunde.

Fig. 6 zeigt den Abschnitt eines Uterus, bei dem die Bakterien (Streptokokken) vornehmlich die Gefässe ergriffen und in ihnen zu einer ausgedehnten Thrombosenbildung geführt hatten. Die Baktorien füllten die Lumina der Venen fast vollständig aus und konnten in allen im Schnitt getroffenen Gefässverzweigungen bis dicht unter die Serosa nachgewiesen werden. An einzelnen Stellen waren die Keime durch die Venenwandung hindurch in das umgebende Gewebe hineingewachsen, In der nekrotischen Zone der 
sू
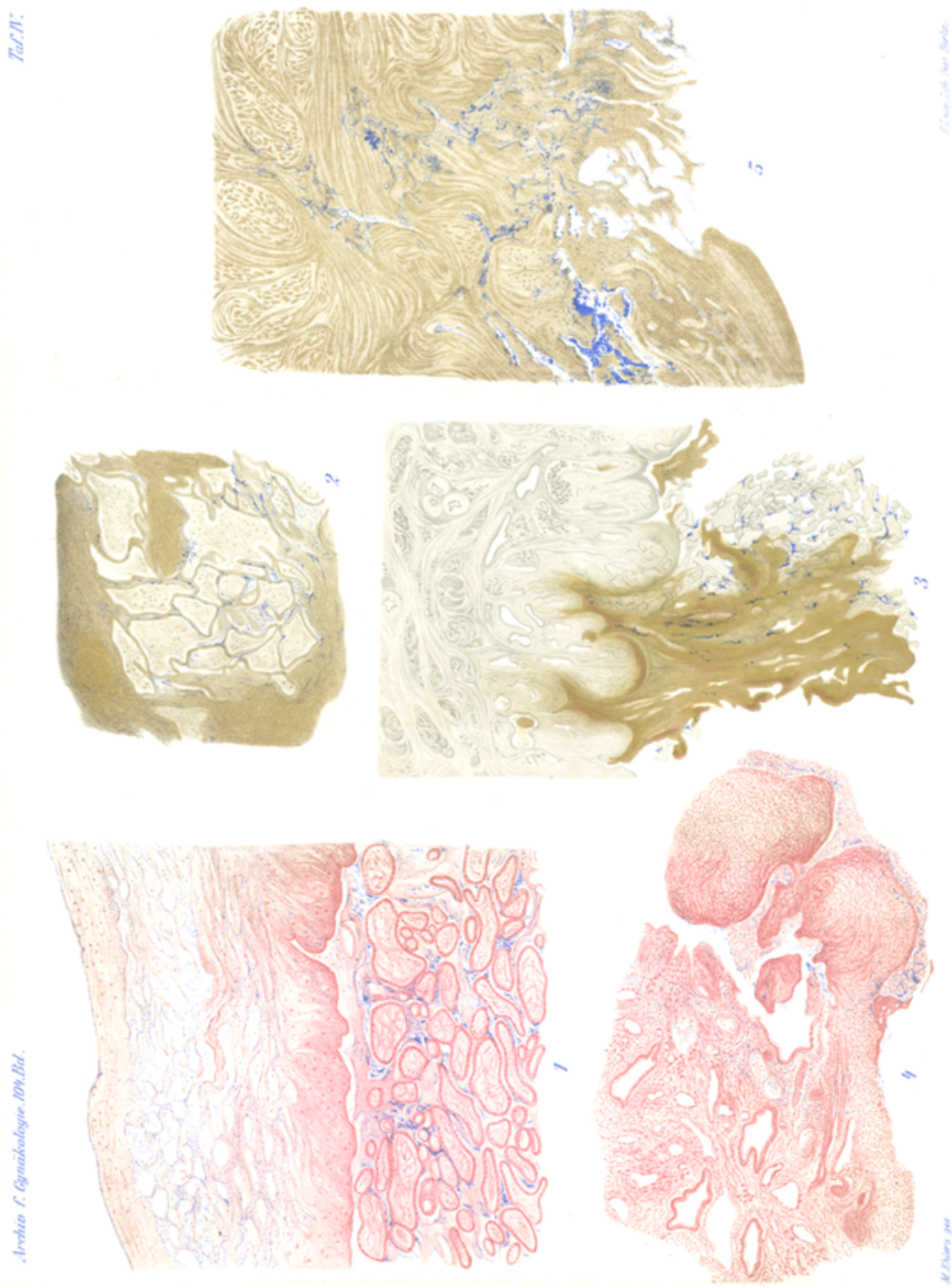
oberlächlichsten Dezidua-Schicht wurden neben den Streptokokken auch noch Stäbchen gefunden; weiter in das lebende Gewebe hinein waren aber nur die ersteren nachweisbar. Die Patientin starb unter dem Bilde einer Pyämie.

Diese Bilder sind der Ausdruck einer enormen Invasionskraft der betreffenden Keime; sie demonstrieren uns die unbegrenzt penetrative Fähigkeit primär virulenter Bakterien und lassen uns den zerstörenden Einfluss der Keime bei diesen Krankheitsprozessen innerhalb der Uteruswand im Gegensatz zu den akuten vorübergehenden Bakteriämien erkennen.

Dagegen ist in den seltenen Fällen von verschleppten Aborten, wo durch sekundär virulent gew ordene Bakterien eine schwere Allgemeinerkrankung und schliesslich ein letaler Ausgang herbeigeführt wird, die Stelle des Bakterienangriffes wiederum allein auf die Plazenta beschränkt. Von hier aus erfolgt vermittels des uteroplazentaren Kreislaufes die kontinuierliche Bakterienaussaat, die aber in diesen Fällen im Gegensatz zu den akuten, mechanischen und geheilten Bakteriämien nach Erlahmen der körperlichen Abwehrstoffe zur Allgemeinerkrankung und zum Unterliegen des erkrankten Organismus führt. Die Uteruswand bildet aber für alle diese Bakterien ohne spontane Penetrationsfähigkeit eine unüberwindliche Barriere. Eine Durchsetzung der Muskulatur, wie wir sie in den vorher beschriebenen und abgebildeten Fällen mit primär virulenten Keimen gesehen haben, werden wir daher hier nicht nachweisen können.

Ich habe von zwei Fällen einer dauernden Bakteriämie mit sekundär-virulenten Keimen, die zur Sektion gekommen sind, Schnittfärbungen durch Plazenta und Uterus angefertigt und jedesmal bestätigt gefunden, dass die Keimaussaat allein von der infizierten Plazenta ausgeht und durch sie unterhalten wird; die Muskulatur erwies sich trotz des letalen Ausganges keimfrei. Die Organe waren deswegen ganz besonders zur Untersuchung geeignet, da sie beidemale noch vor dem Exitus operativ entfernt, aufgeschnitten und in Alkohol konserviert werden konnten, so dass also postmortale Veränderungen, die man an Sektionspräparaten niemals verhindern kann, ausgeschlossen sind.

Fig. 7 (Taf. V) zeigt die Hälfte eines Schnittes, welcher längs durch die Uteruswand mit adhärenter Plazenta gelegt worden ist. Es handelt sich um den Fall von Allgemeininfektion mit Bacillus aerogenẹs capsulatus, Man erkennt schon bei schwacher Ver- 
grösserung aus der blauen Verfärbung die bakterielle Durchsetzung der Plazenta, die durchweg bläschenförmige Auftreibungen als Folge der Gasbildung erkennen lässt.

Betrachtet man ein Stück des Schnittes bei etwas stärkerer Vergrösserung, so findet man am Uebergang zwischen Uteruswand und Plazenta eine scharfe Grenze der Bakterienentwicklung und -ausbreitung (siehe Taf. V, Fig. 8); während die Plazentarzotten mit Keimen gleichmässig austapeziert sind, ist die Muskulatur bakterienfrei; nirgends sind Stäbchen in das mütterliche Gewebe infiltrierend eingedrungen; dagegen sind die Lumina der aus der Plazenta abführenden Venenstämme mit Keimen reichlich angefüllt.

Fig. 9 (Taf. V) zeigt ein in der Decidua basalis verlaufendes venöses Gefäss und Fig. 10 (Taf. V), zwei weitere mehr peripher in der Muskulatur gelegene. Die Bakterien liegen innerhalb des Gefässlumens zwischen den roten Blutkörperchen, ohne aber mit der Gefässwand irgendwie aktiv in Verbindung zu treten; keine Thrombenbildung.

Ebenso konnte man in allen Organen des Körpers, die eine reichliche venöse Durchblutung mit ausgedehnter Kapillarbildung besitzen, die feinen Gefässe mit den Bakterien gleichsam vollgepfropft finden.

Fig. 11 (Taf. V) zeigt einen bakterioskopischen Schnitt aus der Leber; ähnliche Befunde wurden in der Niere und in den Lungen erhoben.

Die bakterioskopischen Bilder dieser Fälle (die Organschnitte des zweiten Falles entsprechen den abgebildeten) liefern uns den direkten Beweis für die Berechtigung einer differierenden Bewertung primär und sekundär virulenter Bakterien. Diese Keime können zwar einen krankmachendon kinfluss ausüben und auch den Tod der betreffenden Patientin herbeiführen; diese deletäre Machtentfaltung ist aber an bestimmte anatomische Vorbedingungen gebunden. Wo diese zu suchen sind, zeigen uns einwandfrei die Organschnitte. Bei ihrer Betrachtung erkennt man aus dem rein plazentaren Sitz der Keime die wichtige und ausschlaggebende Rolle, die die Plazenta mit ihrem Kreislauf als Vermittlung des Koimtransportes bei diesen Krankheitsprozessen spiclt.

Wenn wir schliesslich noch die histologisehen Bilder der erst post abortum auftretenden Infektionsprozesse betrachten, 
so entsprechen diese den bereits in der ersten Gruppe beschriebenen Abbildungen einer fortschreitenden Endometritis und Metritis.

In Frage kommen nur primär virulente Bakterien, die vermöge ihrer Invasionskraft sich selbständig den Weg in und durch die Uteruswand bahnen. Das Fortschreiten kann auf die Lymph- und Gefässwege beschränkt bleiben oder diffus infiltrierend die ganze Uteruswand durchsetzen. Den bevorzugten Angriffspunkt wird auch hier wiederum die Fläche der Plazentarinsertion bilden.

Um sich von den versehiedenen im Vorhergehenden besprochenen Formen des Ablaufes eines fieberhaften Abortes einen möglichst prägnanten und leicht verständlichen Ueberblick zu verschaffen, sind nachfolgend in schematischer Weise die Varianten des Krankheitsbildes dargestellt. Die Abbildungen und Erklärungen sind kurz folgende:

I. Die rechtzeitig ausgeräumten, geheilten Aborte (Taf. VI, Fig. 12 u. 13).

Fig. 12. Uteruswand mit abführenden Venen und adhärenter Plazenta vor der Ausräumung: Uteruskavum und Plazenta mit Bakterien durchsetzt, Endometrium frei; die aus der Plazenta abgehenden uteroplazentaren Venen und die sich daraus entwickelnden Venenstämme sind mit Keimen angefüllt. "Akute mechanische Bakteriämie".

Fig. 13. Derselbe Fall. Plazenta ausgeräumt: Uteruswand gut kontrahiert, Uteruskavum bakterienhaltig; Gefässe kontrahiert und bakterienfrei; beine weitere Verschleppung. Blut steril.

II. Verschleppte Aborte mit tödlichem Ausgang (Taf. VI, Fig. 14 u. 15). Der Zustand vor der Ausräumung lässt sich bei diesen Formen nicht als einheitlicher Typus darstellen; wie wir uns die Uterushöhle nach der Ausräumung vorzustellen haben, zeigt schematisch Fig. 14 u. 15.

Plazenta ausgeräumt:

a) Fig. 14. Uteruskavum bakterienhaltig; Uteruswand mit Bakterien durchsetzt (spontane Invasion); Gefässe bakterienhaltig; Keimvermehrung im strömenden Blut. "Sepsis". 
b) Fig. 15. Uteruskavum bakterienhaltig. Uteruswand mit Bakterien stellenweise bis zum Peritoneum durchsetzt; Gefässe teilweise thrombosiert; Thromben bakterienhaltig; von hier Aussaat in den allgemeinen Kreislauf. "Peritonitis und Pyämie".

Als therapeutische Schlussfolgerung ergibt sich aus den klinischen Erfahrungen und den Resultaten der bakterioskopischen Untersuchung nach unserer Meinung für die Abortbehandlung zweierlei:

1. jeder fieberhafte Abort muss sobald wie möglich ausgeräumt werden, und ferner:

2. die Qualität der in den Lochien gefundenen Bakterien ist insofern prognostisch ohne Belang, da auch Saprophyten sekundär virulent werden können, wenngleich auch die Streptokokken und Staphylokokken unbedingt als die gefährlichsten Keime angesehen werden müssen.

Demnach darf unser Verhalten in keinem Fall von dem Resultat der bakteriologischen Untersuchung des Uterussekretes abhängig gemacht, und vor allem darf nicht aus dem Nachweis primär virulenter Bakterien mit bekannter invasiver Penetrationsfähigkeit eine konservative Therapie als erforderlich abgeleitet werden, da hier um so rascher eine Erlahmung der Widerstandskräfte des Organismus oder eine fortschreitende Infektion zu befürchten ist.

Dass bei dem aktiven Vorgehen die Möglichkeit der Gefahr einer Thrombophlebitis besteht, muss zugegeben werden. Aber diese Gefahr ist sicherlich sehr gering. In keinem unserer Fälle, bei denen das Blut im Fieberabfall noch keimfrei war, die also rechtzeitig zur Behandlung gekommen waren, wurde eine anschliessende Pyämie beobachtet. Die Erklärung hierfür ljegt in den anatomischen Verhältnissen, da die venösen Gefässe des in den ersten Monaten abortierenden Uterus noch klein und deshalb wenig zur Thrombose disponiert sind.

Selbstverständlich verlangt die Ausräumung eine geübte Hand und sichere Technik. Man wird stets in Narkose nach genügender Erweiterung des Zervikalkanals zunächst das Uteruskavum manuell entleeren und zum Schluss mit einer grossen, stumpfen Kurette vorsichtig nachsäubern, aber jedes brüske Kratzen peinlichst vermeiden. Dann steht die Gefahr einer eventuellen Thrombophlebitis 
weit zurück hinter der einer Verschleppung mit allen ihren irreparablen Folgen.

\section{Febris intra partum.}

Im Gegensatz zu den zahlreichen Untersuchungen über die puerperalen Temperatursteigerungen ist das intra partum auftretende Fieber in seiner ätiologischen und prognostischen Bewertung, besonders vom bakteriologischen Standpunkt aus, verhältnismässig wenig in der Literatur berücksichtigt worden. Nach den grundlegenden Arbeiten ron Menge und Krönig beziehen sich die Veröffentlichungen mehr auf statistische Angaben, und erst in letzter Zeit hat Sachs auch auf Grund bakteriologischer Untersuchungen prognostische Rückschlüsse aus seinen Befunden zu ziehen versucht.

Auffallend ist, dass die Blutuntersuchungen bei diesen Temperatursteigerungen bis jetzt fast ganz vernachlässigt worden sind, obwohl es doch nahe lag, auch beim Fieber unter der Geburt das Blut der Kreissenden bakteriologisch zu prüfen, nachdem beim fieberhaften Abort der Beweis vom Uebertritt der Bakterien in die Blutbahn erbracht worden war.

Das Ergebnis der kontrollierenden Blutuntersuchungen vor, während und nach der Geburt ist für das Verständnis des Krankheitsablaufes, sowie für die Beurteilung des jeweiligen Krankheitsstandes von ausschlaggebender Bedeutung. Da ich aber bereits früher ausführlich über die bakteriologischen und histologischen Befunde bei den Fiebersteigerungen unter der Geburt berichtet habe, soll im folgenden der Vollständigkeit halber nur kurz das Ergebnis dieser Untersuchungen mitgeteilt werden; im übrigen verweise ich auf meine Arbeit "Plazentare Bakteriämie" (Arch. f. Gyn,, Bd. 100).

Die regelmässigen, positiven Blutbefunde im Verlaufe eines fieberhaften Abortes waren Veranlassung, auch beim Fieber unter der Geburt das Blut der Patientinnen auf seinen eventuellen Keimgehalt bakteriologisch zu prüfen.

Dazu bedurfte es in jedem Falle bestimmter systematisch durchgeführter Untersuchungen.

1. Sekretentnahme vor der Geburt aus der Uterushöhle.

2. Blutentnahme aus der Vene vor und nach der Geburt.

3. Bakterioskopische Schnittfärbungen der Plazenta und Eihäute. 
Nach diesen Prinzipien sind 30 Fälle von Fieber unter der Geburt untersucht. Es handelte sich in allen Fällen um höhere Temperaturen, über $38,5^{\circ}$.

Die Blutproben, die vor der Geburt bei aufsteigender Temperatur oder während des Frostes abgenommen wurden, fielen unter den 30 Fällen 21 mal positiv aus, d. h. es liessen sich in den grossen Traubenzucker-Agarröhren mehr oder minder zahlreiche Kolonien nachweisen. Meistens handelte es sich um Mischinfektionen.

Die Blutproben, die nach der Entbindung entnommen wurden, blieben mit einer einzigen Ausnahme steril. Diese Patientin starb am dritten Tage post partum an einer Sepsis. Von den übrigen Patientinnen ist noch eine an einer sich im Wochenbett rapide ausbreitenden Tuberkulose gestorben. Alle übrigen Patientinnen entfieberten mehr oder minder rasch und konnten gesund entlassen werden.

Nur 9 mal blieben beide Blutproben steril, so dass also weder vor noch nach der Geburt Keime im Blut gefunden werden konnten. Von diesen Frauen ist keine gestorben. Auf Grund solcher wechselnden Blutbefunde muss man sich das Fieber einmal, und zwar in der grösseren Mehrzahl, bakteriämisch, das andere Mal durch Toxinresorption entstanden, denken.

Der sporadische, nur während der Geburt positive Blutbefund, legt den Gedanken an eine anatomische Gelegenheitsursache nahe, die in der Plazenta gesucht werden muss.

Es wurden daher aus den steril aufgefangenen Plazenten an verschiedenen Stellen Stücke herausgeschnitten, eingebettet und auf Bakterien gefärbt.

Die Untersuchung ergab nun ganz allgemein, dass bei allen langdauernden Geburten, gleichgültig, ob Bakterien im Blute nachweisbar waren oder nicht, die Keime vornehmlich in der subamniotischen Schicht des Chorions anzutreffen waren (s. Taf. VII, Fig. 1 bis 5). Fig. 1 und 2 zeigen Schnittfärbungen der fötalen Plazentarfläche. Die Einwanderung der Bakterien erfolgt zum Teil wenigstens durch das intakte Amnionepithel (Fig. 3); Fig. 4 und 5 demonstrieren dieselben Verhältnisse bei den Eihäuten.

Innerhalb der plazentaren Chorionplatte kann man die verschiedensten Grade der Keimausbreitung und Weiterentwicklung beobachten (s. Taf. VII, Fig. 6-9). In den Fällen, wo die Blutproben positiv ausfielen, konnte man sowohl von der Amnionhöhle 
s
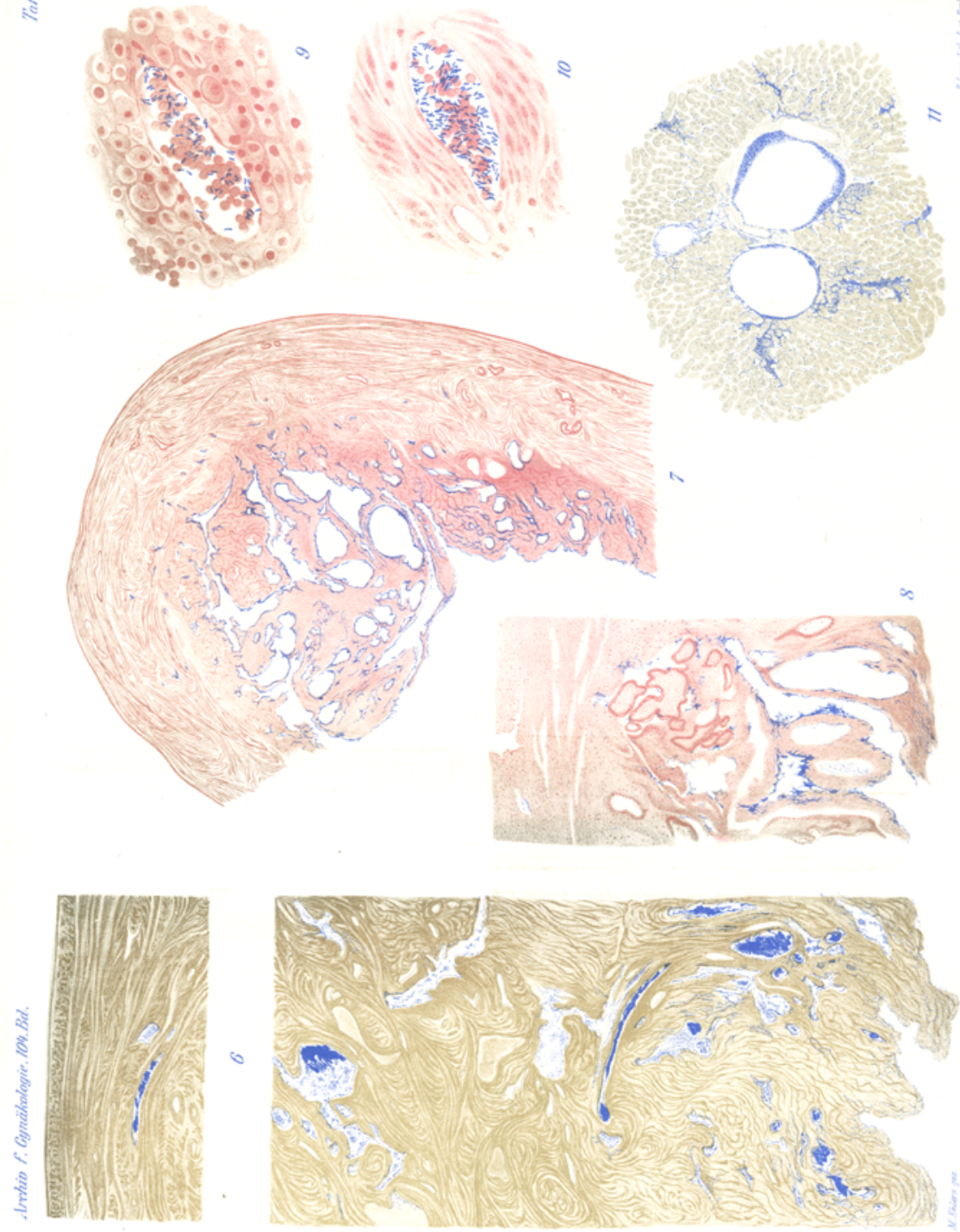
aus eine Durchwanderung der Bakterien durch die ganze Schicht der Eihäute hindurch beobachten (s. Taf. VII-VIII, Fig. 10 u. 11), als auch die Decidua basalis besonders am unteren Plazentarpol reichlich mit Bakterien durchsetzt finden und von hier aus den Einbruch in die intervillösen Räume verfolgen (s. Taf. VIII, Fig. 12 u. 13). In allen diesen positiven Fällen wurden dann auch innerhalb der Plazenta zwischen den Zotten reichlich Bakterien gefunden (s. Taf. VIII, Fig. 14 u. 15).

Von besonderem Interesse war nun auch hier wieder, zu erfahren, wie sich die Bakterien bei diesen temporären plazentaren Bakteriämien der Uteruswand gegenüber verhalten. Der direkte bakterioskopische Nachweis, ob auch bei diesem relativ kurzdauernden Krankheitsbild der positive Blutbefund aus einer rein mechanischen Keimverschleppung erklärt werden könnte, war natürlich schwer zu erbringen, da man eben für gewöhnlich die zur Heilung gelangten Fälle nicht an Organschnitten studieren kann.

Durch einen Zufall kam aber ein solcher Uterus zur Untersuchung. Es handelte sich um eine Patientin, die am Ende der Schwangerschaft hochfiebernd in die Klinik gebracht wurde. Im Blut, das vor der Entbindung entnommen wurde, wuchsen Streptokokken. Die Geburt wurde operativ, d. h. durch Perforation des toten Kindes beendet. Nach der Extraktion des Kindes trat ein schwerer Herzkollaps ein, dem die Patientin erlag.

Die Plazenta war noch im Uterus. Das Organ wurde im Zusammenhang mit der Nachgeburt entfernt, gehärtet und geschnitten.

Die bakterioskopische Betrachtung zeigte eine Infektion der Plazenta; die Bakterien hatten die Eihäute durchwandert und wurden in den intervillösen Räumen gefunden. Weiterhin konnte man sie vereinzelt im Lumen der abführenden Venenstämme nachweisen (s. Taf. VIII, Fig. 16). Nirgends aber hatte eine Infektion der Gebärmutterwand stattgefunden. Die Muskulatur war bakterienfrei.

Es handelte sich demnach um eine rein plazentare Infektion, und man kann diesen Fall als Paradigma aller derjenigen Fälle ansehen, wo die Frauen während der Geburt fieberten, Keime im Blut hatten, rechtzeitig entbunden wurden und rasch entfieberten.

Fasst man die mitgeteilten Befunde zusammen, so lassen sich folgende Schlussfolgerungen ziehen. 
334 Warnekros, Zur. Prognose der puerperalen Fiebersteigerungen.

Sind nach frühzeitigem Blasensprung Keime in die Uterushöhle gelangt, so beginnt zunächst eine bakterielle Zersetzung des Fruchtwassers. Das Blut ist keimfrei, das klinische Bild ist weniger stürmisch, ausgesprochene Schüttelfröste fehlen. Die Erklärung dieser Fiebersteigerungen muss als Folge einer Resorption der im Uterus gebildeten Toxine pathogener Mikroorganismen angesehen werden.

Diese primäre Toxinämie ist aber früher oder später von einem Einbruch der Keime in die Blutbahn gefolgt.

Die Toxinämie ist folglich nur ein Uebergangsstadium, alle schweren Formen von Fieber unter der Geburt sind plazentare Bakteriämien.

Hinsichtlich der Bewertung der intra partum im Blate gefundenen Keime gilt das bereits beim Abort Gesagte. Der temporäre Nachweis aller möglichen Keimarten während der Geburt erlaubt noch keinen Rückschluss auf die Pathogenität bzw. Virulenz und beweist vor allem nicht eine invasive Fähigkeit der betreffenden Bakterien.

Solange eine anatomische Gelegenheitsursache zur Keimverschleppung wie der uteroplazentare Kreislanf besteht, wird eben jedes gerade im Uterus befindliche Bakterium mitverschleppt werden können.

Erst die nach Ausstossung der Plazenta weiterhin positiven Blutproben lassen einen Rückschluss auf den Charakter der Bakterien zu. Es werden natürlich auch hier wiederum zunächst die echten Parasiten, Strepto- und Staphylokokken, als die Erreger einer fortgesetzten bzw. fortgeleiteten Bakteriämie (Sepsis, Pyämie) in Betracht kommen; möglich wäre es aber auch, dass ähnlich wie bei den Aborten gelegentlich andere, saprophytäre Keime sekundäre Virulenz und so einen dominierenden Einfluss über den erkrankten Organismus gewännen.

In den von mir untersuchten 30 Fällen von Fieber unter der Geburt ist die akute Bakteriämie überhaupt nur einmal kontinuierlich in eine chronische, von dem Plazentarkreislauf unabhängige, übergegangen. Es handelte sich aber hier um Streptokokken, also um primär virulente Keime, die natürlich jedesmal die akute Bakteriämie überdauern und eine chronische Allgemeinerkrankung herbeiführen können. Warum das eine Mal der Körper mit den importierten Keimen noch fertig wird, und das andere Mal nicht, 
hängt von den verschiedensten Umständen ab (spezifische Virulenz, Dauer der Erkrankung, Kräftezustand der Patientin ete.).

Kein Mal wurde jedoch wie bei den Aborten eine sich an die Geburt fortgesetzt anschliessende Infektion mit sekundär virulenten Bakterien beobachtet. Die ganze Flora der saprophytären Keime konnte nur intra partum im Blute nachgewiesen werden; nach Unterbrechung des Uteroplazentarkreislaufes waren sie in den von mir untersuchten Fällen wie abgeschnitten aus dem Blute verschwunden. Es handelte sich demnach stets um. mechanische Bakteriämien ohne weitere ungünstige Folgen für die Patientin. Auch der von Hamm mitgeteilte Fall, aus dem er soviel für die Infektionslehre abzuleiten gedenkt, gehört wie ein Paradigma in diese Gruppe der rein mechanischen Verschleppung: Während der Nachgeburtsperiode trat im Anschluss an eine Geburt, bei der das Fruchtwasser bereits seit 24 Stunden abgeflossen war, ein Schüttelfrost mit Temperaturanstieg bis $39,1^{0}$ auf. In der Blutprobe, die während des Frostes entnommen wurde, fand man den B. nebulosus. Nach der Geburt der Plazenta trat prompte Entfieberung ein, und bis auf eine nochmalige leichtere Temperaturerhöhung verlief das Wochenbett normal.

Hamm folgert aus diesem Befund, dass dadurch der endgültige Beweis erbracht sei, dass auch der B. nebulosus zu den echten Parasiten gehöre; "mag er auch noch so selten penetrationsfähig werden, so müssen wir damit rechnen, dass er unter günstigen Bedingungen diese $\mathrm{jhm}$ von Natur aus eigene Fähigkeit zur Geltung bringe".

Dass mit diesem einmaligen durch die anatomischen Verhältnisse bei noch retinierter Plazenta zwanglos erklärten Bakterienbefund niemals die Penetrationsfähigkeit dieses zufälig verschleppten Keimes und seine Klassifizierung zu den echten Parasiten bewiesen ist, bedarf nach dem bei den Aborten hierüber bereits Gesagten keiner weiteren Begründung.

Die Möglichkeit einer sekundären Virulenzentwicklung an sich sonst saprophytärer Keime besteht natürlich bei den anatomischen Verhältnissen hier ebenso wie beim fieberhaften Abort; und es sind entsprechende Fälle in der Literatur mitgeteilt worden. Allerdings sind deren bakteriologische Resultate mit Vorbehalt zu verwerten, da die Untersuchungen meistens erst post mortem angestellt wurden und Blutuntersuchungen zum Teil ganz fehlen.

Gottet beobachtete im Anschluss eines bereits intra partum 
$336^{\circ}$ Warnekros, Zur Prognose der puerperalen Fiebersteigerungen.

bestehenden Fiebers, wo die Geburt operativ und mit manueller Plazentarlösung beendet werden musste, eine fortgesetzte Colibakteriämie, der die Patientin erlag.

Scheidler berichtet über 2 Fälle von Infektionen mit. B. aerogenes capsulatus, die ebenfalls im Anschluss an langdanernde fiebernde Geburten kurze Zeit post partum zum Exitus führten, ohne dass das Blut aber während des Lebens untersucht worden war. Die Diagnose wurde in beiden Fällen erst nach dem Tode bezw. erst bei der Sektion gestellt.

Denselben Bazillus fand Little post mortem neben Streptokokken im Uterussekret und in der Plazenta und führt den tödlichen Ausgang der arg verschleppten fieberhaften Geburt auf diesen Keim zurück, obwohl die Erscheinungen der Gasbildung am Körper der Frau erst mehrere Stunden nach dem Tode bemerkt wurden.

Einen gleichen Fall beschreibt Holmsen, bei dem es sich ebenfalls um eine verschleppte fieberhafte Geburt mit manueller Plazentarlösung handelte.

Der von Schnell mitgeteilte Fall ist nicht zu verwerten, da. bakteriologische Untersuchungen überhaupt nicht angestellt wurden. Es handelte sich auch hier wiederum um eine intra partum hochfiebernde Frau, die operativ entbunden wurde und wenige Stunden später starb. Bei der Sektion wurden in den Organen Gasblasen nachgewiesen.

Wood fand im Uterussekret einer während der Geburt. fiebernden Frau, die ad exitum kam, den B. aerogenes capsulatus, daneben aber Streptokokken und Coli. Das Blut war nicht untersucht worden.

Pruska beschreibt zwei tödlich verlaufene Pneumokokkeninfektionen, anschliessend an verschleppte Querlagen. Blutuntersuchungen wurden intra vitam nicht vorgenommen; die Bakterien wurden in den Lochien und bei der Sektion in den Organen nachgewiesen.

Hamm beobachtete eine tödliche Infektion mit dem B. oedematis maligni, die sich an eine verschleppte Querlage mit schweren Verletzungen, die eine abdominale Totalexstirpation des Uterus erforderten, kontinuierlich anschloss.

Ferner beschreibt Hamm eine zur Peritonitis mit tödlichem Ausgang führende Infektion mit B. faecalis alcaligenes. Auch hier handelte es sich um eine bereits intra partum hochfiebernde Kreis- 
sende, die operativ (Bossi) entbunden werden musste. Das Krankheitsbild war durch eine Enteritis und Pyelonephritis kompliziert. Das Blut war steril; im Eiter und Urin wurden die genannten Bakterien gefunden. $\mathrm{Ob}$ ausserdem eine Verletzung bei der forzierten Entbindung eingetreten war, liess sich nicht entscheiden, da die Sektion verweigert wurde.

Im allgemeinen scheint aber dieser Uebergang einer anfangs akut-temporären Bakteriämie in eine fortgesetzt chronische mit sekundär virulenten Bakterien bei ausgetragenen Geburten seltener zu sein als bei Aborten; wie ich denn überhaupt den Eindruck gewonnen habe, dass man dem Febris inter partum eine relativ bessere Prognose stellen kann als dem fieberhaften Abort.

Das mag in folgenden zwei Momenten begründet sein. Die bakterioskopische Untersuchung der Plazenten fieberhafter Aborte hat jedesmal eine ausgedehnte Durchsetzung der intervillösen Räume mit Keimen ergeben, und dementsprechend fallen auch die Blutproben beim fieberhaften Abort in 90 bis 100 pCt. positiv aus. Es sind somit bei der abortiven Unterbrechung der Schwangerschaft, die ja auch im Gegensatz zur Geburt am normalen Ende mit Blutungen aus zerrissenen Uteroplazentargefässen bei partieller Ablösung der Plazenta beginnt, von Anfang an den Keimen die günstigsten Bedingungen zur Verschleppung gegeben. Die Fiebersteigerungen im Verlauf eines fieberhaften Abortes sind demnach von vornherein der Ausdruck einer Bakteriämie.

Im Gegensatz dazu geht bei den Temperatursteigerungen intra partum dem Stadium der Bakteriämie ein Stadium der Toxinresorption voraus. Die Keime, die während der Geburt in die Uterushöhle gelangt sind, finden nicht so bequeme Transportwege wie beim Abort; entweder müssen sie sich erst durch die Chorionplatte den Weg in die intervillösen Räume bahnen oder mühsam in den Eihäuten hinaufwandern, um am unteren Plazentarpol die hier weit weniger zahlreichen direkten Einbruchspforten in den Uteroplazentarkreislauf zu finden. Dementsprechend fallen hier auch nur in etwa $70 \mathrm{pCt}$. die Blutproben positiv aus. Dass aber jede Bakteriämie, auch wenn sie nur vorübergehend besteht, für den Organismus gefährlicher ist als die Resorption giftiger Stoffe stationär gebliebener Bakterien ist leicht verständlich.

Das zweite Moment, das die Prognose bei fieberhaften Aborten so ungünstig belastet, ist die zeitliche Verschleppung. Frauen, die während der Geburt am normalen Schwangerschaftsende Tem- 
peraturen oder gar Schüttelfröste bekommen, werden ärztliche Hilfe unverzüglich in Anspruch nehmen und so in relativ kurzer Zeit entbunden werden. Trotz eines sehr grossen Materials habe ich niemals eine Frau zur Entbindung bekommen, bei der man schon gleich bei der Aufnahme aus dem Blutbild oder aus dem Allgemeinbefinden eine ausgesprochene eklatante Blutinfektion oder eine manifeste Peritonitis hätte diagnostizieren können. Ganz anders liegen die Verhältnisse beim Abort. Tage- und wochenlang laufen die Frauen blutend und fiebernd umher, freuen sich, besonders wenn der Abort kriminell eingeleitet wurde, dass es blutet und wenden sich erst an den Arzt, wenn die sichtliche Verschlechterung des Allgemeinbefindens oder die andauernde Blutung eine Behandlung erzwingt. Dass ferner in den kriminellen Abtreibungsversuchen, die ebenfalls am Ende der Geburt fortfallen, eine besonders günstige Gelegenheit zur Ausseninfektion mit hochvirulenten Keimen gegeben ist, bedarf nur der Erwähnung.

Ich habe, um an einer grösseren Zahlenreihe die relativ günstigere Prognose des intra partum-Fiebers im Gegensatz zum fieberhaften Abort zeigen zu können, die Geburtsfieberfälle der letzten zwei Jahre zusammengestellt. Eine direkte prozentuale Vergleichung zwischen fieberhaftem Abort und fieberhafter Geburt hinsichtlich ihrer Prognose ist aus diesen Zahlenreihen allerdings nicht angängig, da wir aus Platzmangel viele fieberhafte Aborte abweisen müssen und nur die schweren Fälle in die Klinik aufgenommen haben, während fieberhafte Geburten fast ausnahmslos, also auch leichtere Fälle, Aufnahme gefunden haben. Dadurch werden die Abortresultate natülich versehlechtert, da eine grosse Zahl der leichteren, wahrscheinlich geheilten Fälle fortfällt; trotz-' dem kann aber noch aus dem Vergleich der beiden Zahlenreihen der auffallende Unterschied in der prognostischen Bewertung bei diesen beiden Krankheitsformen erkannt werden.

Es sind in den letzten beiden Jahren 151 Fälle von fieberhaften Geburten, bei denen die Temperatur auf eine intrauterine Infektion zurückgeführt werden musste und die alle über $38, \check{\jmath}$ massen und grösstenteils in schwerkrankem Zustande zur Behandlung kamen, in der hiesigen Klinik entbunden worden. Die Geburt wurde $76 \mathrm{mal}$ operativ beendet (abdom. Kaiserschnitt $5 \mathrm{mal}$, vag. Kaiserschnitt $3 \mathrm{mal}$, Wendung $19 \mathrm{mal}$, Zange $16 \mathrm{mal}$, Perforation $17 \mathrm{mal}$, Extraktion $8 \mathrm{mal}$, Metreuryse $6 \mathrm{mal}$, Bossi und Perfo- 
ration 2 mal). Von diesen Frauen sind 6 an den Folgen der Infektion gestorben, d. h. also nur 4 pCt.

Von fieberhaften Aborten wurden in der gleichen Zeit 145 Fälle in die Klinik aufgenommen und aktiv behandelt. Von diesen sind 12 Frauen gestorben, die allerdings alle schon in arg verschlepptem und hoffnungslosem Zustande (Peritonitis oder Sepsis) in die Klinik kamen und so durch eine rechtzeitige Ausräumung nicht mehr hatten gerettet werden können. Es dürfen daher diese Todesfälle nicht etwa der aktiven Behandlung zur Last gelegt werden; die Patientinnen wären so oder so gestorben; der Verglejeh der beiden Zahlenreihen zeigt aber die relativ ungünstigere Prognose ( 8 pCt. Mortalität) beim fieberhaften Abort, die zweifellos durch die eingangs erwähnten Momente (primäre Baksteriämie, Verschleppung und krimineller Eingriff) erklärt und begründet ist.

Die endgültige Entscheidung über die Prognose des intra partum-Fiebers ergibt sich ebenso wie beim Abort aus den Ergebnissen der fortgesetzten bakteriologischen Blutuntersuchung. Die Höhe der Temperatur besagt wenig, höchstens darf der Schüttelfrost als ein Fortschritt des Krankheitsprozesses insofern aufgefasst werden, als er uns den Uebertritt der Bakterien in die Blutbahn anzeigt. Ebenso wird man eine über viele Tage verschleppte Geburt mit mehrfachen Entbindungsversuchen selbstverständlich prognostisch schlechter beurteilen müssen. Ausschlaggebend aber sind die Resultate der Blutuntersuchungen, und zwar wird man sowohl die positiven und negativen Befunde an sich als auch die Art der betreffenden im Blute nachgewiesenen Bakterien kritisch zu berücksichtigen haben.

Bleibt die ante partum einer fiebernden Kreissenden entnommene Blatprobe steril, so darf die Temperatur als eine durch Toxinämie hervorgerufene Reaktion angesehen und demnach der Prozess durchaus günstig beurteilt werden.

Fällt dagegen die Probe positiv aus, so ist wiederum zu entscheiden einmal, ob es sich um eine Mischinfektion handelt und ob das Wachstum der Kolonien länger als 24 Stunden bis zur makroskopischen Wahrnehmung dauerte, und zum anderen, ob die Bakterien in Reinkultur, vornehmlich Strepto- und Staphylokokken, in weniger als 24 Stunden und in sehr grosser Anzahl in der Röhre gewachsen sind. Die beiden ersteren Punkte sind für die prognostische Beurteilung entschieden günstiger als die letzteren. 
340 Warnekros, Zur Prognose der puerperalen Fiebersteigerungen.

Ausschlaggebend für den weiteren Verlauf des Krankheitsprozesses sind die mehrere Stunden post partum oder die an den folgenden Tagen entnommenen Blutproben. Bleiben diese Röhren steril, so ist der Beweis erbracht, dass eine weitere mechanische Blutüberschwemmung durch Unterbrechung des Plazentarkreislaufes verhindert wurde und dass sich weder die Keime die Fähigkeit der selbständigen Weiterentwickelung im Blute erworben noch sich bereits in den abführenden Venen thrombophlebitische Prozesse gebildet haben. Der Prozess ist, wie diese Untersuchungen uns dann zeigen, auf das Endometrium lokalisiert, und die lokalisierten puerperalen Endometritiden geben eine durchaus gute Prognose.

Werden dagegen in den post partum verimpften Proben unabhängig von dem Plazentarkreislauf noch weiterhin Bakterien im Blute regelmässig und in zunehmender Menge angetroffen, so muss die Prognose infaust gestellt werden.

Die Bakterien haben damit den Sieg über den erkrankten Organismus davon getragen, und es ist nur noch eine Frage der Zeit, wann der Körper der Infektion erliegt. Die primär virulenten Keime müssen auch hier wiederum als noch um einen Grad gefährlicher angesehen werden als alle übrigen.

Es gehört aber zum Bilde der fortschreitenden Infektion, dass die Bakterien wiederholt und in grosser Menge post partum im Blute gefunden werden. Denn wenn auch selten, so kann man doch ausnahmsweise noch einmal in den ersten Tagen nach der Geburt, besonders wenn die Plazentarperiode gestört war und die Plazenta manuell gelöst werden musste, bei plötzlich aufsteigender Temperatur eine akute Blutüberschwemmung beobachten. Ich habe in den von mir untersuchten Fällen ein einziges Mal noch am Tage nach der Geburt 15 Kolonien Coli im Blute gefunden, während alle folgenden Proben steril blieben, und die Patientin gesund entlassen werden konnte. Dieser einmalige Nachschub einer so relativ kleinen Keimmenge ist wahrscheinlich rein mechanisch als Folge irgendeiner Anomalie an der Plazentarstelle zu erklären, und ist somit für die Prognosenstellung belanglos.

Als therapeutische Konsequenz folgt aus den mitgeteilten Untersuchungen, dass man bei fiebernden Frauen die Beendigung der Geburt unbedingt beschleunigen muss. Welche operative Maassnahme in dem einzelnen Fall indiziert erscheint, hängt von den betreffenden Verhältnissen ab. Grössere chirurgische Eingriffe 
(vaginaler bzw. abdominaler Kaiserschnitt) wird man möglichst vermeiden, dagegen Zangen, Perforation, Wendung und das Einlegen eines intrauterinen Ballons, sobald dies ohne grosse Gefahr für die Frau angängig ist, als durchaus berechtigt und erforderlich anerkennen müssen.

Denn wir wissen, dass bei allen Fiebersteigerungen unter der Geburt zunächst eine prognostisch absolut günstige Toxinämie besteht, die erst bei länger dauerndem Geburtsverlauf zur Bakteriämie führt. Wenngleich auch diese temporären Keiminvasionen für die Mutter vorerst noch nicht deletär sind, so weiss man doch nie, ob nicht schliesslich einmal die bakterizide Kraft des Körpers erlahmt und die vorübergehende Blutüberschwemmung eine dauernde bleibt.

\section{Puerperalfieber.}

In dieser Gruppe sollen mit besonderer Berücksichtigung der bakteriologischen Blutbefunde alle die Fälle besprochen werden, bei denen das Fieber erst im Anschluss an eine fieberfreie, spontan verlaufene oder operativ beendigte Geburt in den ersten Wochenbettstagen auftritt. Ich habe bereits bei den Aborten auf die entsprechende Gruppe hingewiesen und dabei erwähnt, dass hier dieser Fiebertypus relativ selten zu beobachten ist. Fis werden natürlich auch anschliessend an die Ausräumung eines fieberfreien Abortes Temperaturen als Zeichen einer Endometritis und einer fortschreitenden Allgemeininfektion auftreten können; im allgemeinen gehören aber höhere Fiebersteigerungen und Todesfälle im Anschluss an einen afebrilen, spontan verlaufenen oder ausgeräumten Abort zu den Seltenheiten.

Anders liegen die Verhältnisse im Verlauf der zweiten Hälfte oder am Ende der Gravidität; hier bilden die verschiedenen Formen der erst im Wochenbett zur Erscheinung kommenden fieberhaften Krankheitserscheinungen die grosse Reihe der Wochenbettsfieber im engeren Sinne.

Je nach der Pathogenität der betreffenden Bakterien und der anatomischen Beschaffenheit des Uteruskavums haben wir uns in jedem einzelnen Fall die zunächst stets lokalisierten Prozesse innerhalb der Gebärmutterhöhle zu erklären.

Wir beginnen mit dem Ausgangspunkt aller uterinen Infektionsprozesse, mit der lokalen Lochialstaung und der lokalisierten puerperalen Endometritis, und werden im Anschluss daran die sich hieraus entwickelnden, auf dem Blut- und Lymph- 
wege fortgeleiteten Allgemeininfektionen vom bakteriologisehen und anatomischen Standpunkt aus betrachten.

Anschliessend an die Geburt steht im Verlauf der ersten Wochenbettstage allen Keimen gleichmässig der Weg in die Uterushöhle offen, so dass wir bei der Lochialentnahme, auch bei völlig. afebrilem Wochenbett, Saprophyten und Parasiten ohne jegliche Reaktion im Uterus antreffen können.

Erst wenn die betreffenden Keime in nähere Beziehung zu dem Uterusinhalt oder zur Uteruswand getreten sind, zeigt der reaktive Temperaturausschlag den krankmachenden Einfluss dieser Affinität zwischen Bakterium und Gewebe bzw. Lochialsekret.

Wir müssen bei der Besprechung der einzelnen puerperalen Krankheitsformen auf diese Trennung zwischen Uterusinhalt und Uteruswand streng achten, da wir uns nur so eine Reihe verschiedener klinischer Erscheinungen mit ihrem abweichenden Verlauf erklären können. Die Ergebnisse der histologischen Untersuchungen, die zur Beantwortung der Frage herangezogen wurden, sollen zum Schluss als Bestätigung der klinischen und bakteriologischen Befunde mitgeteilt werden.

Ich beginne mit den auf den Uterusinhalt (Lochien, Eihautfetzen, Blutkoagulis) beschränkten Zersetzungs- bzw. Fäulnisprozessen, die unter den Erscheinungen des Eintagsfiebers bzw. der Lochiometra bekannt sind, aber in ihrer Entstehung verschieden gedeutet werden.

Als Erreger dieser intrauterinen Erkrankung können alle Bakterien in Betracht kommen, sowohl Saprophyten wie Parasiten. Die Gelegenheit und auch die Möglichkeit der Entwicklung auf dem toten Material ist allen Keimen gleichmässig gegeben.

Meine Untersuchungen erstrecken sich äber eine Reihe von 50 Fällen von sogenanntem Eintagsfieber.

Es handelte sich bei allen Patjentinnen um das bekannte Krankheitsbild: Nach afebrilem Verlauf der ersten Wochenbettstage plötzlich Temperaturanstieg, bisweilen mit leichtem Frösteln, Pulsbeschleunigung, Kopfschmerzen, gar kein oder wenig und übel riechender Ausfluss, leicht druckempfindlicher und vergrösserter Uterus.

Nach Beseitigung der die Staung bedingenden Hindernisse bzw. nach Anregung kräftiger Uteruskontraktionen durch Eisblase und Sekale fiel das Fieber in den meisten Fällen bereits am nächsten Tage wieder kritisch ab und blieb normal bei gleichzeitig beob- 
achtetem stärkeren Lochienabgang; nur wenige Patientinnen zeigten an den folgenden Tagen noch leichte Steigerungen.

Die mittels Doederlein'scher Sondenröhre aus dem Uteruscavum gewonnenen und verimpften Lochien liessen Kulturen der verschiedensten Art aufgehen. Gefunden wurden - und zwar immer als Bakteriengemisch - neben der ganz aeroben und anaeroben Bakterienflora des weiblichen Genitale Streptokokken, Staphylokokken, Diplokokken, Coli, Emphysematosus usw.; fünfmal gelang der Nachweis des obligat anaeroben Streptococcus putridus.

Das Blut blieb in allen diesen Fällen steril, obwohl die Probe jedesmal in genügender Menge und, wie thermometrisch festgestellt wurde, im Fieberanstieg entnommen war.

Es fragt sich nun, wie diese Temperatursteigerungen, die oft eine Höhe von $39-40^{\circ}$ erreichen und die so schnell und plötzlich, wie sie aufgetreten sind, auch wieder verschwinden, zu erklären sind. Handelt es sich um ein Intoxikationsfieber durch Toxinresorption des gestauten und unter einem gewissen Druck stehenden, putride zersetzten Lochialflusses oder um ein echtes Infektionsfieber.

Hamm beantwortet die Frage sehr einfach damit im Sinne einer Infektion, als für ihn der Uterusinhalt erwiesenermaassen ninfiziert" ist, so dass infolgedessen das bei seiner Stauung auftretende Fieber auch als "Infektionsfieber", nicht als reines "Intoxikationsfieber" zu bewerten sei. Diese Beweisführung hat nur den Wert eines Wortspieles; mit weit grösserer Berechtigung: könnte man umgekehrt sagen, dass das Fieber, da der Uterusinhalt erwiesenermaassen "zersetzt" ist, ein reines "Zersetzungsfieber" ist. Die putride Verjauchung eines toten Gewebsmaterials kann niemals als Infektionsvorgang angesehen werden; den gleichen Prozess kann jeder Luftkeim hervorrufen, wenn er auf günstigen Nährboden fällt, ohne dass man dadurch berechtigt ist, ihn zu den infektiösen Keimen zu rechnen. So einfach ist, meiner Meinung nach, die Entscheidung hierüber nicht.

Wir müssen uns die Frage vorlegen, ob wir für die klinische Erscheinung des abrupten Temperaturabfalls ein Analogon kennen, das bakteriologisch erklärt ist, ob hier dieselben histologischen und bakteriologischen Verhältnisse für die Erklärungsmöglichkeit bestehen, und wie wir uns, wenn die gleichen ätiologischen Vorbedingungen nicht gegeben sind, das merkwürdige klinische Bild deuten können. 
344. Warnekros, Zur Prognose der puerperalen Fiebersteigerungen.

Das Analogon einer unmittelbaren Entfieberung finden wir nach der rechtzeitigen Ausräumung eines fieberhaften Abortes. Auch hier fällt nach Entfernung des zersetzten bzw. infizierten Uterusinhalts die Temperatur kritisch ab; wie aber die Blutuntersuchungen ergeben haben, lassen sich hier bis zur erfolgten Ausräumung Keime im Blut als Erreger der Temperatursteigerung nachweisen. Es gibt also hier die durch den Uteroplazentarkreislauf bedingte Keimverschleppung und ihr Aussetzen nach Unterbrechung desselben die Erklärung der Temperaturkurve.

Es lag nun nahe, auch bei dem Lintagsfieber, das die gleiche plötzliche Unterbrechung der Temperaturkure zeigt, das Blut auf seinen eventuellen Keimgehalt unter Benutzung des aeroben und anaeroben Kulturverfahrens zu untersuchen, um sich auch hier, wenn die Blutproben positiv ausfielen, die Fiebererscheinungen im Sinne einer Bakteriämie erklären zu können. Man musste sich allerdings von vornherein sagen, dass die anatomischen Verhältnisse am puerperalen, kontrahierten Uterus ganz anders lagen, als beim nicht ausgeräumten Abort, und daher einen solchen Nachweis wenig wahrscheinlich machten. Trotzdem waren die Untersuchungen in der angedeuteten Richtung erforderlich, um mit Sicherheit eine Bakteriämie ausschliessen zu können. Wie zu erwarten gewesen, fielen die bakteriologischen Blutuntersuchungen bei allen Lochialstauungen negativ aus (Lamers, Warnekros u. a.), und somit konnte eine temporäre Bakteriämie hier nicht als Erklärung der Temperaturkurve herangezogen werden.

Hiergegen wenden nun Schottmüller und Hamm ein, dass es ihnen ja auch gar nicht eingefallen sei, bei den bisher als Resorptionsfieber, von Bumm als Eintagsfieber bezeichneten, leichteren Wundinfektionsprozessen Keime im zirkulierenden Blut nachweisen zu wollen, und dass man den Begriff der Infektion nicht von einer zufälligen Begleiterscheinung, wie sie die Bakteriämie darstelle, abhängig machen dürfe. Diese Feststellung Schottmüller's ist allgemein gefasst zweifellos richtig; denn die Anschauung bei jeder Infektion Mikroorganismen im Blute nachweisen zu können, ist unzulässig.

Was Schottmüller und Hamm aber übersehen haben, und wofür sie uns die Erklärung schuldig geblieben sind, ist die hier vorliegende eigenartige Temperaturkurve mit ihrem plötzlichen Anstieg und Absturz, die wir uns in ihrer Eigenart auch abweichend von der Norm entstanden denken und deuten müssen. 
Nach der Anschauung von Bondy, Schottmüller, Hamm und Zangemeister handelt es sich auch bei diesen leichtesten Fiebersteigerungen, also auch bei dem Eintagsfieber, um einen richtigen Infektionskampf, um eine lokale Entzündung, nicht bloss um eine Resorption von zufällig auf der Oberfläche einer Wunde lagernden oder durch gewisse Momente (Stauung, Druckschwankung) in sie hineingelangenden Giftstoffen.

Für diese Anschauung fehlt aber, ganz abgesehen von dem histologischen Nachweis, auch die klinische Erklärung dieser von jedem anderen Infektionsprozess völlig abweichenden Temperaturkurve.

Die Kurve des Eintagsfiebers ist mit der Annahme einer Infektion, d. h. mit dem Eindringen von Bakterien in das lebende Gewebe, nicht vereinbar. Es gibt keine Erklärungsmöglichkeit dafür, dass die in das Endometrium eingedrungenen Bakterien wie mit einem Schlage aus dem Gewebe entfernt worden seien, wie sie es müssten, wenn der Temperaturanstieg der Ausdruck eines echten Infektionsprozesses wäre. Jeder Infektionsvorgang ist ein sich allmählich entwickelnder und auch so wieder abklingender Entzündungsprozess, wie wir es an der Kurve einer septischen Endometritis und vieler anderer jederzeit ablesen können.

Der klinisch unvorbereitete Temperaturanstieg mit seinem ebenso unvermittelten Absturz, wie wir ihn bei dem Eintagsfieber beobachten, kann aber nur die Reaktion des Körpers auf eine Noxe sein, die nach Erfüllung bestimmter Vorbedingungen (Stauung; Druck) plötzlich in den Organismus hineingelangt, und bei 'Fortfall der ursächlichen Momente ebenso schnell auch wieder aus ihm eliminiert wird. Als Erklärung hierfür gibt es aber nur zwei Möglichkeiten: die Bakteriämie oder die Toxinresorption.

Wie die Untersuchungen ergeben haben, kann eine Bakteriämie entsprechend der Abortfieberkurve hier nicht für die Erscheinung verantwortlich gemacht werden. Es bleibt somit nur die Toxinresorption des zersetzten, gestauten und unter einem gewissen Druck stehenden Lochialflusses. Mit dem Moment der Entspannung, d. h. mit dem ungehinderten Abfluss des gestauten Inhalts fällt die Temperatur zur Norm zurück, da die Vorbedingungen zu einer weiteren Resorption genommen sind.

Wenn man so schon aus der unbefangenen Betrachtung der Temperaturkurve und aus ihrem Vergleich mit anderen zu der Annahme gedrüngt wird, dass hier eine Erkrankung im Sinne einer 
Infektion unmöglich vorliegen kann, so wird diese Annahme durch die histologische Untersuchung zur Gewissheit.

Ich habe einem früheren Vorschlag von Bumm folgend bei den Lochialstaungen und zum Vergleich auch bei sicheren, septischen und putriden Endometritiden Stücke der fraglichen Uterusschleimhaut entnommen und durch bakterioskopische Schnittfärbung in den einzelnen Fällen zu entscheiden versucht, ob wirklich eine lokale Entzündung, d. h. ein Infektionskampf zwischen lebendem Gewebe und den betreffenden Bakterien, auch bei diesen leichtesten Temperatursteigerungen vorliege oder nicht.

Die Technik ist einfach. Man legt sich unter allen Kautelen der Aseptik die Portio frei und holt sich mit einer Kugelzange den äusseren Muttermund möglichst weit herunter. Hierauf werden mit einer kleinen, scharfen Kurette vorsichtig mehrere Stückchen Dezidua ausgeschabt und zur weiteren Untersuchung eingebettet.

Bei den Lochialstauungen fand diese Schleimhautentnahme am Abend des Entfieberungstages statt, bei den puerperalen Endometritiden in den ersten Tagen der Erkrankung. Gleichzeitig wurde durch Lochialausstrich der Charakter der betreffenden Bakterien festgestellt. Geschadet hat der kleine Eingriff keiner Patientin.

Die Schnitte warden einmal nach Gram-Weigert oder mit Methylenblau auf Bakterien gefärbt, zur besseren Orientierung aber auch verschiedentlich einfache Gewebsfärbungen mit Hämalaun-Eosin und Doppelfärbung (Bakterien und Gewebe) vorgenommen. Dabei sei aber bemerkt, dass der Nachweis der Bakterien bei den Doppelfärbungen nur gelingt, wenn sehr viel Keime im Gewebe sind. Zur Kontrolle empfiehlt sich deshalb stets daneben noch die einfache Bakterienfärbung nach Weigert und mit Methylenblau.

Die Untersuchung der Schnitte, die bei den Lochialstauungen angefertigt wurden, ergab nun die interessante Beobachtung, dass bei allen reinen Staungen die Uterusschleimhaut vollkommen bakterienfrei war, dass auch nicht einmal die obersten nekrotischen Deziduaschichten Keime erkennen liessen, dass also von einem Infektionskampf oder von irgend einer lokalen Entzündung bei dieser Wochenbettserkrankung überhaupt nicht die Rede sein konnte.

Die Fig. 1 u. 2 (Taf. IX) zeigen einzelne Typen aus einer grösseren Serie von untersuchten Fällen. Die Schnitte sind einmal mit Hämalaun-Eosin zur Gewebs-Orientierung und das zweite Mal 
nach Gram-Weigert bzw. mit Methylenblau auf Bakterien gefärbt. Man sieht bei den Gewebsfärbungen ausgezeichnet die Struktur der entfernten Deziduafetzen, die in der Hauptsache aus den obersten Partien der Schleimhant bestehen und Drüsen und Gefässdurchschnitte erkennen lassen. In den entsprechenden auf Bakterien gefärbten Schnitten kann man trotz genauester Durchsicht mit Oelimmersion keine Bakterien im Gewebe nachweisen, nur die an einzelnen Schnitten mitgetroffenen, der Schleimhautoberfläche aufsitzenden Blutklumpen zeigen hier und da Bakterien verschiedenster Art und Form.

Damit hat die klinische Erscheinung des abrupten Temperatursturzes ihre histologisch-bakteriologische Erklärung gefunden. Das gestaute Lochialsekret, die putride zersetzten Blutklumpen und Eihautfetzen liefern das von der Uterusschleimbaut resorbierte Toxin, dessen Resorption abhängig ist von dem Druck, unter dem der Uterusinhalt steht. Mit der Entleerung und der Entspannung nach dem Lochialabfluss sistiert die weitere Resorption; die Temperaturkurve, die unvermittelt emporschnelite, fällt, da eine Infektion des Gewebes nicht stattgefunden hat, ebenso plötzlich wieder ab und bleibt afebril. Das Fieber ist toxinämisch erklärt; die Lochialstauung das typische Beispiel einer Toxinämie.

Dass eine reine Lochialstauung sekundär in eine puerperale Endometritis, also eine primäre Toxinämie eventuell in eine Infektion übergehen kann, ist wohl möglich. Man kann sich ohne weiteres vorstellen, dass die Bakterien, die zunächst nur in und auf dem toten Gewebe des Uterusinhaltes vegetiert haben, unter günstigen Verhältnissen und bei hinreichender Virulenz auf das Endometrium übergreifen, und so eine lokale Entzündung im Sinne einer Infektion hervorrufen. Die Fieberkurve zeigt uns dann den Fortschritt der Erkrankung; je nach der Schwere des Prozesses wird sich die Temperatur längere Zeit über der Norm halten, um früher oder später allmählich wieder abzufallen.

Damit wären wir zu der zweiten noch auf den Uterus lokalisierten Wochenbetterkrankung gekommen, zu der puerperalen Endometritis.

Es soll auch hier wieder der klinische Verlauf mit besonderer Berücksichtigung der bakteriologisehen Blut- und der histologischen Schnittbefunde besprochen und so eine Erklärung und prognostische Bewertung der Erscheinungen herbeizuführen versucht werden. 
Die von mir gewonnenen Resultate stützen sich auf die Untersuchungen von 80 Fällen. Leichte Temperatursteigerungen bis zu $38^{\circ}$ sind hierbei nicht berücksichtigt worden, sondern es handelte sich in allen Fällen um ein ausgesprochenes Krankheitsbild.

Meistens stieg die Temperatur einige Tage nach der Geburt. allmählich kletternd in die Höhe und erreichte zuweilen bedrohliche Steigerungen. Die leicht remittierenden Temperaturschwankungen hielten in der Regel mehrere Tage an, um schliesslich wieder lytisch zur Norm abzufallen. Der Puls war stets nur wenig beschleunigt. Häufig stand seine geringe Frequenz in auffallendem Gegensatz zu den Fiebersteigerungen.

Den genannten klinischen Erscheinungen entsprach als örtlicher Befund ein vergrösserter leicht druckempfindlicher und schlecht kontrahierter Uterus. Als Zeichen der entzündlichen Affektion der Gebärmutterschleimhaut bestand reichlicher Ausfluss, der bald schmierig übelriechend, bald serös-eiterig und von fadem Geruch war.

Das Allgemeinbefinden war für gewöhnlich nur wenig in Mitleidenschaft gezogen; während der Temperaturakme klagten die Patientinnen zuweilen über Kopfschmerzen, und bei höheren Temperaturanstiegen empfanden sie mitunter ein allgemeines Gefühl des Unbehagens, der Mattigkeit und ein leichtes Frösteln.

Aber auch ausgesprochene Schüttelfröste, allerdings nie soschwer wie bei Abortbakteriämien oder bei thrombophlebitischen Pyämien, wurden beobachtet; bei mehreren Fällen wiederholten sie sich sogar im Laufe weniger Tage.

Hinsichtlich der Geburtsgeschichte dieser Fälle ist zu erwähnen, dass die Entbindung $45 \mathrm{mal}$ spontan verlaufen und $35 \mathrm{mal}$ operativ beendigt worden war. Erühzeitiger Blasensprung bestand in fast allen Fällen, ebenso waren innere Untersuchungen mehrfach vorgenommen worden.

Die durchschnittliche Dauer des Krankheitsverlaufes, gerechnet von der ersten Fiebersteigerung bis zur Entfieberung, betrug 8 bis 10 Tage; die Temperaturen schwankten zwischen $38-40^{\circ}$. Dreimal wurde $41^{\circ}$ gemessen.

Die bakteriologische Blutuntersuchung fiel in allen Fällen negativ aus, auch wenn die Probe im Schüttelfrost entnommen worden war. In dem Ergebnis dieser Blutuntersuchungen hatte man somit ein prognostisch äusserst wichtiges Kriterium zur Beurteilung der Fälle, besonders dann, wenn der Verlauf durch 
Fröste kompliziert war. Die hierbei täglich vorgenommene Blatuntersuchung sicherte trotz der oft bedrohlichen klinischen Erscheinungen die Diagnose Endometritis und bewies uns die auf das Endometrium beschränkte Infektion.

Mit dieser Sicherstellung der Diagnose gewann man zugleich eine wertvolle Grundlage für die erforderliche Therapie. Blieb die rechtzeitig und in genügender Menge entnommene und richtig verimpfte Blutprobe steril, so wurde unter weiterer Kontrolle des. Blutbildes bei streng konservativer Behandlung abgewartet.

Der Verlauf bestätigte in allen Fällen die Prognose; keine von den Patientinnen, bei denen das Blutbild dauernd steril geblieben war, ist ad exitum gekommen; sämtliche Frauen wurden ohne operativen Eingriff geheilt und gesund entlassen.

Die Erklärung der Fieberkurve bezüglich der Resultate der bakteriologischen Blutuntersuchungen bereitet bei diesen puerperalen Endometritiden insofern einjge Schwierigkeiten, als auch beim. Schüttelfrost, der gelegentlich im Verlauf dieser Erkrankung beobachtet wird, keine Keime im Blute nachweisbar sind. Die frostfreien Temperatursteigerungen können als Reaktion der lokalen Entzündung angesehen oder auch bei der puerperalen Endometritis wenigstens, wie Bumm glaubt, durch die resorbierten chemischen Erzeugnisse des Fäulnisvorganges hervorgerufen werden. Beim Frost sind wir aber nach allen unseren Erfahrungen gewohnt, Bakterien jm Blute zu finden. Möglicherweise ist die Erklärung darin zu suchen, dass bisweilen an der Plazentarstelle ein Zerfall von aseptischen Thromben stattfindet, und dass bei diesem Thrombenzerfall nicht infizierte Blutgerinnsel eines aseptischen. Staungsthrombus abgerissen und in das Gefässsystem geschleadert werden, worauf der Körper mit dem reaktiven Frost antwortet. Andererseits wäre es aber auch denkbar, dass mit den Thromben Bakterien in die Blutbahn verschleppt werden, deren Nachweis jedoch kulturell nicht gelingt, weil in allen diesen zur Heilung. kommenden Fällen eine besonders hohe bakterizide Kraft nicht besonders virulenten Keimen gegenübersteht. Die Keime wären also bei dieser Annahme schon abgetötet und nicht mehr entwickelungsfähig, wenn anschliessend an den Schüttelfrost die Verimpfung auf künstliche Nährböden erfolgt.

Es wären dann diese Schüttelfröste zwar auch Bakteriämien, allerdings mit dem prognostisch äusserst wichtigen Unterschied der Unmöglichkeit des kulturellen Keim- 
nachweises in den entnommenen Proben. Dadurch wären sie in ihrer Bewertung gleichbedeutend der erst erwähnten Annahme, dass mit dem abgerissenen Thrombenmaterial überhàupt keine Bakterien verschleppt worden seien. Wie die Erklärung auch richtig sein möge, klinisch ist der puerperale „aseptische-keimfreie" Schüttelfrost wesentlich anders als der "septische-keimhaltige" zu beurteilen, und das negative bakteriologische Resultat erlaubt bindende prognostische Schlüsse.

Entsprechend den Deziduauntersuchungen, wie sie bei der Lochialstauung an den ausgeschabten Stückchen der Uterusschleimhaut vorgenommen wurden, habe ich auch bei den puerperalen Endometritiden das Verhalten der Bakterien dem Endometrium gegenüber festzustellen versucht.

Die ersten derartigen Untersuchungen sind von Bumm veröffentlicht worden, der ebenfalls das bei der Ausschabung des Uterus gewonnene Material zum Ausgangspunkt seiner "histologischen Untersuchungen über die puerperale Endometritis" gemacht hat.

Bumm unterscheidet vom ätiologischen Standpunkt aus eine putride und eine septische Endometritis.

$\mathrm{Zu}$ der putriden Endometritis gehören alle diejenigen Fälle, wo durch Vermittelung saprophytischer Mikroorganismen eine Zersetzung.der Dezidua stattfindet.

Bereits Bumm erwähnt, dass die genauere bakteriologische Untersuchung gelehrt hat, dass die klinisch anscheinend so häufigen putriden Endometritiden insofern selten sind, als es sich in der grossen Mehrzahl der Fälle um Mischinfektionen handelt, dass also neben dem Fäulniskeim auch noch septische Mikroorganismen, Strepto- und Staphylokokken angetroffen werden. Auch ich habe bei meinen Untersuchungen fast stets, wenn auch manchmal nur vereinzelte, Strepto- und Staphylokokken bei den Verimpfungen der Lochien in Bouillon und auf Blutagar nachweisen können und nur in ganz seltenen Fällen eine rein putride Bakterienflora gefunden.

Immerhin beweist aber der klinische Verlauf und der gleich za besprechende histologische Befund beim Angehen aller möglichen Bakterienarten mit Ueberwiegen der Fäulniskeime, dass wir es mit einem leichteren Krankheitsprozess zu tun haben, und rechtfertigt somit die Einteilung in eine putride und septische Endometritis. 
Die histologischen Befunde bei der putriden Endometritis, um die es sich in meinen Fällen auf Grund der bakteriologischen Lochialuntersuchungen $50 \mathrm{mal}$ handelte, ergaben die bereits von Bumm abgebildeten and eingehend geschilderten Veränderungen: Die oberflächliche Schicht der Dezidua ist mit Mikroorganismen dicht durchsetzt. Man sieht Stäbchenformen der verschiedensten Art, lange Fäden, Kokken von allen Grössen. Oft sind die Pilze zu förmlichen Kolonien ausgewachsen. Soweit die Pilze reichen and noch etwas darüber hinaus ist das Gewebe im Zustand der Nekrose, des Zerfalls, glasig und trüb. Eine Kernfärbung gelingt hier nicht mehr. Auf diese Zone, welche verschieden tief stellenweise durch die spongiöse Schicht hindurch bis an die Muskularis heranreicht, folgt eine Zone der zelligen Infiltration. Kleine Rundzellen liegen in dicker Schicht so eng aneinander, dass von der Grundsubstanz nur wenig mehr sichtbar bleibt. Die zellige Infiltration hört gegen die Muskularis zu allmählich auf.

In die Granulationsschicht, die als eine Reaktion des Organismus aufzufassen ist, dringen die Mikroorganismen nirgends mehr ein.

Fig. 3 (Taf. IX) zeigt den Typus einer solchen lokalisierten oberflächlichen Bakterienansiedelung bei einer putriden Endometritis, bei der am 9. Tage des Wochenbetts ein Deziduastückchen mit der Kurette entfernt wurde. Das Bild ist der Arbeit von Bumm entnommen.

Die nekrotische Schicht ist mit Fäulniskeimen durchsetzt, während die Reaktionsschicht ganz bakterienfrei geblieben ist.

Auf Grund solcher histologischen Befunde bei der reinen putriden Endometritis kann man, glaube ich, das Fieber nicht im Sinne einer Infektion auffassen, da es sich nicht um ein Einwandern virulenter Keime in das lebende Gewebe, sondern um ein Wuchern aller möglichen Bakteriensorten auf abgestorbenen oberfiächlichen Gewebsmassen handelt.

Der auch hier bisweilen zu beobachtende Temperatursturz nach tagelanger Temperaturerhöhung, wenn nach anfangs verbindertem Lochialabfluss plötzlich eine reichliche Entleerung erfolgt, spricht ebenfalls für ein durch Resorption toxischer Stoffe entstandenes Fieber.

Anders liegen die Verhältnisse bei der septischen Endometritis. Unter diese Bezeichnung fallen alle diejenigen Prozesse, wo die Krankheitserscheinungen durch die bekannten Mikroben 
352 Warnekros, Zur Prognose der puerperalen Fiebersteigerungen.

der menschlichen Sepsis allein hervorgerufen werden, oder wo diese doch im Ausstrich und in den Kulturen neben vereinzelten Saprophyten in überwiegender Mehrzahl nachgewiesen werden können.

Bei weitem am häufigstèn sind es Streptokokken, die man bei der septischen puerperalen Endometritis findet; und es sind nur vereinzelte Beobachtungen mitgeteilt (Bumm, Fehling u. a.), bei denen pyogene Staphylokokken als alleinige Erreger der Endometritis angetroffen wurden. In Reinkulturen habe ich Staphylokokken bei meinen Untersuchungen niemals gefunden, häufig dagegen Streptokokken.

Das Krankheitsbild war in allen den Fällen, wo schon durch die Untersuchung des Lochialsekretes ein Ueberwiegen der Streptound Staphylokokken festgestellt werden konnte, ein schwereres als bei der putriden Endometritis.

Die Temperaturen erreichten höhere Grade und der Verlauf erstreckte sich durchschnittlich über eine längere Zeitdauer. Niemals fiel die Temperatur kritisch ab, sondern in allen Fällen trat. eine allmähliche, sich über Tage erstreckende Entfieberung als. Zeichen der langsam ausheilenden Infektion ein.

Denn hier, bei der septischen Endometritis, handelt es sich tatsächlich um eine Infektion, um einen, wenn auch lokalisierten, Infektionskampf zwischen virulenten, penetrativen Bakterien und lebendem, reaktionsfähigem Gewebe.

$\mathrm{Bum}$ beschreibt allerdings in der bereits mehrfach zitierten Arbeit auch bei der septischen Endometritis ähnliche histologische Befunde wie bei der putriden, d. h. eine auf die oberflächliche Deziduaschicht beschränkte Bakerienwacherung und eine als Grenzwall funktionierende Granulationsschicht, in und durch die auch die pathogenen Streptokokken nicht dringen können.

Ich habe bei meinen Untersuchungen, die sich auf reine Streptokokkeninfektionen beziehen, diese durch eine Rundzelleninfiltration begrenzte und nur oberflächliche Bakterienansiedelung. nicht beobachten können. Vielmehr fand ich die ausgeschabten Gewebsstücke gleichmässig mit Streptokokken durchsetzt, und es gelang mir an den kurettierten Deziduafetzen nicht, bakterienfreie Gewebsabschnitte gegen infizierte abzugrenzen. Es bestand zwar auch hier eine sehr starke zellige Infiltration, die aber mehr diffus durch die ganze Dezidua hindurchging, und nicht als Scheidewand zwischen Gesundem und Krankem angesehen werden konnte. Be- 
trachtet man die Figuren, so sieht man die Streptokokken nicht nur in den oberllächlichen abgestorbenen Gewebsschichten, sondern durch das ganze Endometrium, soweit man es bei der Ausschabung bekommen konnte, zwischen den Drüsen- und Gefässdurchschnitten zerstreut. Wahrscheinlich bildet die Muskularis bei diesen lokalisierten septischen Endometritiden die Grenze gegen den Infektionsprozess; ich habe an den von mir kurettierten Stücken Muskelgewebe nicht mehr finden können.

In den Figg. 4 u. 5 (Taf. IX) sind Stückchen der Dezidua wiedergegeben, die von 2 Fällen schwerer septischer StreptokokkenEndometritiden im Verlauf des Krankheitsprozesses mit der Kurette gewonnen wurden.

In Fig. 4 ist eine einfache Bakterienfärbung vorgenommen worden; man sieht die Keime durch das ganze Gewebsstück hindurch zwischen den Gefäss- und Drüsenquerschnitten zerstreut liegen; in Fig. 5 ist das Gewebe gegengefärbt, so dașs man neben den blaugefärbten Bakterien die Struktur des kurettierten Gewebsstückchens sehr gut erkennen kann.

Vergleicht man die bei der Ausschabung gewonnenen bakteriologisch-histologischen Bilder der verschiedenen innerhalb der Uterushöhle sich abspielenden Krankheitsprozesse miteinander, so ergibt sich aus ihnen eine präzise Erklärung der klinischen Erscheinungen und eine Bestätigung des für den einzelnen Fall angenommenen Temperaturagens (Intoxikation bzw. Infektion). Zugleich liefern sie aber auch einen weiteren wertvollen Beitrag zur Beantwortung der Frage, welche Keime wir als echte Parasiten anzusehen berechtigt sind.

Das Carum uteri, sein Inhalt und die oberflächlichen nekrotischen Deziduaschichten stehen post partum allen Bakterien zur Entwicklung frei, und so finden wir auch unterschiedslos die ganze Flora der Scheidenkeime, Saprophyten und Parasiten, in dem Lochialsekret und in den abgestorbenen, oberflächlichsten Schichten des Endometriums.

Das bakteriologische Bild ändert sich aber mit einem Male, sobald wir es mit einer Erkrankungsform zu tun haben, die eine penetrative Fähigkeit der krankmachenden Bakterien voraussetzt.

Während wir bei der Lochialstauung und auch noch bei der putriden Endometritis das ganze Bakteriengemisch der verschiedensten Keime kulturell und bakterioskopisch nachweisen können, ist, die 
septische Eindometritis den primär virulenten Mikroben vorbehalten. Streptokokken und Staphylokokken, und insonderheit die ersteren, trennen sich schon hier scharf ab als echte Parasiten gegen die grosse Gruppe saprophytärer Keime. Sie allein haben gezeigt, dass ihre Existenz nicht an nekrotisches Gewebe gebunden ist, sondern dass sie sich kraft ihrer Virulenz, wenn auch bei der septischen Endometritis vorläufig nur an begrenzten Stellen und bis zu einer gewissen Tiefe, aber doch im lebenden Gewebe verbreiten können. Kein einziger der übrigen Keime hat dieselbe Progredienzfähigkeit bewiesen; niemals gelang der Nachweis eines der zahlreichen übrigen Bakterien des Lochialsekretes so weit innerhalb der kurettierten Gewebsmassen.

Die verschiedenen histologischen Bilder bestätigen uns, dass nach wie vor die Gruppe der Erreger infektiöser Prozesse auf die kleine Zahl primär virulenter Keime (Strepto- und Staphylokokken) beschränkt bleibt, und sie zeigen uns ferner, dass sich bei den schon klinisch und aus den Lochialverimpfungen festgestellten verschiedenen Krankheitsprozessen auch tatsächlich verschiedene histologische Vorgänge im Innern des erkrankten Organs abspielen.

Diese gleiche exzeptionelle Stellung der genannten echten Parasiten, wie wir sie schon bei der septischen Endometritis an umschriebener Stelle beobachten konnten, zeigt sich nun aber in noch weit prägnanterer Weise bei allen infektiösen Prozessen der Uterushöhle mit nachfolgender Allgemeininfektion.

Bekanntlich können sich die Bakterien vom Endometrium aus auf zwei Wegen im Körper weiter verbreiten: auf dem Blut- oder auf dem Lymphwege, und zwar allein auf dem einen oder anderen, oder auf beiden gleichzeitig.

Dieser Prozess stellt aber stets einen exquisit progredienten Infektionsvorgang dar und verlangt von den betreffenden Keimen, sofern sich die Erkrankung erst in den ersten Tagen des Wochenbetts an eine spontane oder ohne gröbere Verletzung operativ beendete Geburt anschliesst, die Fähigkeit der spontanen Invasionskraft.

Es ist bereits bei der Besprechung der intra partum fieberhaften Geburten auf die Möglichkeit hingewiesen worden, dass sich bei bestehendem Uteroplazentarkreislauf gelegentlich auch nicht primär virulente Keime einen krankmachenden Einfluss über den Organismus erwerben und diesen dann auch noch anschliessend an die Entbindung im Wochenbett geltend machen können, und ebenso werden wir bei Komplikationen des Geburtsverlaufes (perforierender Ver- 
letzung, Plazentarretention usw.) neben den echten Parasiten andere Keime im Körper verimpft oder verschleppt nachweisen können, aber in allen den Fällen, wo diese Gelegenheitsursachen fortfallen und die Keime auf sich angewiesen sind, ist die Fähigkeit zur Erregung der puerperalen Allgemeinerkrankung den wenigen Mikroben der menschlichen Sepsis vorbehalten.

Es sollen auch hier die einzelnen Krankheitsbilder in ihrem klinischen Verlauf unter besonderer Berücksichtigung der bakteriologischen Lochial-, Blut-, und Gewebsuntersuchungen besprochen werden, um aus einer möglichst exakten Erklärung auch eine möglichst sichere prognostische Bewertung der klinischen Symptome gewinnen zu können.

Ich beginne mit den auf dem Blutwege fortgeleiteten Infektionsprozessen: der puerperalen Pyämie und Septikämie (Sepsis).

Mit Ausnahme der puerperalen Sepsis, die sich bisweilen fast. unmittelbar an eine fieberfreie Geburt anschliessen und in wenigen Tagen zum Tode der Patientin führen kann, geht allen diesen Prozessen für gewöhnlich ein Stadium der noch lokalisierten Endometritis voraus. Die Temperaturkurve zeigt während dieser Zeit einen unregelmässigen Verlauf ohne ausgesprochenen Charakter; der Puls ist nicht besonders beschleunigt, kräftig und rhythmisch.

Das Ergebnis der Lochialuntersuchungen ist während dieser Zeit häufig ebenso unbestimmt, wie die Temperaturkurve; wenn man jedoch regelmässig von Tag zu Tag das Sekret kontrolliert, wird man in vielen Fällen allmählich ein Ueberwiegen der parasitären Keime beobachten können, sofern es sich nicht von vornherein um eine reine Strepto- bzw. Staphylokokken-Endometritis handelte.

In diesen Tagen der noch lokalisierten septischen Endometritis fällt die Entscheidung über den weiteren Verlauf; entweder ist die Reaktion des Körpers kräftig genug, bzw. die Virulenz der betreffenden Bakterien zu gering, und der Prozess heilt langsam aus, oder besonders pathogene Keime überwinden jegliche reaktive Barrière und verbreiten sich schrankenlos in dem befallenen Organismus.

Solange die Infektion lokalisiert ist, fallen die Blutproben negativ aus oder, genauer gesagt, die Infektion ist so lange lokalisiert, bis die Blutuntersuchungen zum ersten Male Keime kulturell nachweisen lassen. Klinisch macht sich 
356 Warnekros, Zur Prognose der puerperalen Fiebersteigerungen.

dieser Uebergang in das zweite Stadium je nach der Art der Ausbreitungsweise, die die Bakterien in dem einzelnen Fall wählen, oder die durch besondere anatomische Verbältnisse bedingt ist, verschieden bemerkbar.

Handelt es sich um den Ausbruch einer puerperalen Pyämie, die zuerst besprochen werden soll, so leitet ein Schüttelfrost diese Form der Allgemeininfektion ein.

Den pathologischen Prozess, der sich bis zu diesem Moment an dem erkrankten Organ abgespielt haben muss, kann man sich anatomisch verschieden entstanden denken.

Es ist möglich, dass es an der Plazentarstelle, z. B. nach Zwillingsschwangerschaft, Placenta praevia oder bei mangelhafter Zusammenziehung der Gebärmutter aus irgendeinem anderen. Grunde von vornherein zu einer zunächst aseptischen Thrombose der Uteroplazentarvenen gekommen ist, die jetzt für die allmählich aszendierenden Bakterien einen willkommenen Angriffspunkt abgibt. Es kann aber auch durch Infiltration oder durch Abszessbildung an irgendeiner Stelle innerhalb der Gebärmutterwand zu einer venösen Stauung mit sekundärer Vereiterung der thrombosierten Massen gekommen sein. Schliesslich können auch die Bakterien direkt in das Lumen der Venen eingewandert sein und hier primär eine entzündliche Erkrankung des Endothels mit nachfolgender Gerinnungsthrombose bewirkt haben.

Der klinische Verlauf, die Geburtsgeschichte und die Ergebnisse der bakteriologischen Blutuntersuchungen werden uns in den einzelnen Fällen die Entstehung mehr in dem einen oder anderen Sinne wahrscheinlich machen.

Jedenfalls ist der Schüttelfrost mit positivem Blutbefund der Ausdruck dafür, dass durch den pyogenen Einfluss der infizierenden Bakterien ein Zerfall der Massen innerhalb der Venen und eine Verschleppung der abbröckelnden infizierten Stücke mit dem Blutstrome stattgefunden hat.

Es ist aber für die klinische Entscheidung, dass der Infektionsprozess über das Endometrium hinaus in seine zweite Periode getreten ist, das positive Resultat der Blutuntersuchung unbedingt erforderlich.

Der Schüttelfrost allein, so verdächtig er auch rein klinisch für eine Progredienz des Krankheitsverlaufes ist, beweist ebenso wenig, wie eine plötzlich höher aufschnellende Temperatur ohne 
Frost, die bereits eingetretene Allgemeininfektion. Wie bei der Besprechung der septischen Endometritis erwähnt wurde, werden gelegentlich auch bei den noch lokalisierten Entzündungsprozessen des Endometriums Fröste beobachtet, aber mit dem prinzipiell wichtigen Unterschied, dass die in gleicher Weise verimpften Blutproben steril bleiben. Dieser bakterienfreie aseptische Frost lässt, wie gesagt, keinen Vergleich mit dem bakterienhaltigen $\mathrm{zu}$; beide sind prognostisch durchaus different $\mathrm{zu}$ bewerten.

Wir müssen daher, um uns in jedem einzelnen, puerperalen Fieberfall ein möglichst sicheres Bild über den jeweiligen Stand der Infektion machen zu können, fortgesetzt, an einem Tage eventuell mehrmals, bakteriologische Blutuntersuchungen als Kontrolle der klinischen Erscheinungen vornehmen.

Lässt die im Frost entnommene Probe Keime in der Blutagarsäule angehen, so ist damit der Beweis erbracht, dass der Prozess in sein zweites Stadium getreten ist, d. h. dass die lokalisierte Erkrankung eine allgemeine geworden ist. Da uns jetzt im Wochenbett dieser Nachweis den selbständigen Fortschritt der Infektionserreger ohne vermittelnde anatomische Gelegenheitsursache anzeigt, werden wir von vornherein annehmen müssen, dass es sich um besonders pathogene und spontan invasionsfähige Keime handelt.

Das Resultat der bakteriologischen Untersuchung bestätigt dann auch ausnahmslos diese Befürchtungen. Wir werden in allen Fällen, wo eine grobmechanische Gelegenheitsursache oder eine Komplikation, wie ein zurückgebliebener Plazentarrest, als Erklärung der Keimverschleppung fortfällt, stets die bekannten Erreger der menschlichen Sepsis, Strepto-oder Staphylokokken, in den Kulturen angegangen finden. Ich habe in den 12 von mir untersuchten Fällen von puerperaler Pyämie, die sämtlich ad exitum gekommen sind, 9 mal Streptokokken und 3 mal Staphylokokken im Blute nachweisen können, d. h. mit anderen Worten: die tödlich verlaufenen Fälle einer puerperalen Allgemeininfektion (unter Ausschluss der Fälle, die bereits intra partum fieberten, bei denen perforierende Verletzungen stattgefunden hatten, oder bei denen Plazentarstücke zurückgeblieben waren) sind das Reservat primär virulenter Keime; nur den Strepto- und Staphylokokken ist die Fähigkeit der eigenmächtigen, unbeschränkten und von jeder anatomischen Gelegenheitsursache unabhängigen Infektionsmöglichkeit des 
menschlichen Körpers allen organischen und bakteriziden Kräften zum Trotz gegeben.

Von dieser allgemein gültigen Regel machen nun einige seltene Fälle von puerperaler Pyämie eine schein bare Ausnahme.

Man wird bisweilen in den Blutkulturen neben den Streptobzw. Staphylokokken noch andere Keime nachweisen können, denen man nach allen bakteriologisehen Erfahrungen eine primäre Virulenz absprechen muss.

Betrachtet man die Krankengeschichten dieser Fälle genauer, so wird man in dem Geburtsverlauf sehr häufig eine Störung der Nachgeburtsperiode angegeben und somit eine Erklärung für eine schon rein mechanisch bedingte Thrombose der UteroplazentarVenen finden können.

Die nach irgend einer Anomalie der Nachgeburtsperiode knopfartig vorspringenden Thromben an der Plazentarstelle werden in diesen Fällen für alle Bakterien einen besonders günstigen Angriffspunkt und Nährboden abgeben, da die Thrombenmasse zweifellos ein Gewebe von verminderter Vitalität darstellt.

Kommt es nun in einem derartigen, zunächst nur von Fäulniskeimen durchsetzten, Venenpfropf zu einer sekundären Entwicklung virulenter Streptokokken, so kann man sich leicht vorstellen, dass beim eiterigen Zerfall der Thromben mit den abbröckelnden Massen neben den ursächlichen Parasiten auch die zufällig dort wuchernden harmlosen Saprophyten mitverschleppt und im Blute nachgewiesen werden können. Umgekehrt kann auch durch eine primär durch virulente Bakterien hervorgerufene Thrombose saprophytären Keimen beim Zerfall der Thromben gelegentlich der Weg in die Blutbahn so erleichtert werden, dass sie ohne eigene Invasionsfähigkeit auf den präformierten Wegen mitverschleppt werden. Für diese letzte Auffassung spricht die Beobachtung, dass man für gewöhnlich in den ersten Blutproben nur Strepto- oder Staphylokokken und im weiteren Verlauf neben diesen auch noch andere Keime findet.

Ich habe unter den von mir beobachteten Fällen einmal neben Streptokokken Stäbchen gefunden. Es handelte sich um eine Placenta praevia, bei der ein Teil der Nachgeburt manuell gelöst werden musste. Auch hier gelang der Nachweis erst im fortgeschrittenen Stadium der Infektion. Aehnliche Fälle sind in der Literatur mehrmals beschrieben worden; sehr oft in der fälschlichen Annahme, dass es sich um eine besondere Puerperalinfektion 
handele, und dass die gefundenen Keime mit diesem Nachweis im Blut ihre invasive Fähigkeit bewiesen hätten. Das gleichzeitige Angehen primär virulenter Keime wird von vielen nor ganz nebensächlich registriert.

Melzer beschreibt zwei Fälle von Puerperalinfektion mit dem Micrococcus tetragenus albus. In beiden Fällen handelte es sich um Mischinfektion mit Streptokokken; einmal anschliessend an die Geburt, wobei im Blute bei einer einmaligen Entnahme neben Streptokokken der genannte Keim gefunden wurde. Da aber weder das Uterussekret noch später die Uteruswand einer bakteriologischen Untersuchung unterzogen wurde, ist der Fall bakteriologisch nicht einwandsfrei, da der Vorwurf einer zufälligen Verunreinigung nicht auszuschliessen ist. Bei dem zweiten Fall, der erst drei Monate nach der Geburt zur Beobachtung kam und ein ungeklärtes Krankheitsbild bot, das mit der Entbindung scheinbar nichts mehr zu tun hatte, wurden ebenfalls bei einer einmaligen Entnahme Streptokokken und Tetragenus gefunden. Der Fall ist ungeheilt entlassen worden und konnte weder klinisch noch bakteriologisch weiterhin beobachtet und untersucht werden.

Banti beschreibt eine tödlich verlaufende pyämische Puerperalinfektion, wo neben den Streptokokken der B. aerogenes capsulatus im Blute gefunden wurde.

Die gleische Mischinfektion fand Hussy, allerdings erst in den bei der Sektion verimpften Blutproben.

Marquis sah eine tödlich verlaufende Pyämie, wo im Blut der Patientin Streptokokken und Coli gewachsen waren.

Halban beobachtete im Anschluss an eine operative Entbindung ein Emphysem des Uterus, wo der Nachweis dieser Bakterien allerdings nur in den Lochialsekreten gelang; im Blut waren allein Streptokokken vorhanden.

Einen für die anatomische und bakteriologische Aetiologie besonders instruktiven Fall teilt $\mathrm{Hamm}$ mit. Im Anschluss an eine spontane Geburt trat im Laufe des Wochenbettes stärkere Blutung auf, sodass man an einen retinierten Plazentarrest dachte, in Narkose nachtastete und einen walnussgrossen Körper entfernte. Die Untersuchung der entfernten Massen ergab aber, dass es sich nicht um einen Kotyledon, sondern um ein Stück Gebärmutterwand selbst handelte. Darauf heisse Uterusspülung und Tamponade. Unmittelbar anschliessend an diesen operativen Eingriff entwickelte sich das typische Bild einer Pyämie, wobei in 
360 Warnekros, Zur Prognose der puerperalen Fiebersteigerungen.

den Blutkulturen Streptokokken angingen. Am 8. Tage wurde, nachdem in den ersten Blutproben stets nur Streptokokken gefunden worden waren, auf einmal auch der B. haemophilus neben den Streptokokken nachgewiesen. Dieser Fall zeigt, wie im Experiment, das gelegentliche Entstehen und die allmähliche Entwicklung einer Mischinfektion: nachdem durch mechanische Verletzung der Uteruswand eine Thrombose in den arrodierten Gefässen entstanden war, wurden bei dem Zerfall der infizierten Thromben zunächst nur die ursächlichen Keime (Streptokokken) und schliesslich auch einmal die zufällig dort wuchernden Saprophyten mitverschleppt und im Blute nachgewiesen. Damit ist aber keineswegs, wie Hamm annimmt, die Penetrationsfähigkeit dieser Keime bewiesen, sondern nur die rein mechanische Verschleppung besonders prägnant illustriert.

Dass das Entstehen einer Mischinfektion wohl stets eine besondere anatomische Disposition als Ursache verlangt, beweist die relative Seltenheit dieses Nachweises; für gewöhnlich finden wir nur einen der beiden Keime (Strepto- oder Staphylokokken) in Reinkultur.

Betrachten wir die bakterioskopischen Bilder solcher infizierten Venenthromben an der Plazentarstelle, so finden wir an ihnen auch die Erklärung dafür.

Bereits Bumm hatte in 2 Fällen von puerperaler Pyämie die Verhältnisse am Endometrium und besonders das Verhalten der Plazentarstelle an Schnittfärbungen genau untersuchen können.

Bumm fand in jenen Teilen der Thromben, welche der Oberlläche der Dezidua zunächst lagen, neben den Kettenkokken auch noch Fäulniskeime. Tiefer im Uterusparenchym waren aber an den infizierten Thromben nur noch Streptokokken in Reinkultur sichtbar. Es wanderten also nur die mit invasiven Eigenschaften ausgerüsteten pathogenen Formen ein; die Saprophyten blieben zurück.

Damit sind die Ergebnisse der bakteriologischen Blutuntersuchung vollauf erklärt; wir werden in den weitaus häufigsten Fällen nur die aktiv in die weiteren Venenverzweigungen und von dort in die Blatbahn fortgewanderten Bakterien nachweisen können, sofern eben nicht durch besondere anatomische Verhältnisse auch eine abnorme Gelegenheit zur Keimverschleppung gegeben ist.

Das Widal'sche Gesetz, dass das Endometrium wie ein Filter wirke, das nur die pathogenen Keime eindringen lasse, die Fäulnis- 
keime aber zurückhalte, muss sich demnach für die thrombotische Form des Puerperalfiebers die obige Einschränkung einer mechanischen Mischinfektion zwar gefallen lassen; im allgemeinen hat es aber auch hier seine Gültigkeit bewiesen.

Sind also in der Blutprobe, die während des ersten Schüttelfrostes entnommen wurde, virulente Bakterien angegangen, und hat sich somit der Eintritt des zweiten Stadiums im Verlauf der Infektion dokumentiert, so lässt sich der weitere deletäre Einfluss und das allmähliche Uebergewicht, das die Bakterien im Kampf mit dem Organismus von Tag zu Tag gewinnen, direkt aus den Blutkulturen ablesen.

Für gewöhnlich beanspruchen die in den ersten Proben entnommenen und verimpften Keime die längste Zeit zur Entwicklung, d. h. bis zu ihrer makroskopischen Wahrnehmung in den Agarröhren vergehen zwei oder mehrere Tage. Diese Verzögerung mag in dem vorläufig noch wachstumshemmenden Einfluss der bakteriziden Blutkräfte zu suchen sein; jedenfalls gibt uns die Schnelligkeit, mit der die Keime in den verimpften Kulturen angehen, vorläufig die sicherste Auskunft über den jeweiligen spezifischen Virulenzgrad der Bakterien. Auch die Zahl der angehenden Keime ist in der Regel in den ersten Blutproben noch relativ gering, wahrscheinlich als Folge daron, dass die noch weniger virulenten und dem neuen Medium noch nicht angepassten der verschleppten Bakterien von den Abwehrkräften des Körpers vernichtet werden. Hierbei kann allerdings auch die noch geringere Menge der anfangs in die Blutbahn gelangten Keime eine Rolle spielen.

Mit dem Fortschritt der Infektion, der sich kliniseh in der Schwere und Häufigkeit der Schüttelfröste äussert, ändern sich auch die Resultate der Blutuntersuchungen. Die Keime gehen in wesentlich kürzerer Zeit und in grösserer Anzahl auf.

Solange aber auf den Frost noch eine kräftige Reaktion des Körpers erfolgt, die Temperatur unter Schweissausbruch rapide abfällt und die Patientinnen ein gewisses Gefühl des Wohlbehagens empfinden, kann man einen weiteren prognostisch wichtigen Abschnitt im Verlauf der bereits manifesten Allgemeininfektion aus den Ergebnissen der Blutuntersuchungen abgrenzen: das ist die Blutreinheit im fieberfreien Stadium, als Zeichen dafür, dass der Körper mit den importierten Keimen des letzten Schüttelfrostes noch fertig geworden ist. Untersucht man das Blut mehrere 
Stunden nach dem Frost oder bei einer tiefen morgendlichen Remission, so wird man im Beginn der Erkrankung, sofern es sich um eine reine thrombophlebitische Pyämie handelt, das Blut bakterienfrei finden. Diese Selbstreinigung ist als ein günstiges Zeichen einer kräftigen Organreaktion anzusehen, und dieses Stadium gilt, wenn überhaupt noch Chancen auf Heilung bestehen, als die letzte Etappe, die eventuell noch die Hoffnung auf eine dauernde Keimelimination zulässt. Bekanntlich gehört diese Spontanheilung zu den grössten Seltenheiten; einzelne Fälle (Baisch, Benthin, Fromme u. a.) sind beschrieben worden. Ich habe niemals einen Prozess, bei dem wiederholt die Blutproben im Wochenbett positiv ausfielen, zur Heilung kommen sehen.

Für gewöhnlich schreitet die Erkrankung, wenn es erst einmal soweit gekommen ist, allen therapeutischen Massnahmen zum Trotz vor unseren Augen unaufhaltsam fort; die Blutproben lassen in kurzer Zeit, oft schon nach 10 Stunden, Tausende von Kolonien in den Röhren erkennen und auch die im Fieberabfall entnommenen Proben zeigen Keime in stetig wachsender Anzahl. Damit ist das Schicksal der Patientin besiegelt; der Körper hat, wenn man so sagen darf, Bankrott erklärt, die in die Blutbahn gelangten Keime finden keine wachstumshemmenden Einflüsse mehr, ihrer Entwrickelung steht nichts mehr im Wege. Man muss aus den Befunden der Blutuntersuchung, besonders aus der stetig zunehmenden Menge der Bakterien in den Agarröhren, annehmen, dass nicht nur die bakterizide Kraft des Körpers erlahmt ist, sondern dass sich auch die Bakterien, vielleicht als Folge hiervon, die Fähigkeit der selbständigen Weiterentwickelung in dem neuen Medium erworben haben.

Ich habe in einem Fall diese Anpassung und Virulenzsteigerung der Bakterien in ganz besonders anschaulicher Weise beobachten können. Es handelte sich um eine am 4. Tage post partum auftretende Fiebersteigerung im Anschluss an eine spontane Geburt. Die ersten Blutproben am 5. und 6. Tage blieben steril; am 7., 8., 9. und 10. Tage positive Blutbefunde (Streptokokken) in steigender Keimzahl, aber nur während der Fröste; vom 12. bis 20. Tage Streptokokken auch im Fieberanfall, ebenfalls in steigender Menge; rom 22. Tage ab ausgesprochene Hämolyse, am 30. Tage Exitus. Dieser Fall zeigt nicht nur die allmählich fortschreitende und sich immer weiter etablierende Infektion, sondern auch die sich erst im Verlauf entwickelnde Virulenzsteigerung der 
Infektionserreger durch das Auftreten einer typischen Hämolyse der anfangs nicht hämolysierenden Streptokokken. Aehnliche Beobachtungen, wenn auch nicht so ausgesprochen, habe ich mehrmals gemacht.

Die anatomischen Befunde bei der Sektion sind bei diesen puerperalen Pyämien verschieden je nach der Schwere, der Dauer und der Lokalisation des Krankheitsherdes. Der Prozess kann rein intravenös fortgeschritten sein, oder die entzündlichen Prozesse können auf die Umgebung übergegriffen und zu einer sulzigen Infiltration oder auch eiterigen Einschmelzung des benachbarten Gewebes geführt haben. Bei dem meist chronischen Verlauf der thrombotischen Form des Puerperalfiebers sind die Erscheinungen am Uterus selbst fast stets zur Ausheilung gelangt, wenn die Patientinnen der Infektion erliegen. Mit den abgerissenen septischen Thromben können die Keime allerorts verschleppt werden und metastatische Eiterherde in den verschiedenen Organen entstanden sein.

Auffallend ist oft die enorme Ausbreitung dér thrombophlebitischen Prozesse in den abführenden Venen und die geringen oder ganz fehlenden Stauungserscheinungen in den von der Zirkulationsstörung betroffenen Organen. Ich habe bereits früher zwei bis in die Vena cava fortgeschrittene Fälle einer puerperalen Pyämie mit fast vollständig fehlender Staung beschrieben und abgebildet, und habe in letzter Zeit einen noch eklatanteren Fall beobachten können, wo die obliterierende Thrombose der Vena cava bis zum Durchtritt durch das Zwerchfell vorgeschritten war, ohne dass auch nur die geringste vorübergehende Schwellung in den Extremitäten oder eine funktionelle Störung in einem der übrigen Organe hätte bemerkt werden können.

Fig. 6 (Taf. IX) zeigt das im Zusammenhang bei der Sektion entnommene Präparat einer puerperalen Pyämie mit den freigelegten thrombosierten Venen. Der Prozess war von den lliakalvenen aus durch die Vena iliaca com. bis hoch hinauf in die Cava fortgeschritten und hatte zum vollkommenen Verschluss dieser Gefässe geführt. Die Erkrankung war rein venös fortgeschritten; die nächste Umgebung der thrombosierten Gefässe zeigte weder sulzige Infiltrationen noch eiterige Einschmelzung des Gewebes. Die direkte Verfolgung der Thrombose bis zur Ursprungsstelle am Endometrium war hier bei dem über 4 Wochen sich erstreckenden Verlauf nicht mehr möglich. Es handelte sich um den vorher kurz skizzierten Fall einer puerperalen Streptokokken-Pyämie mit allmählich auftretender Hämolyse. 
364 Warnekros, Zur Prognose der puerperalen Fiebersteigerungen.

Fig. 7 (Taf. IX) demonstriert an einem anderen Fall einer schweren puerperalen Pyämie, bei dem die Thrombose bis zur Cava vorgeschritten war, die ausgedehnten periphlebitischen. Prozesse in der Umgebung der erkrankten Gefässe.

Fig. 8 (Tal. IX) zeigt eine ausgesprochene sulzige Infiltration des umgebenden Gewebes mit eiteriger Einschmelzung und Abzessbildung im Parametrium. In den beiden letzten Fällen war noch der erfolglose Versuch gemacht worden, den' Fortschritt des Prozesses operativ durch die Ligatur der Venen aufzuhalten (s. Archiv für Gynäk.; Bd. 97).

Die bakterioskopisch-histologischen Verhältnisse bei dieser thrombotischen Form des Puerperalfiebers sollen an der Hand weiterer eingehend untersuchter Fälle besprochen und abgebildet werden.

Fig. 9 (Taf. X) zeigt einen grösseren Abschnitt aus dem Uterusfundus; das Organ stammt von einer Patientin, die am 12. Tage post partum an einer schweren Streptokokken-Pyämie zugrunde ging.

Die Verhältnisse am Endometrium entsprechen im grossen und ganzen dem Bild einer septischen Endometritis; die Bakterien haben sich mehr oder minder weit in den oberflächlichen Schichten der Schleimhaut ausgebreitet; jedoch ergibt die genauere Untersuchung, dass an einzelnen Stellen auch vom Endometrium aus ein Vordringen der Bakterien bis in die Muskulatur stattgefunden hat und dass die hier verlaufenden venösen Gefässe zum Teil mit Streptokokken angefüllt sind. Eine solche Stelle ist in Fig. 10 (Taf. X) bei stärkerer Vergrösserung abgebildet. Im allgemeinen war aber die Erkrankung am Endometrium lokalisiert.

Ganz anders liegen die Verhältnisse an der Plazentarstelle, die man schon makroskopisch an der rauhen Beschaffenheit erkennen konnte. Die Ablösung des Mutterkuchens war anscheinend nicht ganz glatt erfolgt; es konnten, besonders mikroskopisch, in den hier auflagernden Blutmassen noch nekrotische Zotten nachgewiesen werden. Eine entsprechende Stelle ist in dem abgebildeten Schnitt getroffen. Ein grösserer, zum Teil organisierter Blutklumpen mit nekrotischen Plazentarzotten liegt der Uterusfläche auf und ist mit Bakterien (Streptokokken in langen Ketten) vollständig durchsetzt. Die von hier abgehenden klaffenden Uteroplazentar-Venen sind mit Keimen vollgepfropft und, wie die Verfolgung ihres Verlaufes durch die Muskulatur erkennen lässt, sind. 
alle weiteren im Querschnitt getroffenen Verzweigungen bis dicht unter die Serosa gleichmässig mit Keimen angefüllt. Die Bakterien liegen aber nicht nur im Lumen der thrombosierten Gefässe, sondern sind mit der Venenwandung in Kontakt getreten und als Zeichen ihrer spontanen Invasionsfähigkeit durch sie hindurch infiltrierend in das umgebende Gewebe hineingewachsen, wie eine solche Stelle bei stärkster Vergrösserung in Fig. 11 (Taf. X) abgebildet ist.

Die Arterien sind allerorts gut zusammengezogen, thrombenfrei und nicht infiziert.

Fig. 12 (Taf. X) stammt ebenfalls vom Uterus einer am 20. Tage an Pyämie gestorbenen Patientin. Im Gegensatz zu dem ersten Fall war aber hier der Einbruch in die Gefässbahn nicht vornehmlich von der Plazentarstelle aus erfolgt, sondern die mikroskopische Untersuchung des Uteruskavums ergab an allen Stellen des Endometriums eine tiefgehende Nekrose und einen eiterigen Zerfall der Schleimhaut mit ausgedehnter Thrombose und Bakterienanhäufung im Lumen der venösen Gefässe. Auch hier waren die Keime, besonders an den mehr oberflächlich gelegenen Gefässen, vermöge ihrer penetrativen Fähigkeit durch die Wandung hindurch in das umgebende Gewebe hineingewachsen und hatten an umschriebenen Stellen kleinere Abzesshöhlen durch eiterige Einschmelzung des Gewebes gebildet. Eine solche Stelle ist in Fig. 13 (Taf. X) bei Oelimmersionsvergrösserung gezeichnet.

Die Untersuchung der Uteri ergab in fast allen von mir beobachteten Fällen puerperaler Pyämie die gleichen oder ähnliche histologische Bilder.

Es handelte sich in den 12 Fällen meiner Beobachtungsreihe 9 mal um eine Streptokokken- und $3 \mathrm{mal}$ um eine StaphylokokkenInfektion, die in der Art ihrer Ausbreitung keinen Unterschied erkennen liessen. Die Geburten waren 5 mal spontan verlaufen und 7 mal operativ beendigt worden; 2 mal hatte es sich um eine Placenta praevia gehandelt. Die Blutproben fielen nach einer anfangs lokalisierten Endometritis durchschnittlich am 5. bis 6. Tage zum ersten Male positiv aus; die Keime konnten dann regelmässig in zunehmender Menge im Blute nachgewiesen werden; sämtliche Franen sind gestorben. $4 \mathrm{mal}$ war der vergebliche Versuch gemacht worden, durch Venenunterbindung den Krankheitsprozess zum Stillstand zu bringen. 
So ungünstig man danach auch im allgemeinen die Prognose bei der ausgesprochenen thrombophlebitischen Pyämie quoad vitam stellen muss, so ist sie doch von den verschiedenen puerperalen Allgemeininfektionen insofern als die günstigste anzusehen, als es wenigstens im Beginn der Erkrankung zu einer Lokalisation des Krankheitsprozesses innerhalb der Gefässwand mit nur zeitweise auftretender Keimüberschwemmung des Blutes kommt. Die Blutuntersuchungen haben gezeigt, dass die bakteriziden Kräfte mit diesen ersten Bakterieninvasionen fertig werden, dass also bis zu einem gewissen Zeitpunkt die Möglichkeit der Heilung besteht, wenn aus irgend einem Grunde der weitere Zerfall der Thromben ausbleibt oder durch einen operativen Eingriff verhindert wird.

Weit ungünstiger liegen die Verhältnisse bei der zweiten Art der auf dem Blutwege fortgeleiteten und verallgemeinerten Puerperalinfektion bei der sogenannten Septikämie.

Auch hier geht für gewöhnlich dem Stadium der Allgemeininfektion eine kurze Periode der lokalisierten septisehen Endometritis voraus. Das klinische Bild und die bakteriologischen Befunde entsprechen während dieser Zeit dem bereits mehrfach beschriebenen Typus dieser Erkrankungsform: unregelmässig remittierendes Fieber und etwas beschleunigter Puls, negativer Ausfall der Blutproben, dagegen häufig schon von vornherein Reinkulturen von Streptokokken bzw. Staphylokokken in den Verimpfungen des Lochialsekretes. Je nach der Virulenz der betreffenden Infektionserreger erstreckt sich dieses erste Stadium über kürzere oder längere Zeit. Für gewöhnlich überdauert es aber nicht 2 bis 3 Tage, in einzelnen Fällen fehlt es ganz, und es schliesst sich die Allgemeininfektion fast unmittelbar an die Geburt an und führt in wenigen Tagen unter dem Bilde einer foudroyanten Blutvergiftung zum Tode der Patientin.

Den Uebergang der lokalisierten zur allgemeinen Infektion zeigt klinisch die plötzlich aufschnellende und kontinuierlich hochbleibende Temperaturkurve und das sichtlich sich verschlechternde Allgemeinbefinden der Erkrankten an.

Die Blutuntersuchung bestätigt die klinischen Erscheinungen. Die verimpften Proben lassen bereits nach kurzer Zeit zahlreiche Kolonien in den Agarröhren angehen und als Zeichen der fortgesetzten Ueberschwemmung des Blutes mit den betreffenden Mikroben fallen die Blutproben dauernd positiv aus. Eine auch nur vorübergehende Blutreinheit wird bei diesen septikämischen 
Puerperalinfektionen, sobald der Prozess in sein zweites Stadium getreten ist, nicht mehr beobachtet.

Die Erklärung dieser Sepsisform kann nicht in disponierenden anatomischen Verhältnissen, sondern nur in den Erregern selbst gesucht werden. Man muss annehmen, dass es sich hier um ausgesucht hochvirulente Bakterien handelt, die jegliche Organreaktion spielend überwinden, denen der Körper mit seinen bakteriziden Abwehrstoffen so gut wie machtlos gegenübersteht, und denen auch die Fähigkeit der spontanen Weiterentwickelung im Blute im besonders hohen Masse gegeben ist. Die Schnelligkeit, mit der die Kolonien in den Verimpfungen aufgehen, und die rapide Zunahme der Keimzahl von Tag zu Tag geben uns die bakteriologische Bestätigung dieser Annahme.

Wir werden daher bei der reinen Septikämie niemals neben den spezifischen Erregern der puerperalen Infektionen noch andere Keime in den Blutproben als Mischinfektion angegangen finden, wie wir es gelegentlich bei der thrombophlebitischen Form beobachten konnten. Dort nahmen wir zur Erklärung an, dass mit Fäulniskeimen durchsetzte Thromben sekundär infiziert und so mit den zerfallenden Thrombenmassen auch saprophytäre Keime in die Blutbahn mitgenommen wurden.

Diese Transportmöglichkeit fällt hier fort. Ohne dass sich gröbere Einbruchsstellen nachweisen lassen, dringen die exquisit penetrationsfähigen Keime direkt in das Gewebe und in die Gefässlumina ein und finden hier einen ihnen zusagenden Nährboden zur Weiterentwicklung.

Alles, was zur Ausbreitung einer anatomischen Gelegenheitsursache bedarf, bleibt auf dem Endometrium zurück; eine Sepsis nicht primär virulenter Keime gibt es nicht.

Häufig ist diese Form mit einer gleichzeitig lymphatischen Ausbreitung der Infektionserreger verbunden, die neben der Blutsepsis zur eiterigen Peritonitis führt. Bumm hat das histologische Bild der Uteruswand der Gebärmutter einer Wöchnerin, die am 4. Tage des Wochenbettes an akuter Sepsis mit gleichzeitiger septischer Peritonitis starb, in seiner Arbeit abgebildet. Die Rundzellenanhäufung fehlte hier vielfach ganz, und gerade an diesen Stellen wuchsen die Streptokokken in die muskulöse Gebärmutterwand weiter hinein und einfach durch dieselbe hindurch. Neben mehreren mit Kokkenrasen erfüllten grösseren Lymphspalten 
wurden auch in zahlreichen kleineren und grösseren Venen Streptokokken nachgewiesen. An der Plazentarstelle waren die mejsten Venenspalten gut geschlossen, thromben- und kokkenfrei.

Bei den von mir untersuchten 6 Fällen von puerperaler Septikämie handelte es sich 3 mal um eine reine Blutsepsis und $3 \mathrm{mal}$ um eine gleichzeitige Kombination mit einer lymphatisch fortgeleiteten Peritonitis. Die Erreger waren 5 mal Streptokokken und 1 mal Staphylokokken in Reinkultur. Das Krankheitsbild verlief wesentlich rascher als bei der pyämischen Form; schon nach wenigen Tagen wurden die Keime im Blut nachgewiesen. Alle Patientinnen sind gestorben.

Die histologischen Bilder entsprachen den von Bumm abgebildeten und beschriebenen Verhältnissen.

Zum Schluss sollen noch kurz die ausschliesslich lymphatisch fortgeleiteten, zur Peritonitis führenden Infektionen ohne Uebertritt der Bakterien in die Blutbahn besprochen werden. Nach meinen Beobachtungen sind die rein auf dem Lymphwege fortgeschrittenen Fälle von Puerperalinfelstionen selten; für gewöhnlich besteht, wie die Blutuntersuchungen gezeigt haben, gleichzeitig auch ein in die Blutgefässbahn eingebrochener und von hier aus fortgeleiteter Infektionsprozess.

Ich habe nur zweimal eine septische Peritonitis als die alleinige Manifestation der puerperalen Erkrankung im Anschluss an eine ausgetragene Geburt klinisch und bakteriologisch beobachten können. Einmal handelte es sich um eine perforierende Verletzung im unteren Uterinsegment, die in wenigen Tagen zu. einer ausgebreiteten Streptokokken-Peritonitis und zum Exitus führte. Die Blutproben fielen während dieser relativ sehr kurzen Krankheitszeit negativ aus; es ist aber wohl möglich, dass bei einem mohr chronischen Verlauf der Erkrankung, ohne die artifizielle direkte Keimverimpfung in die Bauchhöhle, auch das Gefässsystem infiziert worden wäre. Bei dem zweiten Fall handelte es sich um eine sehr langdauernde aber spontan verlaufene Geburt, bei der am 8. Wochenbettstage durch Punktion die eitrige Bauchfellentzündung diagnostiziert wurde. Auch hier fand man Streptokokken; die Patientin starb am 12. Tage post partum.

Man muss bei der lymphatischen Ausbreitung des Krankheitsprozesses zwei Wege unterscheiden. Die Bakterien können den feinsten Lymphgängen entlang zwischen den Gewebselementen durch die Uteruswand hindurchwachsen und so auf der serösen Ober- 
fläche angelangt die tödliche Peritonitis hervorrufen, oder die Ausbreitung der Infektionsträger hält sich im wesentlichen an die gröberen Lymphgefässe.

Der klinische Verlauf entspricht während dieser Progredienz durch die Barrière der Muskelwand einer schweren septischen Endometritis, bis die erfolgte Lokalisation auf dem Peritoneum die eklatanten Erscheinungen der entzündlichen Bauchfellerkrankung hervorruft. Damit ist der Prozess in sein zweites Stadium getreten; der positive Ausfall der Bauchdeckenpunktion entspricht prognostisch hier dem Angehen der Keime in den Blutagarröhren bei den pyämischen und septikämischen Allgemeininfektionen.

Auch bei dieser rein lymphatisch fortgeschrittenen Puerperalerkrankung werden wir, wenn nicht eine perforierende Gewebsverletzung die anatomische Gelegenheitsursache zur Keimverschleppung abgibt, nur primär virulente Keime als Erreger der tödlichen Peritonitis antreffen; allen übrigen Keimen fehlt die enorme Penetrationsfähigkeit, wie sie die Strepto- und Staphylokokken besitzen müssen, wenn sie in wenigen Tagen die dicke puerperale Uteruswand in einem Znge durchsetzen. Die Prognose ist somit bei diagnostizierter Peritonitis eine sehr schlechte.

Die folgenden Figuren zeigen die histologischen Bilder der beiden Ausbreitungsarten auf lymphatischem Wege. Fig. 14 (Taf. X) entspricht der zuerst beschriebenen Form, bei der die Mikroben den feinsten Lymphgängen zwischen den Gewebselementen folgen und regellos infiltrierend das Organ durehwandern, Fig. 15 (Taf. X) einer Stelle aus der Muskulatur bei starker Vergrösserung.

In Fig. 16 (Taf. X) sind die grösseren Lymphgefässe die Transportwege der Infektionserreger:

Von der Plazentarfläche aus, die noch mit schmierig zersetzten und infizierten Blutmassen und an einzelnen Stellen mit nekrotisehen Zotten bedeckt ist, dringen diesmal die Keime auf dem Wege der grösseren Lymphgefässe in die Muskulatur ein und können bis dicht unter die Serosa nachgewiesen werden. Die Gefässe sind bakterienfrei und nicht thrombosiert.

Als Abbildungen sind, soweit es möglich war, reine Typen für die verschiedenen Arten der Progredienz gewählt; häufig wird man jedoch die thrombophlebitische, septische und lymphatische Form der Ausbreitung in einem Fall kombiniert finden, je nach 
der Virulenz der Bakterien und den zufälligen anatomischen Verhältnissen.

Im allgemeinen beherrscht bei allen puerperalen Infektionen das betreffende Bakterium die Situation; es ist in seiner deletären Machtentfaltung von den anatomisch-pathologischen Verhältnissen unabhängig, und nur sein Weg bzw. die Form der weiteren Ausbreitung wird gelegentlich durch irgendeine anatomische Anomalie beeinflusst. Sie ist aber für den Endeffekt nebensächlich; der primär virulente Keim trägt das Rüstzeug für den erfolgreichen Kampf mit dem Organismus in sich, er bedarf keiner Unterstützung. Darin liegt der grosse Unterschied echter Parasiten allen anderen Keimen gegenüber, für die zur Entfaltung ihres Einflusses auf den Körper eine anatomische Gelegenheitsursache als unerlässliche Vorbedingung erforderlich ist.

Gerade die histologischen Bilder der puerperalen Infektionen zeigen uns, wie gerechtfertigt die scharfe Trennung zwischen Parasiten und Saprophyten ist. Hier, am paerperalen Uterus, spielen sich die Krankheitsprozesse auf einem zur Abwehr vorbereiteten Gebiet ab, ohne dass, Komplikationen ausgenommen, einer passiven Progredienz unbefähigter Keime irgendwie Vorschub geleistet wird. Das bakterioskopische Resultat trifft hier die Entscheidung: Niemals werden wir einen bis jetzt als Saprophyten bewerteten Keim in dem gleichen Gewebskampf finden wie die Strepto- und Staphylokokken.

Es werden zwar auch hier immer wieder in der Literatur Fälle beschrieben, die scheinbar eine Ausnahme von dieser Regel machen und die Zahl der primär virulenten Keime für die Puerperalinfektion erweitern. Unterzieht man aber diese Fälle einer kritischen Betrachtung, so ergibt sich ausnahmslos, dass es sich entweder um eine Komplikation im Wochenbett handelt, die mit dem Puerperium direkt gar nichts zu tun, hat, oder dass eine operative bzw. spontane Verletzung oder eine Anomalie der Plazentarperiode die Rolle der anatomischen Gelegenheitsursache übernommen hat. Es sind auch Fälle als Beweis für diese Anschauung mitgeteilt worden, bei denen die notwendigen bakteriologisehen Untersuchungen zur Entscheidung dieser Frage nicht angestellt wurden.

Als zufällige Komplikation des Wochenbetts müssen die von Hüssy und Chirié und Howard mitgeteilten Fälle angesehen werden. Bei Hüssy handelte es sich um ein Rückenfurunkel, 
in dem der Micrococcus tetragenus gefunden wurde. Die Patientin starb. Auch im Blut und in den Organen wurden bei der Sektion die gleichen Keime nachgewiesen.

Chirié fand im Blut und im Spatum einer schwer tuberkulösen Frau mit bronchopneumonischen Herden den Bacillus pneumoniae Friedländer, als es im Wochenbett zu einer typischen Exazerbation der Lungenerscheinungen kam. Weder im Uterus noch in den Lochien wurden die Bakterien nachgewiesen. Diese Patientin wurde gebessert entlassen.

$\mathrm{Zu}$ den anschliessend an operative Verletzungen auftretenden Infektionen mit nicht primär virulenten Keimen, wo also durch den mechanischen Insult eine abnorme Einbruchspforte den betreffenden Keimen gegeben war, gehören die von Fehling und Looten und 0 ui beschriebenen Fälle.

Fehling verlor eine Patientin an Colisepsis, bei der die Entbindung durch Pubiotomie mit hoher Zange und manueller Plazentarlösung beendet werden musste. Es kam zur Bildung eines Hämatoms, das platzte und eine breite Kommunikation zwischen Scheide und Knochenwunde bedingte. Von der Knochenwunde ausgehend kam es zur allgemeinen Sepsis.

Looten und Oui beschreiben einen Fall, wo sie bei einer mit hoher Zange und manueller Plazentarlösung entbundenen Patientin am 8. Tage wegen Plazentarretention eine Ausschabung mit nachfolgender Uterusspülung vornahmen. Anschliessend daran kam es zu einer einmaligen Temperatursteigerung, während welcher sie im Blute den Micrococcus tetragenus nachweisen konnten. Die Autoren machen selbst die Ausschabung und Spülung als mechanische Ursache für den einmaligen Keimbefund im Blut verantwortlich. Die Patientin wurde gesund entlassen.

Fouleton und Bonney beobachteten eine anschliessend an eine operative Entbindung auftretende Peritonitis. Die vermittelnde Rolle spielte hier ein retiniertes Plazentarstück; im Uterussekret waren Pneumonie-Diplokokken, Staphylokokken und Coli gewachsen; der Peritonitis-Eiter war aber nicht bakteriologisch untersucht worden, so dass man nicht weiss, ob die Staphylokokken oder, wie die Autoren annehmen, die Pneumonie-Diplokokken die fortgeleitete Infektion verursacht haben. Aber selbst wenn die Pneumokokken, die ausserdem rom Streptococcus pyogenes nicht streng abgrenzbar sind, die eiterige Peritonitis verursacht haben, so genügt der Plazentarrest vollkommen zur Erklärung der klinischen Erscheinung. 
Einen ebenso bakteriologisch nicht genügend untersuchten bzw. nicht aufgeklärten Fall beschreibt Schmidlechner, der aber in der Literatur fälschlich als tödlich endigende Infektion mit dem B. fusiformis zitiert wird. Der Bazillus wird aber von Schmidlechner selbst nicht als Erreger der allgemeinen puerperalen Erkrankung angesehen; er spricht ihn nicht, wie Hamm schreibt, als Ursache einer tödlich verlaufenden Pyämic an, sondern betont ausdrücklich, „dass in der während der Geburt entstandenen Dammläsion die Vincent'schen Bakterien eine schwere lokale Erkrankung hervorriefen, welche, sich rasch ausbreitend, an der Oberfläche des Genitalschlauches weitergriff ....... die in den Lungen und den regionären Venen vorhandenen Veränderungen müssen einem anderen Mikroorganismus zugeschrieben werden, welcher vielleicht in der Gebärmutterhöhle vorhanden war". In dem Uterussekret waren Diplokokken nachgewiesen worden, sodass es sich wahrscheinlich um eine Streptokokkeninfektion handelte, deren Ausbreitung allerdings durch die lokalen Veränderungen im Endometrium begünstigt worden sein kann.

Betrachten wir die bei den einzelnen Erkrankungsformen bereits kurz gestreifte Frage der sich aus den bakteriologischen Resultaten und klinischen Erscheinungen ergebenden prognostischen Rückschlüsse im Zusammenhang, so ergibt sich ganz allgemein, dass man jeden erst im Wochenbett auftretenden positiven Blutbefund ungünstig für den weiteren Verlauf des Krankheitsprozesses betrachten muss.

Dieser Keimnachweis ist in allen Fällen, wo eine gröbere Verletzung oder irgend eine Komplikation als Erklärungsmöglichkeit fehlt, als der Ausdruck einer deletären Progredienz eines eminent virulenten Bakteriums anzusehen, das sich allen organischen Abwehrmassregeln zum Trotz kraft seiner Penetrationsfähigkeit den Weg über das Cavum uteri hinaus in den Körper gebahnt hat. Das bakteriologische Resultat bestätigt diese Anschauung und zeigt uns, dass die reinen Formen der puerperalen Infektion den eigentlichen Erregern der menschlichen Sepsis, den Strepto- und Staphylokokken, vorbehalten sind.

Der gelegentliche, äusserst seltene Nachweis eines anderen Keimes in Reinkultur bei einer in diese Gruppe gehörenden Puerperalerkrankung ist stets an eine besondere lokale, anatomischpathologische Gelegenheitsursache gebunden. Sein wiederholter 
Befund im Blut in zunehmender Menge lässt aber schliesslich die Prognose gleichfalls schlecht stellen. Er beweist uns nämlich den allmählich zur Entwicklung gekommenen dominierenden Einfluss dieses auf präformierten Wegen in die Blutbahn gelangten Bakteriums.

Finden wir daher im Verlauf des Wochenbetts an mehreren aufeinanderfolgenden Tagen Bakterien im Blute der Patientin, so müssen wir, gleichgiltig ob es sich um primär oder sekundär virulente Bakterien handelt, die Prognose als durchaus infaust bezeichnen. Es sind zwar in der Literatur einige Fälle beschrieben, wo dieser mehrmalige Keimnachweis selbst von Streptokokken gelang und die trotzdem zur Heilung gekommen sind; sie gehören aber zweifellos zu den grössten Seltenheiten und sagen somit nichts gegen die allgemein gültige Regel. Umgekehrt dürfen wir bei negativer Bauchpunktion und bei dauernder Blutreinheit selbst bei den bedrohlichsten klinischen Erscheinungen die Prognose günstig stellen, vorausgesetzt, dass die Blutentnahme genau nach den eingangs erwähnten Prinzipien angestellt wurde. Diese Fälle gelangen ausnahmslos zur Heilung, sofern nicht die Patientinnen durch ausgedehnte phlegmonöse Prozesse oder durch Bindegewebseiterungen an allgemeiner Kachexie zugrundegehen. Hier geben dann die lokalen Veränderungen die Erklärung eines eventuell letalen Ausganges auch beim Fehlen der vorher genannten bakteriologischen Symptome.

Es fragt sich nun aber, ob wir uns aus den einzelnen positiven Ergebnissen der Blutuntersuchungen und dem differenten klinischen Bild im Verlauf des Krankheitsprozesses eine Vorstellung über den jeweiligen Stand der Infektion machen können, und ob trotz der an sich ungünstigen positiven Blutbefunde dennoch eine verschiedene Bewertung der anatomisch verschiedenen Krankheitsbilder zulässig oder praktisch wichtig erscheint.

Wie bereits bei den einzelnen Formen der Puerperalinfektionen hervorgehoben wurde, kann man insofern die eine Art der Erkrankung ungünstiger als die andere bewerten, als sie sehneller zum Tode führt oder jegliche therapeutische Bemühung von vornherein unmöglich macht.

Wir haben gesehen, dass bei den reinen thrombophlebitischen Prozessen, bei der puerperalen Pyämie, die Blutinfektion zunächst nur temporär auftritt und an den Zerfall und die Verschlep- 
pung septischen Thrombenmaterials gebunden ist. Es gibt also hier im Intervall der Fröste noch eine temporäre Blutreinheit, entsprechend den Blutbefunden bei fieberhaften, noch nicht ausgeräumten Aborten, bei denen auch nur im Fieberanstieg der Keimnachweis gelingt, obwohl sich bei der Pyämie der Krankheitsprozess im Gegensatz zum Abort bereits über das erkrankte Organ hinaus in den abführenden Venen etabliert hat. Beim Abort wird durch die rechtzeitige Plazentarausräumung die Erkrankung kupiert; die rechtzeitige Entfernung des Uterus mit den infizierten Venen bzw. die technisch richtig ausgeführte Venenligatur oberhalb aller krankhaften Veränderungen müsste dementsprechend die gleichen oder wenigstens annähernd ähnlich gute Erfolge liefern. Zwei Momente werden aber hier stets die Resultate ungünstig beeinflussen: die verzögerte Indikationsstellung zum Eingriff und die bei weitem schwierigere technische Ausführung mit allen Operationskomplikationen.

Man wird sich nicht scheuen, sofern man nicht einen exspektativen Standpunkt bei der Abortbehandlung vertritt, die infizierte Plazenta eines fieberhaften Abortes unverzüglich auszuräumen. Schwerer wird man sich dagegen zu einer so eingreifenden Operation wie der Uterusexstirpation oder Venenunterbindung entschliessen. Und doch glaube ich, dass man bei weiterem bessere Erfolge als bisher erzielen würde, wenn man konsequent nach jedem ersten keimhaltigen positiven Schüttelfrost im Wochenbett die eine oder die andere Operation ausführte. Wartet man ab, so gewinnt nicht nur der Prozess an Ausdehnung, und wird operativ schwieriger angreifbar, sondern es ändern sich auch, wie uns die kontrollierenden Blutuntersuchungen gezeigt haben, die günstigen bakteriologischen Blutverhältnisse. Die bakterizide Kraft erlahmt, die Keime passen sich dem neuen Medium an, und als Schlusseffekt dieser Verzögerung lassen uns die Blutproben den Eintritt einer dauernden Bakteriämie erkennen. Hand in Hand mit dieser Progredienz geht das prognostisch so ungünstige schnelle Wachstum der Kolonien in zunehmender Menge.

In seinem Referat über die operative Behandlung des Puerperalfiebers auf dem Gynäkologen-Kongress zu Strassburg hat Bumm die bis 1909 in der Literatur veröffentlichten operativ in Angriff genommenen Fälle puerperaler Infektionen mitgeteilt. Die aus der Zusammenstellung gewonnenen Prozentzahlen geben aber trotz der schon recht beträchtlichen Mortalitätsziffer immer noch kein einwandsfreies Bild, denn, wie Bumm selbst schreibt, zeigt 
die genauere Durchsicht der Fälle, dass sie nur zum geringsten Teil beweiskräftig sind. Um sich ein Urteil über den Wert der Operation zu gestatten, müssten nicht nur die klinischen Daten, sondern auch die bakteriologischen Befunde der Wunden, sowie des Blutes vor und nach der Operation erbracht und durch eine vollständige bakteriologisch-anatomische Untersuchung des ausgeschnittenen Uterus darüber Aufschluss gegeben werden, wie weit die Keime verbreitet waren, ob irreparable Veränderungen vorlagen, oder solche, die noch eine Ausheilung durch die natürliche Reaktion würden zugelassen haben. Diese Angaben fehlen aber bei den meisten Fällen. Trotz dieser mangelhaften anamnestischen Daten, wodurch die Zahl der scheinbar dureh den Eingriff geheilten Fälle weit überschätzt und die Mortalitätsziffer wesentlich zu klein angegeben wird, fallen die Prozentzahlen der noch operativ in Angriff genommenen puerperalen Infektionen bei der pyämischen Form, wie folgt, aus:

1. Die Mortalität betrug bei der Exstirpation des Uterus $68 \mathrm{pCt}$.

2. Bei der Venenunterbindung $62,7 \mathrm{pCt}$.

In dieser Statistik sind Geburten und Aborte zusammengenommen berechnet. Eine Trennung lässt sich leider nicht durchführen, da bei sehr vielen Fällen die entsprechenden Angaben fehlen.

Im Gegensatz zur Pyämie zeigt uns das. Blutbild bei der puerperalen Sepsis von vornherein eine dauernde Bakteriämie und ist somit prognostisch weit ungünstiger zu beurteilen, weil diese ununterbrochene Blutvergiftung in viel kürzerer Zeit ein letales Ende herbeiführen muss und die Chancen eines erfolgreichen operativen Eingriffes so gut wie aussichtslos macht.

Mit der Sicherung der Diagnose Septikämie jst somit vorläufig beim Fehlen eines spezifischen, den Krankheitserreger direkt angreifenden Heilmittels zugleich unsere operative Hilfslosigkeit fostgestellt; man wird zwar auch hier durch Exstirpation des Uterus den Herd and somit eine weitere Ueberschwemmung der Blutbahnen auszuschalten versuchen, aber mit wenig Aussicht auf Erfolg. Man muss nämlich annehmen, dass sich in diesen Fällen der Keim nicht erst die Fähigkeit der selbständigen Weiterentwickelung im Blute za erwerben braucht, sondern diese von vornherein besitzt. Ist er daher im Blute nachgewiesen und durch fortgesetzte Untersuchungen seine dauernde Anwesenheit sichergestellt, so wird unser therapeutischer Eingriff stets zu spät kommen. 
Das fortschreitende und von Tag zu Tag zunehmende Uebergewicht der Bakterien bzw. das allmähliche Erlahmen der bakteriziden Kräfte des Körpers kann man bei dem ausgesprochen progredienten Verlauf der Erkrankung auch hier wiederum aus den Resultaten der verimpften Blutproben ersehen. Die anfangs erst nach 24 Stunden oder nach noch längerer Zeit sichtbar werdenden Kolonien gehen immer schneller und in zunehmender Anzahl in den Agarröhren an.

Die seltenen, rein auf dem Lymphwege fortgeleiteten und zur eiterigen Peritonitis führenden Puerperalinfektionen ohne Uebertritt der Bakterien ins Blut sind insofern wieder prognostisch als etwas günstiger anzusehen, als hier in gewissen Fällen durch rechtzeitige Exstirpation des Uterus und durch Drainage eine Lokalisation und Abkapselung des intraperitonealen Prozesses herbeigeführt werden kann.

Bei dem virulenten Charakter der am häufigsten in Betracht kommenden Bakterien (sofern nicht eine Gelegenheitsursache auch anderen, sekundär virulenten Keimen den Uebergang in die Bauchhöhle gestattet) wird man allerdings auch hier recht oft schon eine weit fortgeschrittene Infektion des Peritoneums bei der Operation antreffen, wenn durch die klinischen Erscheinungen und durch die Probepunktion das Uebergreifen des Krankheitsprozesses auf das Bauchfell festgestellt wird. Dann aber kann durch den operativen Eingriff nur in den seltensten Fällen noch ein Stillstand der Infektion herbeigeführt werden, um so weniger, als nicht selten mit der lymphatischen Ausbreitung gleichzeitig auch die Blutbahn der betreffenden Patientin von den Keimen ergriffen und infiziert worden ist.

Handelt es sich demnach um eine reine Streptokokkenperitonitis, so wird die Operation fast ausnahmslos zu spät kommen, da sich die Bakterien entsprechend ihrer hohen Virulenz in wenigen Tagen über die Barriere des Colon transversum hinweg bis zur Leber und zum Zwerchfell verbreitet haben.

Werden dagegen im Eiter Bakteriengemische oder überhaupt nur sekundär virulente Keime angetroffen, ein Ereignis, das nach perforierenden Verletzungen, nach dem Aufbruch von jauchigen Abszessen, nach Nekrosen und ähnlichen Zufällen eintreten kann, so ist die Prognose ungleich günstiger. Hier kann der ganze Krankheitsprozess durch einen rechtzeitigen operativen Eingriff günstig beeinflusst und nicht selten durch ihn auch noch zur Heilung gebracht werden, 
In der von Bumm veröffentlichten Statistik der in der Literatur mitgeteilten Fälle operativ behandelter puerperaler Peritonitiden ergibt die allgemeine Peritonitis eine Mortalität von 64,6 pCt. und die abgesackte Peritonitis bei einer nahezu gleich grossen Zahl von Fällen nur eine von 12 pCt. Da aber hier wiederum Aborte und Geburten zusammengenommen berechnet sind und nur bei den wenigsten Fällen überhaupt bakteriologische Untersuchungen des Eiters angestellt wurden, ist die Mortalitätszahl der allgemeinen Peritonitis trotz der 64 pCt. sicherlich doch noch viel zu niedrig ausgefallen.

Das Fazit dieser bakteriologisch-histologischen Untersuchungen lässt sich dahin zusammenfassen, dass wir durch sie in den $A b-$ lauf der verschiedenen fieberhaften Erkrankungen bei Abort und Geburt einen gewissen Einblick gewonnen haben. Die Strukturbilder der Plazenten und Uteruswände fieberhafter Aborte und Geburten haben uns die wechselnden Blutbilder verständlich gemacht und erklärt; die bakteriologischen Blutproben wiederum haben uns mit hinlänglicher Sicherheit die Prognose stellen lassen, und deduktiv entwickelte sich aus diesen Beobachtungen die erforderliche Therapie: wir werden fieberhafte Aborte so bald wie möglich ausräumen und fiebernde Kreissende sobald wie möglich entbinden.

Auch die erst im Wochenbett auftretenden Fiebersteigerungen haben durch die kombinierte histologische und bakteriologische Untersuchungsmethode in vielen Fällen eine ergänzende Erklärung gefunden. Wir wissen, dass es harmlose prognostisch durchaus günstige auf Intoxikation beruhende Fiebersteigerungen gibt; und die kontrollierenden Blutuntersuchungen haben uns ferner bei eingetretener Infektion eine präzise Trennung der lokalisierten Erkrankung von der allgemeinen erlaubt.

Diese Erkenntnis verlangt notwendigerweise in allen Fällen puerperaler Fiebersteigerungen eine fortgesetzte bakteriologische Kontrolle des Blutes; einerseits, um nicht auf Grund einer falschen rein klinischen Diagnosenstellung eine nicht indizierte Operation vorzunehmen, andererseits um rechtzeitig den Uebergang der lokalen in die allgemeine Erkrankung erkennen und durch einen eventuellen Eingriff den drohenden Fortschritt noch aufhalten zu können. 
378 Warnekros, Zur Prognose der puerpera?en Fiebersteigerungen.

\section{Erklärung der Abbildungen auf Tafel IV-X.}

$$
\text { Tafel IV-VI. }
$$

Figur 1. Abortplazenta: Durchwanderung der Keime durch die Eihäute; die intervillösen Räume sind mit Bakterien angefüllt.

Figur 2. Abortplazenta: Bakterien zwischen den Zotten; Blutungen in der Plazenta.

Figur 3. Schnitt durch Uteruswand mit adhärenter Plazenta eines fieberhaften Abortes. Plazenta mit Bakterien (blau) durchsetzt; Muskulatur bakterienfrei.

Figur 4. Curettiertes Deziduastückchen, aus dem Endometrium eines fieberhaften Abortes zwei Tage nach der Ausräumung. Zahlreiche Bakterien in der oberflächlichen Schicht; tiefere Partien keimfrei.

Figur 5. Schnitt aus der Gebärmutterwand eines fieberhaften Abortes; Iymphatische Infiltration; Tod an eitriger Peritonitis.

Figur 6. Schnitt durch die Gebärmutterwand eines fieberhaften Abortes, thrombotische Form der Bakterienausbreitung; Tod an Pyämie.

Figur 7. Schnitt aus der Gebärmutterwand mit adbärenter Plazenta; fieberhafter Abort (Emphysematosus-Sepsis); Plazenta mitBakterien durchsetzt, Gasbildung. Muskulatur bakterienfrei.

Figur 8. Ein Stüok des vorigen Schnittes bei stärkerer Vergrösserung: Muskulatur mit ansitzender Plazenta; die intervillöse Räume mit Bakterien ausgefüllt; Muskulatur und Dezidua bakterienfrei.

Figur 9. (Derselbe Fall.) Ein in der Decidua basalis verlaufendes venöses Gefäss mit zahlreichen Bakterien.

Figur 10. (Derselbe Fall). Ein in der Muskulatur verlaufendes Gefäss mit zahlreichen Bakterien; kein Eindringen der Keime in das umgebende Gewebe.

Figur 11. (Derselbe Fall.) Bakterioskopischer Schnitt ans der Leber.

Figur 12. Fieberhafter Abort. Plazenta im Uterus; akute, temporäre Bakteriämie.

Figur 13. Plazenta rechtzeitig ausgeräumt; kein weiterer Bakterientransport mehr; Biut steril.

Figur 14. Verschleppter Fall; Plazenta zu spät a asgeräumt. Eindringen der Bakterien in die Muskulatur; Weiterentwicklung der Keime in den abfübrenden Venen auch nach Unterbrechung des Uteroplazentarkreislaufes: Sepsis.

Figur 15. Verschleppter Fall. Plazenta zu spät ausgeräumt. Durchwandern der Bakterien dorch dio Muskulatur: Peritonitis. Lokalisation der Bakterien in den thrombotischen Gefässen: Pyämie.

$$
\text { Tafel VII-VIII. }
$$

Figur 1. Schnitt durch die fötale Plazentarfläche; strichförmige Ausbreitung der Bakterien (blau) in der Chorionplatte.

Figur 2. Schnitt durch die fötale Plazentarfläche bei stärkerer Vergrösserung. Bakterien (blau) in der Chorionplatte. 
Figur 3. Fötale Plazentarfläche (Amnion und Chorion) bei Immersionsvergrösserung. Durchwandern der Bakterien durch das Amnionepithel; Ausbreitung in der Chorionplatte.

Figur 4. Schnitt durch die Eihäute; Ausbreitung der Bakterien (blau) in dem Chorion.

Figur 5. Derselbe Schnitt durch die Eihäute wie in Figur 4, bei stärkerer Vergrösserung. Durchwandern der Bakterien durch đas Amnionepithel.

Figur 6. Schnitt durch die fötale Plazentarfläche (Amnion und Chorion). Vordringen der Bakterien (blau) in breiten Zügen von der Amnionoberfläche gegen die intervillösen Räume.

Figur 7. Schnitt durch die fötale Plazentarfläche (Amnion, Chorion und Choriongefässe). Vordringen der Baliterien; beginnende Durchsetzung der Wandung eines Choriongefässes.

Figur 8. Schnitt durch die fötale Plazentarfläohe (Amnion, Chorion und Choriongefässe). Tieferdringen der Bakterien; Durchsetzung der Wandung eines Choriongefässes.

Figur 9. Schnitt durch die fötale Plazentarfläche (Amnion, Chorion, Choriongefässe und intervillöse Räume). Vollkommene bakterielle Durchsetzung der Wandung eines Choriongefässes.

Figur 10. Schnitt durch die fötale Plazentarfläche. Bei $\times$ trennt nur eine schmale Zone den blaugefärbten Kokkenstrich in der Chorionplatte von den intervillösen Räumen.

Figur 11. Schnitt durch die fötale Plazentarfläche bei stärkster Vergrösserung. Durchwandern der Bakterien von der Amnionoberfläche aus durch die Chorionplatte bis in die intervillösen Räume. Bakterien zwischen den Zotten.

Figur 12. Schnitt durch den unteren Plazentarpol. Bakterienentwicklung yornehmlich in der Decidua basalis. Einbruch in die intervillösen Ränme (Lupenvergrösserung).

Figur 13. Schnitt durch die uterine Plazentarfläche. Einbruch der Bakterien in die intervillösen Räume.

Figur 14. Schnitt durch die uterine Plazentarfläche. Decidua basalis fehlt an dieser Stelle. Sehr reichliche Bakterienansammlung zwischen den Zotten (Immersionsvergrösserung).

Figur 15. Schnitt durch den mittleren Teil der Plazenta. Sehr reichliche intraplazentare Bakterienentwicklung; Bakterien liegen zwischen den Zotten.

Figur 16. Schnitt durch die Gebärmutterwand einer intra partum gestorbenen, fiebernden Kreissenden. Streptokokken-Bakteriämie. Bakterien (blau markiert) zwischen den Zotten und im Lumen der abführenden venösen Gefässe. Muskulatur bakterienfrei.

$$
\text { Tafel IX }-\mathrm{X} \text {. }
$$

Eigur 1. Schnitt durch ein Deziduastückchen, welches bei einem Eintagsfieber mit der Curette entfernt wurde. Gewebefärbung.

Figur 2. Dasselbe Stückchen nach Gram-Weigert auf Bakterien gefärbt; nirgends Bakterien nachzuweisen. 
Figur 3. Schnitt durch ein Deziduastückehen, das boi putrider Endometritis mit der Curette entfernt wurde. Nekrotische Schicht mitFäulniskeimen durchsetzt; Reaktionsschicht bakterienfrei.

Figur 4. Schnitt duroh ein Deziduastückchen, das bei septischer Streptokokken-Endometritis mit der Gurette entfernt wurde. Einfache Bakterienfärbung, die Keime sind diffus durch das curettierte Stückchen zerstreut (Bakterien bJau).

Figur 5. Schnitt durch ein Deziduastückchen, das bei septischer Endometritis mit der Curette entfornt wurde. Gewebe- und Bakterienfärbung; die Keime sind diffus durch das ganze curettierte Stückchen zerstreut.

Figur 6. Ausgedehnte Thrombose Vv. jliaca med. und int. fortgeleitet durch die V. iliaca com. bis in die Vena cava, die bis zum Durchtritt durch das Zwerchfell vollkommen thrombosiert war.

Figur 7. Thrombose der Venailiacecom. und der Vena femoralis, ausgehend von einer Thrombose der Uterinvenen. Periphlebitische Auflagerungen. Ligatur der Vena cava.

Figur 8. Thrombose der Vena iliaca media und interna; Abscess im rechten Parametrium. Ligatur der V. iliaca com. dextr.

Figur 9. Schnitt durch die Gebärmutterwand (Plazentarstelle) bei der thrombotischen Form des Puerperalfiebers. Gefässe mit Bakterien angefüllt; bis in die feinsten Verzweigungen unter der Serosa Bakterien intravenös nachweisbar (Lupenvergrösserung).

Figur 10. Derselbe Fall. Ein Abschnitt des Endometriums bei stärkerer Vergrösserung. Spontanes Einaringen der Keime bis in die Muskulatur.

Figur 11. Derselbe Fall, spontaner Einbruch der Bakterin von den Gefässen aus in das umgebende Gewebe.

Figur 12. Sahnitt durch die Gebärmutterwand einer an Pyämie + Wöchnerin. Ausgedehnte Nekrose des Endometriums und der Muskulatar; Einbruch der Bakterien in die Gefässe unabhängig von der Plazentarstelle.

Figur 13. Derselbe Fall; spontanes Durchwandern der Bakterien ron einem thrombosierten Gefäss aus in das umgebende Gewebe.

Figur 14. Schnitt durch die Gebärmutterwand bei der lymphatischen Form des Puerperalfiebers; Ausbreitung der Bakterien in den feinsten Lymphspalten ( + Streptokoklienperitonitis).

Figur 15. Schnitt aus demselben Präparat bei starker Vergrösserung: Streptokokken zwischen den Muskelfasern.

Figur 16. Schnitt durch die Gebärmutterwand bei der lymphatischen Form des Puerperalfiebers: Ausbreitung der Bakterien in den grösseren Lymphspalten ( + Streptokokkenperitonitis). 